Portland State University

PDXScholar

3-15-2021

\title{
Creating Systems of Shared Accountability for Early Leaver Students: Perspectives of Principals
}

Lorna Kay Fast Buffalo Horse

Portland State University

Follow this and additional works at: https://pdxscholar.library.pdx.edu/open_access_etds

Part of the Educational Leadership Commons, and the Higher Education Administration Commons Let us know how access to this document benefits you.

Recommended Citation

Fast Buffalo Horse, Lorna Kay, "Creating Systems of Shared Accountability for Early Leaver Students: Perspectives of Principals" (2021). Dissertations and Theses. Paper 5663.

https://doi.org/10.15760/etd.7535

This Dissertation is brought to you for free and open access. It has been accepted for inclusion in Dissertations and Theses by an authorized administrator of PDXScholar. Please contact us if we can make this document more accessible: pdxscholar@pdx.edu. 
Creating Systems of Shared Accountability for Early Leaver Students:

Perspectives of Principals

by

Lorna Kay Fast Buffalo Horse

A dissertation submitted in partial fulfillment of the requirements for the degree of

\title{
Doctor of Education
}

in

Educational Leadership: Administration

\author{
Dissertation Committee: \\ Deborah Peterson, Chair \\ Pat Burk \\ Christopher Pinkney \\ Yves Labissiere
}

Portland State University

2021 
(C) 2021 Lorna Kay Fast Buffalo Horse 


\begin{abstract}
Alternative high schools in the United States perform a significant role for students who drop out, are pushed out, or fall out of conventional high schools. An essential function of alternative high schools is to support some of the most underserved students in the country to graduate from high school. High school graduation is a major factor associated with higher incomes, better health, longer life expectancy, and less involvement in the criminal justice system. It also positively impacts local, state, and national economies. Despite these positive impacts, many alternative high schools are stigmatized as low-performing and even "drop-out factories" by state and local governing bodies and the media. The Every Student Succeeds Act (2015) requires that all public schools reach a 4 -year cohort graduation rate of $67 \%$ or higher, but $75 \%$ of alternative high schools nationally do not meet this threshold, and only two alternative high schools in one Pacific Northwest state have met this level since the Every Student Succeeds Act became the law. While there are likely many reasons for this, some scholars assert that this is a function of conventional high schools "discharging" their potential nongraduating students into alternative schools in an effort to boost their own graduation rates. Using critical pedagogy as a framework to interrogate the legacy of rational systems theory thinking and Taylorism on public schooling, this basic qualitative study explores the experiences of principals of alternative high schools with relatively high percentages of Black, Indigenous, People of Color (BIPOC) students with state accountability systems. Qualitative interviewing and document analysis were the primary
\end{abstract}


methods used. Results confirm much of the research literature, but also point to a potential solution of local, shared accountability. 


\section{Dedication}

This work is dedicated to the thousands of students who each year drop out, fall out, and are pushed out of schools in the United States and to the countless educators and supporters who work to reengage them in school. We must do better. 


\section{Acknowledgements}

I am indebted to many people for their support, feedback, and encouragement before and during the years I spent working on my doctorate. Just a few of these include:

\section{Dissertation Committee Members}

Dr. Deborah Peterson: I thank you for always believing in me, for pushing me to do my best and encouraging me to pursue career opportunities. I cannot thank you enough for taking me on as a doctoral student when you already had more than your share.

Dr. Pat Burk: Thank you for your years of support, counsel, and feedback and for always remembering what it means to be a school administrator who also happens to be working on a dissertation.

Dr. Chris Pinkney: Thank you for agreeing to be a part of my committee, even though we did not know each other. Not only do you have alternative education experience, but you also have enriched this work with your insights and support.

Dr. Yves Labissiere: The College of Education keeps you very busy as the Graduate Office Representative for many dissertation committees and I understand why. Thank you for your encouragement, engagement, and critical feedback.

\section{Other Professors}

Many thanks to all of my undergraduate, graduate, and doctoral program professors who, over the years, pushed me to think, analyze, and write in the ways this problem of practice deserve: Dr. Jane Atkinson, Dr. Dick Adams, Dr. Zaher Wahab, Dr. 
Nancy Meltzoff, Dr. Andy Job, Dr. Karen Haley, Dr. Candyce Reynolds, Dr. Moti Hara, and Dr. Dot McElhone.

\section{Professional Colleagues and Supervisors}

Many thanks to colleagues and supervisors who supported me, challenged me, gave me feedback, and helped me keep going through the challenges of being a principal and central office school administrator and the tragedy my family experienced during this dissertation process: Korinna Wolfe, Allison Adams, Cheryl James, TaLisa Green, Nyewusi Askari, Dr. Matt Eide, Dr. Alexa Pearson, Dr. Nettie Legters, Carla Gay, Drake Shelton, as well as others.

\section{Research Participants}

I remain grateful to the individuals who gave of their time and shared their insights for this study.

\section{Cohort Members}

I so appreciate the camaraderie, collegiality, and understanding that each of you was able to share with me. Thank you, Dr. Kevin Walker and future Drs. Ryan Carpenter, Jeremy Cohen, Sheryl Lipski, Jorge Meza, and Efrain Rivas.

\section{Students}

My students over the years have taught me the most, pushed me to be better, inspired me to write this dissertation and work in any way that I can to help create a better educational system. 


\section{Family}

Last, but far from least, I want to thank my family for believing in me and encouraging me. Mom and Dad, your medical conditions prevent you from being able to read this document or discuss the ideas embedded in it, but I thank you for all your love and support over the years. I know that you are proud of me, deep down. My sister, Linda, thank you for all you have done to support our parents and me. My sons, Warren and Cody and late son, Samuel, I love you all to the moon and back and I am proud of the men you have become. My life partner, JC, thank you for never complaining about the many hours I spent on the course work, research, and writing, for always supporting and encouraging me, and for letting me bounce so many ideas off your head. 
Table of Contents

Abstract

Chapter One: Problem Statement 1

Early Leaver Problem ...........................................................................................



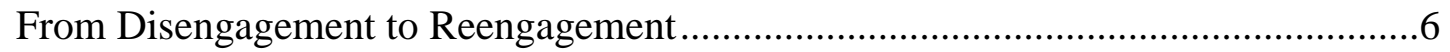

Historical, Socio-Cultural, Racial Context ............................................................

Historical Context ................................................................................ 7

National Accountability Mandates .............................................................

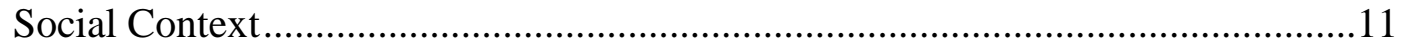

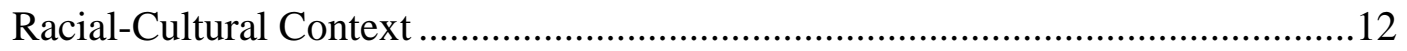

Alternative Schools Versus Alternative Programs ...................................................14

Statement of the Research Problem and Introduction to the Study ...........................16

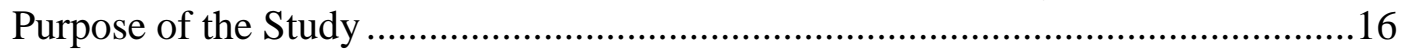

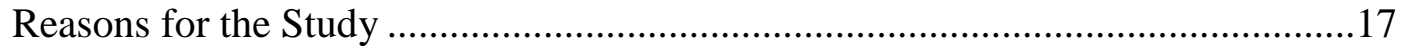

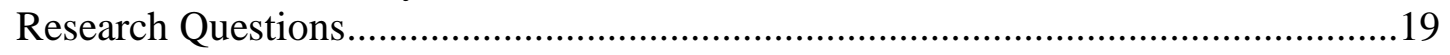

Educational Significance of the Problem...........................................................19

Personal Significance of the Problem ................................................................20







Chapter Two: Literature Review 29

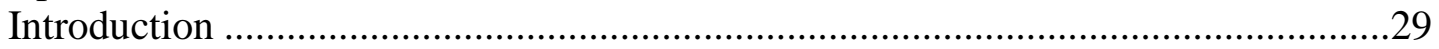

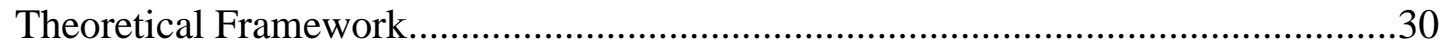

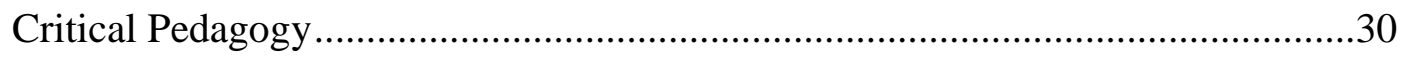

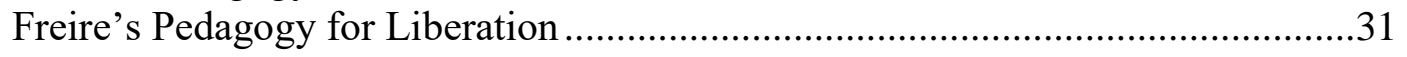

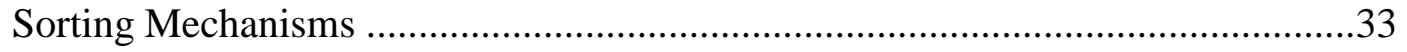

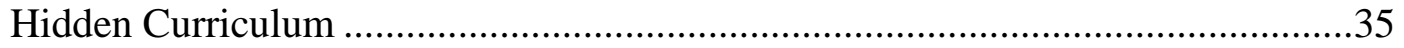

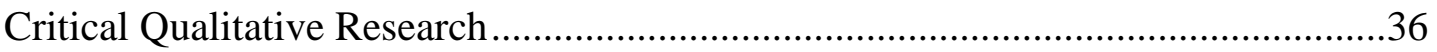

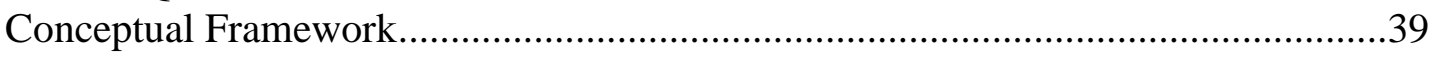

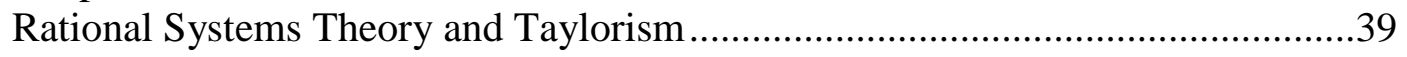



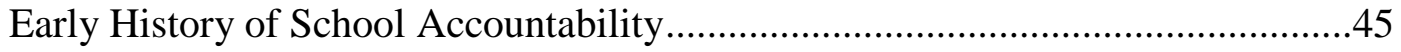

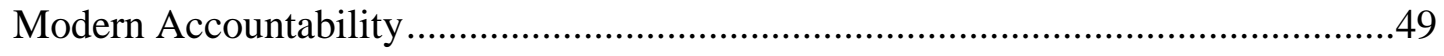








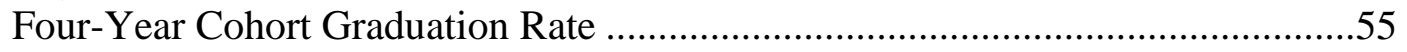

Compulsory School Attendance Age ...............................................................56

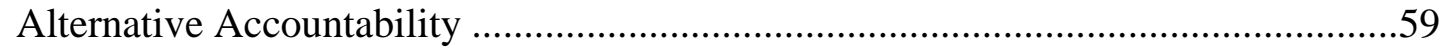

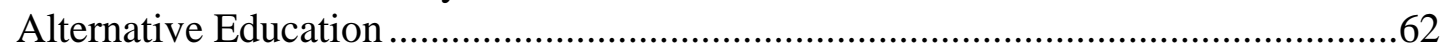

Alternative Schools ......................................................................................62

The Research Literature: Alternative Schools vs. Conventional Schools ..............64

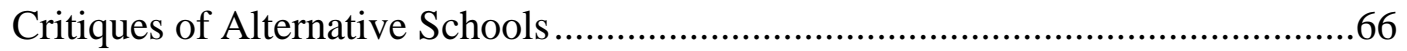

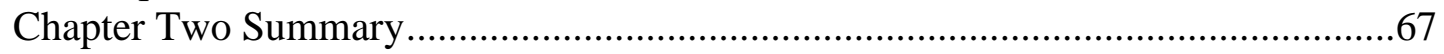

Chapter Three: Methodology $\quad 70$

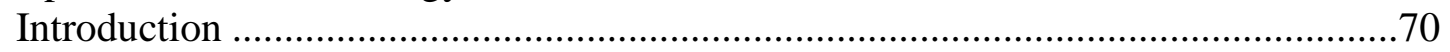

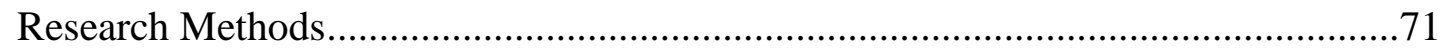

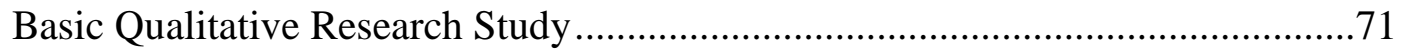



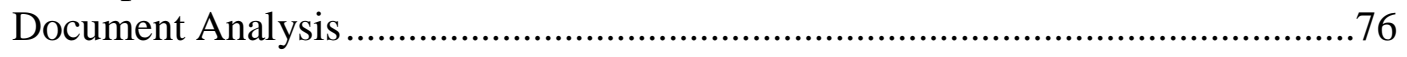

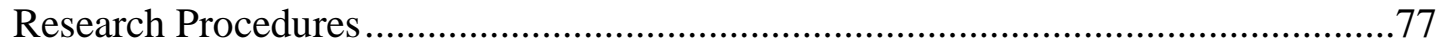

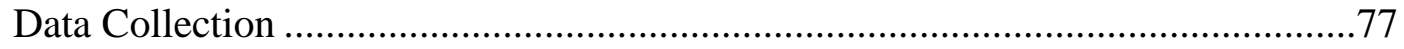

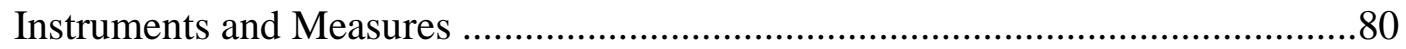





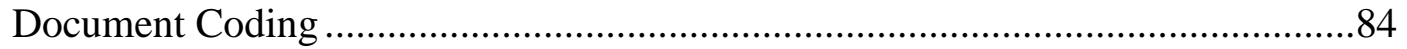

Role of the Researcher: Positionality, Reflexivity, Bias ......................................84

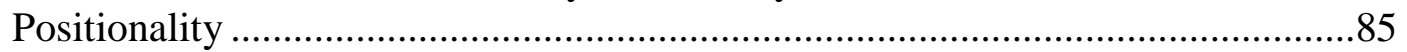

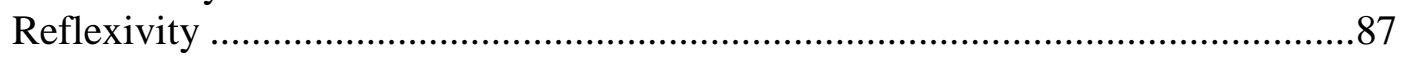

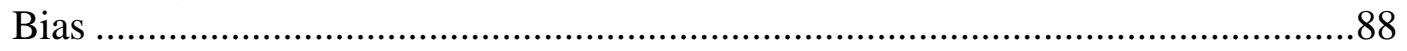

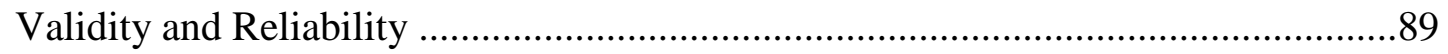

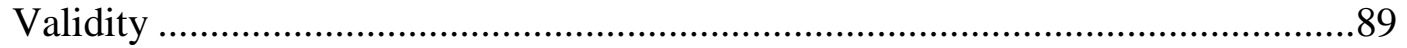



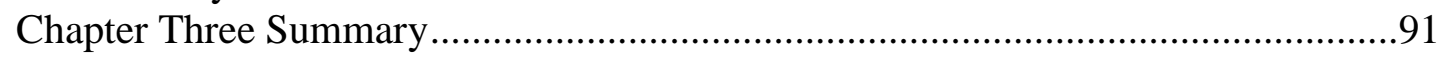

Chapter Four: Findings 92



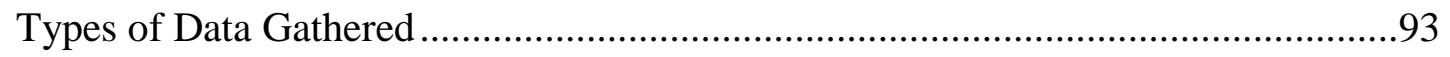

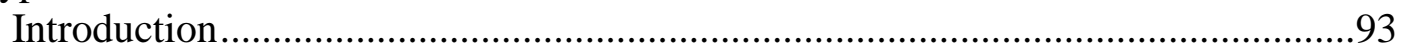

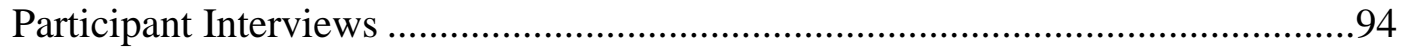

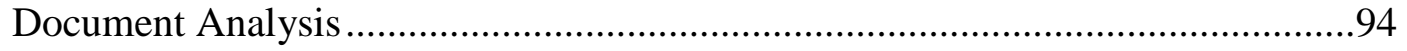



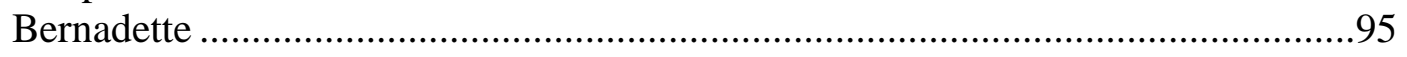

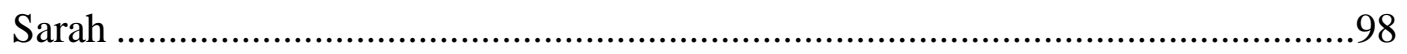

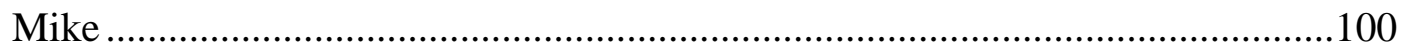

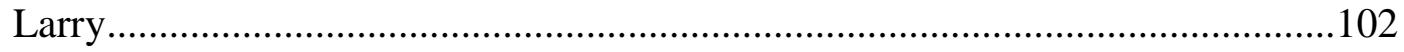






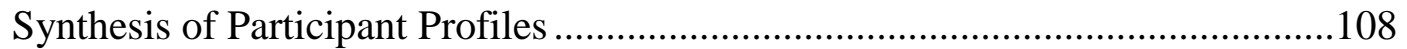

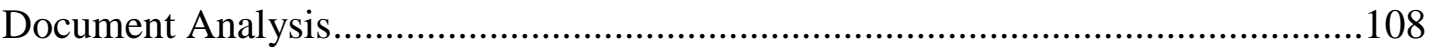

Youth Development Alternative High School Documents.....................................109

Achievement Alternative High School Documents ..............................................111

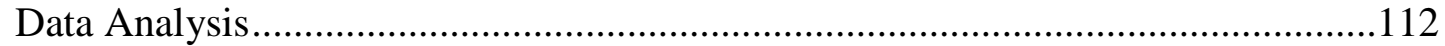

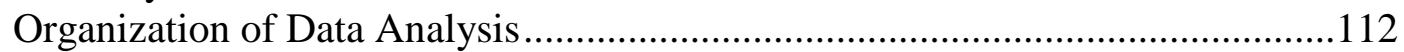

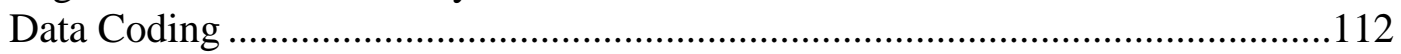

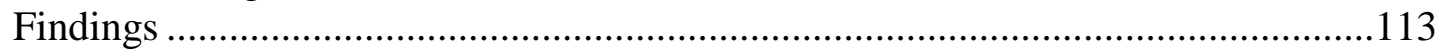

Categories Consistent Among All Participants ...................................................113

Mental Health Concerns and the Need for Trauma-Sensitive Safe Havens ..........113

An Over-Representation of Students With Disabilities .........................................115

Standardized Accountability Metrics Poorly Capture the Work of Alternative

High Schools ...........................................................................................117

The Importance of Promoting Alternative Schools as Schools of Choice ...........118

Ambivalence About District Support for Low Student-Staff Ratios .....................119

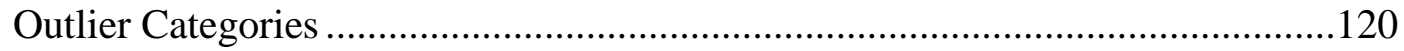

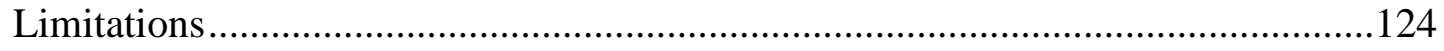

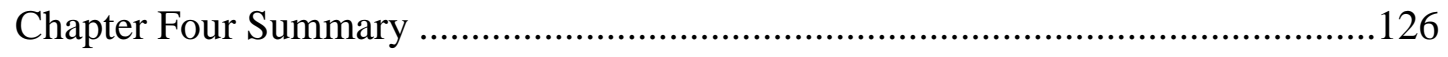

Chapter Five: Discussion, Conclusions, and Recommendations 127

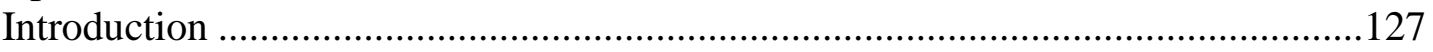

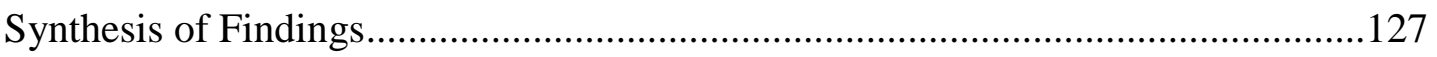

Validation of Research Literature on Early Leavers..........................................128

Larger Context of Findings....................................................................................131

The Value of Alternative Schools vs. Taylorism...............................................131

Alternative School Report Cards vs. District Solutions ........................................132

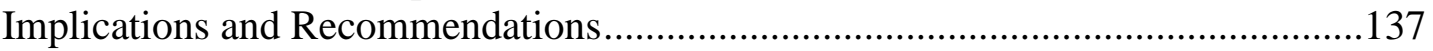

Shared Accountability and Transparency ........................................................138

Shared Accountability Through Enrollment Designations ...................................141

Shared Accountability Through Growth Metrics ................................................142

Shared Accountability Through Communication and Collaboration ....................142

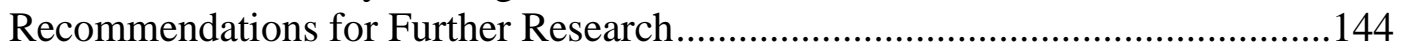

Chapter Five Summary ……………………………........................................145

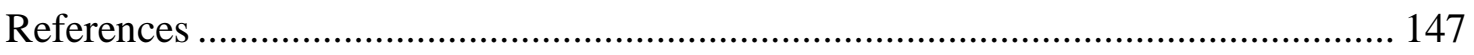

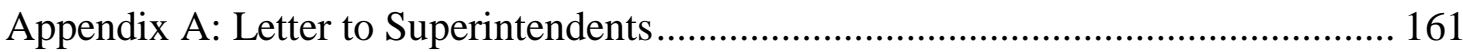

Appendix B: Letter to Research Participants ......................................................... 162

Appendix C: Informed Consent Form................................................................ 163 
Appendix D: Interview One Guide ................................................................ 167

Appendix E: Original Interview Two Guide .................................................. 169

Appendix F: Newer Interview Two Guide, Approved by IRB Amendment ............. 170

Appendix G: Provisional Codes From Literature ............................................. 172

Appendix H: Guidance for School District Leaders on Shared Accountability for Early Leaver Students and Improved Graduation Rates ................... 173 
List of Tables

Table 1. 2017 Sub-Group Graduation Rates, National Averages .....................................2

Table 2. Grade 9-12 Student Population Characteristics, 2015-2016 School Year Statewide Alternative Schools and Programs ................................................16

Table 3. Sample of States With Alternative Pathways for Exit Exams ..........................54

Table 4. Characteristics of Alternative Accountability in Six States.............................60

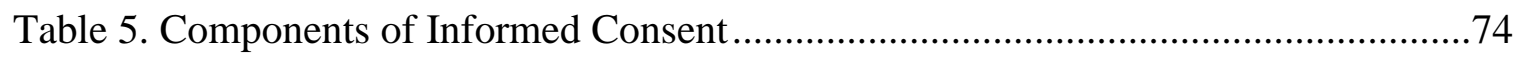

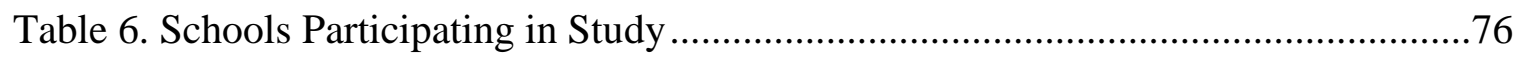

Table 7. Qualitative Validity Strategies and Their Application to This Study ................89

Table 8. Qualitative Reliability Strategies and Their Application to This Study .............90

Table 9. Principal Participants in This Study...........................................................93

Table 10. Comparison of Special Education Levels in Alternative Schools and Their Districts ................................................................................... 116

Table 11. Contrasting Majority and Outlier Themes in the Data ................................134 


\section{Chapter One: Problem Statement}

\section{Early Leaver Problem}

In 2017, the United States reached its highest graduation rate of all time, with $84.6 \%$ of young adults graduating from high school within four years (Atwell et al., 2019). This rate is a $5.6 \%$ gain over the national graduation rate in 2011 , a year in which an estimated 7,000 young people dropped out of United States high schools every day (Alliance for Excellent Education, 2011b; Atwell et al., 2019). Ten years ago, one fourth of all high school students and nearly one half of all Black, Indigenous, People of Color (BIPOC) students were leaving high school nationwide without graduating (Lee \& Burkam, 2003; Miller, 2011). Thankfully, a great deal of progress has been made in the last decade, including significant progress by BIPOC students (Atwell et al.).

There are still, however, disparities in graduation rates nationwide for BIPOC students, English Language Learner students, low-income students, homeless students, and students with disabilities. Rumberger (2013), for example, found that students from low-income families are five times more likely to drop out of high school than are wealthier students. Atwell et al. (2019) provided the following percentages of on-time graduation in 2017 among some of the nation's student sub-groups in Table 1. Unfortunately, the researchers did not include all racial groups in their analysis. 
Table 1

2017 Sub-Group Graduation Rates, National Averages

\begin{tabular}{|l|l|}
\hline \multicolumn{1}{|c|}{ Sub-Group } & \multicolumn{1}{|c|}{ National On-Time Graduation Rate } \\
\hline African-American Students & 77.8 \\
\hline Chicanx Students & 80 \\
\hline English Language Learner Students & 66.4 \\
\hline Homeless Students & 64 \\
\hline Low-Income Students & 78.3 \\
\hline Students With Disabilities & 67 \\
\hline
\end{tabular}

Source: Atwell et al. (2019)

In a 2004 national study of dropout and graduation by high school, Balfanz and Legters found that there were 2,000 high schools in the United States in which the freshman class shrank by $40 \%$ by the time that group of students reached their senior year. They found between 900 and 1,000 high schools in the United States in which graduation is a 50/50 proposition at best (Balfanz \& Legters, 2004). The outlook was particularly stark for BIPOC students. Nearly half of African American students and 40\% of Chicanx students attend high schools where graduation is not the norm, compared to only $11 \%$ of White students nationally (Balfanz \& Legters, 2004). Out of 30 countries for whom high school graduation rate data are available, the United States is tied with New Zealand for a ranking of $17^{\text {th }}$, placing it behind many European and Asian countries (Amos, 2006). 
Young people who leave high school before graduating in the United States earn $\$ 200,000$ less than a high school graduate over their lifetime. That difference in lifetime earnings becomes almost a million dollars less than college graduates (Resmovits, 2014). Put yet another way, the high school dropout earns an average of 37 cents for every dollar earned by a high school graduate (Ream \& Rumberger, 2008).

According to Muennig (2008), people who graduate from high school live six to nine years longer than those who leave early, and they also live healthier lives. Muennig attributes this to the fact that graduates have better employment opportunities with potential health care benefits and that graduates are more likely than non-graduates to seek health care. Additionally, graduates, according to Muennig have less stress than those who leave high school early. These reasons, as well as "cognitive ability, social standing, other psychological or emotional factors, (and) behavioral risk factors" (Muennig, 2008, p. 127) lead to the fact that early leavers have higher rates of cardiovascular disease, cancer, infection, injury, lung disease, and diabetes. Finally, the costs of health care alone that could be saved by early leavers graduating from high school are estimated at $\$ 35,000$ per person (Viehweg, 2015).

Youth who do not graduate from high school also impact their communities and societies as a whole. Hanover Research (2015) stated that, "youth who fail to complete high school cost their communities an average of $\$ 300,000$ over their lifetimes" (p. 5). The Alliance for Excellent Education (2011b) has employed an economic modelling analysis to decipher the amount of gross domestic product which could be gained nationally and by each state in the event of increased graduation rates. For Oregon, with a 
reported $72.6 \%$ graduation rate in 2011, its 12,187 Class of 2011 dropouts would have earned an additional combined $\$ 1.39$ billion over their lifetimes, had they graduated that year with their classmates. Oregon's 2017 graduation rate is ranked $48^{\text {th }}$ overall for the country (United Health Foundation, 2017). Nationally, the additional earnings for the class of 2011 students who did not graduate would pour an additional \$154 billion into the national economy over their lifetimes (Alliance for Excellent Education, 2011b), with devastating economic consequences over the next decade. The Alliance for Excellent Education warned that "unless high schools are able to graduate their students at higher rates, nearly 12 million students will likely drop out over the next decade, resulting in a loss to the nation of $\$ 1.5$ trillion" (p. 2).

Youth who do not graduate from high school are also linked in significant ways to the criminal justice system. According to Viehweg (2015), 75\% of all crimes committed in the United States are by early leavers and $82 \%$ of all American prisoners are early leavers. Sum et al. (2009) stated that 1 in every 10 young male early leavers is incarcerated, compared to less than 1 of every 33 young male high school graduates. Sum et al. further noted that only 1 out of every 500 men with a bachelor's degree is incarcerated and that "for all young males, high school dropouts were 47 times more likely to be incarcerated than their similar aged peers who held a four-year college degree" (p. 11). Additionally, a 4-year study in San Francisco found that $94 \%$ of murder victims under age 25 in that city were early leavers (Harris, 2013).

\section{Push, Pull, and Fall-Out Factors}

While leaving high school before graduating is dramatic in its long-term impacts, it is nonetheless, not a single event. It is rather a manifestation of an often years-long 
process of academic, social, and emotional disengagement from compulsory education (Finn, 1989; Garnier et al., 1997; Rumberger \& Lim, 2008). Ream and Rumberger (2008) explained that "dropping out is perhaps best viewed as a long-term process of disengagement and withdrawal from school that often begins in early elementary school" (p. 110).

Scholars have identified both push and pull factors present in the lives of students who eventually become early leavers (Boylan \& Renzulli, 2014; Bradley \& Renzulli, 2011; Doll et al., 2013; Johnston-Goodstar \&VeLure Roholt, 2017; Jordan et al., 1996; Stearns \& Glennie, 2006; Zammit \& Anderson-Ketchmark, 2011). Push factors, such as exclusionary discipline, unwelcoming environments, rigid school and district policies, and bullying are forces within schools that have the effect of pushing students out of school. Pull factors, on the other hand, refer to influences outside of school that pull students away. Examples of these include employment, parenting, and gang activity. There is also a phenomenon termed fall out which is a third category scholars have identified as reasons students leave school before graduation (Doll et al., 2013). Students who fall out of high school do so due to a lack of belonging or connection to schools (Doll et al., 2013). According to Doll et al.,

The key difference between push, pull, and falling out factors has to do with agency. With push factors, the school is the agent, whereby a student is removed from school as a result of a consequence. With pull factors, the student is the agent, such that attractions or distractions lure them out of school. Finally, with falling out factors, neither the student nor school is the agent." (p. 2)

For the purposes of this study, I refer to the group of students who drop out, fall out or are pushed out collectively as early leavers, unless the distinction of agency is relevant. 


\section{From Disengagement to Reengagement}

Many early leaver students find their way back to school through an alternative school or program. Some early leaver students may attempt to return to their original high school after leaving, as well, but this can be precarious. Bland et al. (2012), for example, found that $75 \%$ of students who returned to the school from which they previously left as early leavers, left again. Eskolta Research Associates studied 70,000 New York City public high school students and found that one eighth of all these students fell two or more years behind in credits during their first three years of high school (Jimenez et al., 2018). Of those who did not fall behind, $88.9 \%$ graduated from high school (Jimenez, et al., 2018). Of those who did fall behind, however, the likelihood of them ever graduating was slim. Those from this sub-group who remained in conventional high school settings graduated at a rate of only $13.2 \%$, while those who transferred to an alternative setting graduated at a rate of $29.9 \%$, more than 50\% higher (Jimenez et al., 2018).

If alternative schools across the country resemble New York City's track record of a 50\% higher graduation rate for disengaged students or students returning to school after becoming early leavers, states would do well to find out what is and is not working to support these students. We would expect that school, district, and state accountability systems would also accurately report the percentages of these students who graduate. While a rate that is $50 \%$ higher is a good sign, an overall graduation rate for former early leavers of $29.9 \%$ is still unacceptable. In fact, the federal government's Every Student Succeeds Act of 2015 (ESSA) sets the bar of an acceptable graduation rate for each school in the country at $67 \%$, resulting in a sobering track record for alternative high 
schools who work to reengage early leaver and other transfer students. Three-quarters or $75 \%$ of these alternative high schools fall below the $67 \%$ threshold, identifying them as comprehensive support and improvement schools or schools in need of comprehensive support and intervention (Lovell, 2019). This begs the question, then, about whether current accountability systems are effectively measuring the work of alternative high schools or whether they may have a role in deepening the marginalization of students who attend them, which include many kinds of Historically Underserved students. Accountability systems that can guide alternative schools and district and state policymakers toward higher levels of high school graduation for all students could potentially indirectly support a group of young people to higher levels of income and economic progress, better physical and mental health, and lower levels of incarceration, as noted earlier in this paper.

School accountability is one arena where public policy and law meet with daily school operations. To better understand the intersections of school accountability with alternative high schools, we must grapple with the historical, legal, socio-cultural, and racial context of schooling in the United States.

\section{Historical, Socio-Cultural, Racial Context}

\section{Historical Context}

So how did we get to this place in the United States of America in the $21^{\text {st }}$ Century where only some students graduate from a schooling system which is funded by tax-payers? How did we get to a place where the majority of those who do not graduate are BIPOC students and students from low-income families, as well as students with disabilities or who are learning English as an additional language? We must look back 
hundreds of years to understand the historical context of drop-out, push-out, and fall-out, as well as school accountability. Chapter 2 highlights some of the ways in which schools in the United States were only intended to benefit White students, as well as the fact that this history of racism and exclusion persists today in many forms. Among these are the ways in which conventional high schools push BIPOC students out of school.

The writers of the United States Constitution did not add the educational system to the Constitution. It was not until the Tenth Amendment was ratified in 1791 that jurisdiction for education was clarified to be implicitly granted to states, due to the fact that it was not explicitly mentioned in the original constitution nor in the first nine amendments (Fowler, 2014). More than 200 years later, educational policy in the United States continues to be primarily the purview of local districts and states. Cross (2014) stressed that the lack of a national educational policy is due, in part, to the fact that individual states joined the nation at different times, are comprised of different sizes, and have different resources. The number of school districts in each state ranges from one single school district in Hawaii, to the states of Texas and California, which each have about 1,000 school districts. These differences in size, wealth, capacity, and tradition contribute to stronger local cultures and values than a sense of national identity that would serve as a foundation for national educational policies of larger scope and coherence (Cross, 2014).

\section{National Accountability Mandates}

One area where federal policy has a great impact on schools throughout the nation, including alternative schools, is with respect to mandated accountability systems. Accountability systems that sanction educators and school districts for a lack of progress 
began with the No Child Left Behind Act of 2001, also known as NCLB, developed in the George W. Bush administration. In January 2001, three days after his inauguration to be the $43^{\text {rd }}$ president of the United States, George W. Bush announced this educational policy (Cross, 2014). While most school funding comes from states and local districts, large federally-funded programs like Special Education, student nutrition for those qualifying for free or reduced-price lunch, and Title 1 are important to districts and can be withheld from districts and schools who do not comply with federal laws and directives (Orfield et al., 2004).

NCLB created a great deal of high stakes accountability, moving the role of the federal government in education to more of a regulatory role and less of an open funding stream for states and local districts. NCLB stressed four main principles: testing, flexibility, assisting failing schools, and choice (Cross, 2014). The consequences for failing to meet increasingly higher targets in the first of these principles, testing, placed teachers, administrators, and other educators under enormous pressure. This pressure included the limiting of funding, removing educators from their roles, and publicly labeling schools as failing (The Advancement Project et al., 2011). Each of these tactics has had impacts on the early leaver issue, particularly with respect to the act of pushing students out of school and further stigmatizing the students enrolled in "failing" schools.

Since the initial inception of NCLB, the principal federal law for K-12 education has changed multiple times and is now the ESSA. ESSA became law in December, 2015, and requires states to have a school report card. Each state chooses five indicators to measure school performance. Four of these measures are achievement-related with the 
fifth being a measure of school quality or success (Chang et al., 2018). Oregon's state ESSA plan for high schools includes ratings for chronic absenteeism, English Language Arts achievement and growth, Math achievement and growth, English learner progress, $9^{\text {th }}$ grade on-track, and 4- and 5-year graduation rates (Oregon Department of Education, n.d.-c).

As is the case with most states, Oregon's ESSA plan evaluates alternative high schools by the same metrics and criteria that it does regular high schools. In rating all schools in the state on the percentage of students who graduate within four or five years and assigning that rating to the last school a student attends assumes that all students are part of a cohort that begins in ninth grade and proceeds without interruption to grade 12 . “The reality, however," according to Jimenez et al. (2018), "is that measures like the four-year or (five)-year graduation rate simply do not do justice to the lived experiences of these students" (p. 4). Students who experience the disruptions of trauma, homelessness, teen pregnancy and parenthood, mobility, substance abuse, incarceration or other events frequently fall behind in credits, diminishing the likelihood of an on-time graduation. Schools that serve higher percentages of students impacted by these conditions should not be rated as less competent than schools with higher percentages of students who do stay together in a cohort that progresses through high school in a more linear fashion.

Alternative accountability systems provide one remedy to this problem. Although ESSA allows states to use the same or different accountability systems for alternative high schools (Jimenez et al., 2018), only six states have both a standard and an alternative 
accountability system. These states are California, Colorado, Florida, North Carolina, Oklahoma, and Texas (Almeida et al., 2010; Griffin \& Stahl, 2020; Schlessman \& Hurtado, 2012). Jimenez et al. (2018) posited that one reason so few states have developed alternative accountability systems may be that "there is a knowledge gap when it comes to understanding how students navigate the alternative school experience and how effectively the federally required school performance measures assess these schools" (p. 1).

\section{Social Context}

The demographics of alternative high schools do not reflect the demographics of the general population. Alternative high schools are over-represented with students who are low-income (Finn et al., 2005; Ou et al., 2007; Rumberger, 2011; Sweeten, 2006); have learning disabilities (Lehr et al., 2009); have substance abuse and/or mental health challenges (Hagan \& Foster, 2001; Koch \& McGeary, 2005; Krohn et al., 1997; WilcoxGök et al., 2004); are off-track for graduation (Jimenez et al., 2018); are BIPOC students (Forste \& Tienda, 1992; Perzigian et al., 2017); have high mobility (Ensminger et al., 2003); are pregnant and/or parenting (Ensminger et al., 2003; Ensminger \& Slusarcick, 1992; Forste \& Tienda, 1992; Lehr et al., 2009); and are adjudicated or involved in the foster care system (Robison et al., 2017; Sweeten, 2006). Given these realities, it is important to understand the crucial role alternative education plays in helping these underserved populations get through high school and transition to the next steps in their lives.

If alternative schools are serving the most underserved students and these schools are judged by an accountability system that was not designed for schools with their 
particular set of circumstances, what impact does the accountability process have on these schools, the people who work in them, and the students who attend them? Heilig (2001) posited that "the prevailing theory of action underlying . . . accountability ratings is that schools and students held accountable to these measures will automatically increase educational output as educators try harder, schools will adopt more effective methods, and students will learn more" (p. 2633). There is an assumption in the design of accountability systems that in-tact cohorts move in a linear fashion toward graduation after 4 years of high school. There is also an assumption that maintaining this focus as a measure of educators' quality will make educators "try harder" as Heilig (2001, p. 2) indicated is the intent. There is a lack of research or data suggesting that this intended impact is met.

\section{Racial-Cultural Context}

With nearly half of BIPOC students becoming early leavers, the racial-cultural context of alternative schools and alternative accountability is immense. Because many educational policies and practices fall within the purview of state and local governments, it is not surprising that there is also no national or uniform method for compiling or reporting numbers of students who leave high school prior to graduation.

For example, in the New York City and Houston school districts, both of which have a majority population of Chicanx students, the overall graduation rates reported in 2004 are very low. New York City's was 38\% and Houston's was 40\% (McNeil et al., 2008). School districts with African American majorities share similarly disturbing statistics. Among these predominantly African American districts are Oakland, California with a $30.4 \%$ graduation rate, Atlanta, Georgia with $39.6 \%$, Cleveland, Ohio with $30 \%$ 
and Columbus, Ohio with 34.4\% (Orfield et al., 2004). In Texas, the state's official dropout rates were reported in the 2.8 to $3.2 \%$ range in 2002, but McNeil et al. (2008) contended that this is misleading, because at least 135,000 youth leave Texas schools each year prior to graduation. The state of Texas, they assert, has more than 20 leaver codes used to remove students from their grade cohort, thus obfuscating who is and who is not counted. Further, school officials in Texas can apply leaver codes at their discretion without procedures to verify transfers (McNeil et al., 2008).

Perhaps part of the problem in generating reliable information is the fact that our nation spends much more money on checking test data than what we spend measuring whether students graduate. According to Phillip Kaufman (as cited in Orfield et al., 2004), "the federal government spends over $\$ 40$ million on the National Assessment of Educational Progress. It probably spends less than $\$ 1$ million on dropout statistics” (p. 7). Additionally, the numbers of BIPOC students, students with disabilities, and students living in poverty, are seldom reported accurately (Hall, 2005; Orfield et al., 2004).

Orfield et al. (2004) stressed that a more accurate method for tracking high school graduation rates would be a system in which students are issued lifetime school identification numbers that would follow them through the years and across any school district or state lines. This method would solve problems of under-identifying early leavers, such as what happens in the state of Texas. In Texas, according to Orfield et al., students are removed from graduation cohorts when they earn a GED and disappear from enrollment records without explanation. Swanson and Chaplin (2003), who studied four graduation rate data systems, concurred with Orfield et al. and pointed out that accurate 
and uniform systems are missing and greatly impede the ability of educators and policy makers to effectively track graduation rates as a way to meet students' needs and as a key performance indicator. This is further exacerbated by the way that the Common Core of Data, a census of public sector state and local agencies, sponsored by the National Center for Educational Statistics, a branch of the U.S. Department of Education, works. The Common Core of Data, according to Swanson and Chaplin (2003), either does not report early leaver data for large numbers of states and districts or it greatly understates the numbers.

Due to the Tenth Amendment's implicit granting of most rights and responsibilities for public education to states, ESSA has increased states' autonomy to define more of their educational plans than was the case with NCLB (Saultz et al., 2017). The impact of these plans and policies, both at the state and federal levels, have not resulted in addressing the issue of BIPOC students leaving school at higher rates than do White students. If policy makers were hoping to hold schools more accountable to BIPOC students through disaggregated tracking of their progress, it is clear that schools have found ways to skirt this effort.

\section{Alternative Schools Versus Alternative Programs}

The Oregon Secretary of State performed an audit of the state's alternative schools in 2017 and included 33 stand-alone alternative schools and more than 100 alternative school programs in its data-gathering (Richardson \& Memmott, 2017). An alternative education school is described in Oregon Revised Statutes (ORS 336.615) as "a school or separate class group designed to assist students to achieve the goals of the 
curriculum in a manner consistent with their learning styles and needs (to) best serve students' educational needs and interests and assist students in achieving the academic standards of the school district and the state" (Oregonlaws.org, 2020a, para. 1).

Alternative schools tend to be stand-alone, brick and mortar schools designed to serve the needs of students who are not well-served in more conventional school settings (Richardson \& Memmot, 2017)). An alternative program, however, differs from an alternative school in ways that are relevant to school accountability. Alternative programs frequently operate within regular high schools, juvenile detention facilities, community colleges, and non-profit organizations. Alternative programs do not have their own state report card, like alternative schools; rather, the accountability metric data for alternative program students are folded into high school or district results (Richardson \& Memmott, 2017)). In practice, the successful graduation of a student who attends an alternative program is credited, then, to their last "accountable" high school of record. Accountable schools refer to schools with state report cards.

In practice, both alternative schools and programs in Oregon and throughout the United States are schools that educate students who are not well-served by conventional schools (Slaten et al., 2015). Table 2, which has been created from the Oregon Secretary of State audit of alternative and online education, includes the demographics of alternative school students in Oregon (Richardson \& Memmott, 2017). (Online school data have been omitted.)

As is seen in Table 2, even though alternative schools' demographics demonstrate the need for additional resources and are commonly understood as a safety valve for 
students who would not otherwise graduate, they are also commonly under-resourced for the complex task of helping students who fall through the cracks in other settings (Newton, Thompson, Oh, \& Ferullo, 2017; Slaten et al., 2015).

\section{Table 2}

Grade 9-12 Student Population Characteristics, 2015-2016 School Year Statewide Alternative Schools and Programs

\begin{tabular}{|l|c|c|c|}
\hline & Statewide & $\begin{array}{c}\text { Alternative Schools } \\
\text { (data from 33) }\end{array}$ & $\begin{array}{c}\text { Alternative Programs } \\
\text { (data from > 100) }\end{array}$ \\
\hline Highly Mobile & $19 \%$ & $60 \%$ & $73 \%$ \\
\hline Economically Disadvantaged & $48 \%$ & $70 \%$ & $51 \%$ \\
\hline Disabilities & $14 \%$ & $21 \%$ & $38 \%$ \\
\hline $\begin{array}{l}\text { Historically Underserved } \\
\text { (Race and Ethnicity) }\end{array}$ & $26 \%$ & $35 \%$ & \\
\hline
\end{tabular}

Source: (Richardson \& Memmott, 2017).

\section{Statement of the Research Problem and Introduction to the Study}

Purpose of the Study

This study has aimed to understand how the state accountability system influences the work of alternative high school principals and their students who have not been well-served in conventional schools (Alliance for Excellence in Education, 2011a, 2011b; Bickerstaff, 2010; Bridgeland et al., 2006; de la Ossa, 2005; Iachini et al., 2013). By exploring the experiences and perspectives of these alternative high school principals, the study has further aimed to identify a potential counter narrative to the prevailing ideas of alternative high schools as failing (The Advancement Project 
et al., 2011) or deviant (Bickerstaff, 2010). A particular focus of this study is the examination of how state accountability systems label alternative high schools and what effect this labeling may have on the work of providing an alternative school option for the enrolled students. Finally, this study seeks to examine how the role of alternative high schools and state accountability intersect with race and the overrepresentation of BIPOC students in alternative schools throughout the United States (Orfield et al., 2004). The sample of principal participants are those whose school populations have higher than average percentages of BIPOC students relative to other alternative high schools in their state. Data were gathered to address how alternative high school administrators conceptualize school effectiveness in helping underserved students to learn skills and content, persist toward graduation, and pursue positive life paths after high school.

\section{Reasons for the Study}

At present, about one tenth of Oregon's high school students are served by the state's 33 alternative high schools and more than 100 alternative high school programs (Richardson \& Memmott, 2017). Every alternative high school except two identified by the Oregon Secretary of State's (Richardson \& Memmott, 2017) audit has a 4-year graduation rate that falls below 67\%, which the federal government and Oregon Department of Education (2018) used as a threshold for identifying schools that are or are not meeting expectations. This one data point, however, does not tell the whole story. The Oregon Secretary of State's audit of alternative education in the state indicates that 4-year graduation and 5-year completion rates for alternative high schools are more a reflection of the at-risk status of the students when they arrive at the school than they are a measure 
of the schools' effectiveness (Richardson \& Memmott, 2017). The two alternative high schools that do exceed the $67 \%$ four-year cohort graduation rate are both located in urban areas in the state. One partners with a local community college to deliver an early college model and the other has a student population that is $11 \%$ historically underserved, much lower than that of other alternative schools and programs in the same urban area. These factors may play a role in these two schools serving as the exception to the trend.

Since Oregon does not have a system which is designed to measure the specific work of alternative schools through student learning growth, reengagement from early leaver status, persistence to graduation, or other measures, the state and individual school districts do not have a clear picture of the impact of these schools on the lives and educational outcomes of the students who attend them. There is also a lack of understanding of the impact alternative high schools have on the graduation and completion rates of conventional high schools who can be rewarded for their own graduation rate increases that happen when students are pushed out, drop out or fall out (Doll et al., 2013). Knowing that alternative schools are under-resourced in the state of Oregon compared to conventional schools and knowing that BIPOC students are overrepresented in these schools calls for scholars and educational practitioners to shine a light on yet another system of disinvestment and racial discrimination (Orfield et al., 2004; Richardson \& Memmott, 2017)). Soliciting input from school administrators working in these schools is one step toward a larger discussion within the state about how to ensure that Oregon's most under-served students are equitably treated by its public education system. 


\section{Research Questions}

RQ 1: How do alternative high school administrators in one West Coast state describe the experience and the needs of BIPOC students in their school?

$>$ RQ 2: In what ways, if any, do the state accountability measures influence the work of alternative high school administrators in one West Coast state?

$>$ RQ 3: How do alternative high school administrators describe their role in their respective school districts as compared to the role of administrators in their districts' conventional high schools?

\section{Educational Significance of the Problem}

In 2011, the Oregon State Legislature adopted Senate Bill 253, which is commonly known as the 40/40/20 bill (Oregon Learns, 2018). This bill, which has been widely publicized, is very focused on post-secondary enrollment and graduation. What is less commonly part of the conversation, however, is the fact that moving a state to boasting a $40 \%$ level of residents with a bachelor's degree, $40 \%$ with an associate's degree or career certificate, and $20 \%$ with a college or career-ready high school diploma implies that $100 \%$ have graduated from high school (Oregon Learns, 2018). Oregon's state accountability system does not accurately identify who eventually graduates from high school, given that student-level graduation data for students in alternative education is often folded into district data or into the data of the last conventional high school attended (Richardson \& Memmott, 2017). Students who take more than 5 years to graduate from high school are also counted as drop outs, even if they eventually earn the same diploma earned by their conventional high school counterparts.

The invisibility of these students, along with incentives for conventional high schools to push them out of school, creates a crisis of inequity for students who are 
more likely to be BIPOC students, low-income students, and students with disabilities. According to Rumberger (2011), the mere fact that schools are accountable only for their currently enrolled students encourages them to subtlety or overtly move students who may reflect poorly on the schools' accountability status to alternative or other schools. Reflecting poorly can be defined as low test scores or not being on track to graduate with one's cohort, however arbitrary the cohort designation is.

Educators who work with these students every day could play a crucial role in identifying the significance of these schools in the lives of their students, as well as the best way to measure student progress, while keeping alternative and conventional schools accountable to their students, communities, and state taxpayers. Within public schools and school districts, principals, in particular, are named on state report cards and are considered the most responsible people for ensuring student achievement and graduation (Fowler, 2014). There is, however, scant research that includes the perspectives of alternative high school principals. In reviewing literature for this dissertation, the only studies that included principal voices in studies regarding alternative high schools were those from outside of the United States.

\section{Personal Significance of the Problem}

In October, 2013, I was in my second full month as the principal of an urban alternative high school and attended my state's annual principal conference. Among the presentations I chose to attend at that conference was one by a fellow principal in another school district. This principal had recently won a national award for his work to "turn around" a "failing" high school. This presenter made it very clear at the beginning of his presentation how he moved his school's data from failing to exemplary. "The first thing I 
did," he shared, "was to move all the kids who would not graduate on time to the alternative school." It became clear to me in that very moment that it was no secret to this individual and perhaps to others, that excluding students from a conventional public high school and moving them to a public alternative high school could result in improved data for the conventional school and that this action is rewarded at local, state, and national levels. Further, it became clear that this move was seen as the most expedient first action for a new principal; rather than focusing on ways to improve the learning conditions for all students in his school, he identified a way to improve only his perceived performance as a school leader.

This example is not an isolated one. I have met many students in my teaching and administrative career who said they felt pushed out of their conventional schools into alternative schools because they would not graduate on time. I have also spoken with fellow principals and district officials who understand how to improve their own school data by moving off-track students out of their schools. When an alternative high school then enrolls students who are pushed out of conventional high schools, and the newlyenrolled student is included in the alternative school's accountability data, there are many implications for the alternative high school principal. This study has sought to understand the point of view of these alternative high school principals on this issue.

\section{Introduction of Research Methods}

Data for this study comes from two sources: semi-structured interviews of five alternative high school principals from one West Coast state, as well as from analysis of documents pertinent to the schools these principals lead. The individual principals and their schools were chosen because they are among the half of alternative high schools in 
the state with the highest percentages of BIPOC students. Alternative programs are excluded from this study, given that they currently do not have school report cards. Alternative programs also vary considerably in their student population, purpose, and scope of services, depending upon whether they exist within a conventional high school setting, community college, or non-profit agency and depending upon the region of the state in which they reside. The interview guides (see Appendices D, E, and F) seek to identify the role of current school accountability practices in these schools, focusing on the role of the Oregon State School Report Card and the 4-year cohort graduation rate for each of these schools. The interview guides also are designed to reveal possible counter narratives to the commonly-held idea that small schools and alternative high schools are inherently failing or deviant.

The data-collection methods of interviewing and document analysis make this a basic, multi-method qualitative study (Creswell \& Creswell, 2018). Maxwell (2013) cited two major reasons for using more than one data-collection method in a qualitative study. The first reason is that using multiple methods affords the opportunity to triangulate data or check findings from one approach with another. Maxwell's (2013) second purpose for multiple methods was that more than one kind of data will help the researcher understand additional aspects of the phenomena under study.

Weiss (1994) contended that "research aims should dictate the research method" (p. 9). He went on to highlight seven reasons for engaging in qualitative research. Among these are four which are most relevant to this study: the desire to develop detailed descriptions, the call for multiple perspectives, the development of holistic descriptions, 
and the "bridging of intersubjectivities" (p. 10). A full description of the study's methodology is detailed in Chapter 3.

\section{Chapter One Summary}

This study has aimed to understand how the state accountability system influences the work of alternative high school principals and the experience of students in these schools, which typically serve students who have not been well-served in conventional schools (Alliance for Excellence in Education, 2011a, 2011b; Bickerstaff, 2010; Bridgeland et al., 2006; de la Ossa, 2005; Iachini et al., 2013). These alternative high schools on average serve higher percentages of BIPOC students (Balfanz \& Legters, 2004; Balfanz \& West, 2006; Orfield et al., 2004), students living in poverty (Glassett Farrelly \& Daniels, 2014; McNeil et al., 2008; Newton et al., 2017), and students with disabilities (Lehr et al., 2009; McNeil et al., 2008). Alternative high school principals are charged with leading schools filled with students who have these enormous challenges, while they are also required to answer to an accountability system that may deepen the marginalization of their students.

Principals from urban, rural, and suburban alternative high schools in one Pacific Northwest state have been purposefully chosen, because their schools are in the $50 \%$ of alternative schools with the highest percentage of BIPOC students, compared to other alternative schools in the state. All of these schools reside in a state that does not use a different accountability system for its alternative and conventional high schools. This lack of attention to the unique circumstances of alternative high schools and their students could contribute to a narrative that these students are failures and that the 
alternative high schools in which they have landed are also failures, rather than recognizing the unique role of alternative schools in helping early leaver students to graduate.

\section{Key Concepts}

Adequate Yearly Progress (AYP)—A requirement in the 2001 NCLB federal law, requiring schools and school districts to meet annual benchmarks in testing participation, results, attendance and/or graduation rate. The general goal for AYP was that all students within all schools and all states would demonstrate academic proficiency, as defined by each state, at the end of a 12-year period. Parents of students in these schools that repeatedly do not achieve AYP, according to the law, can choose to send their children to another public school (Cross, 2014).

Alternative Program - A program within a school or community setting to support students to graduate from high school. Alternative programs are supplemental in nature and are not bound to all of the same accountability provisions as are schools, including alternative schools. When a student graduates from an alternative program, the former school they attended claims the student on their graduation count, thus effectively boosting the graduation rate of that last school.

Alternative School—A school operating under state alternative education provisions that also must meet federal, state, and local accountability measures. An alternative education school is described in Oregon Revised Statutes (ORS 336.615) as a school or separate class group designed to assist students to achieve the goals of the curriculum in a manner consistent with their learning styles and needs (to) best serve students' educational needs and interests and assist students in 
achieving the academic standards of the school district and the state.

(Oregonlaws.org, 2020a, para. 1)

BIPOC students, students with disabilities, students with challenging behavior, students in poverty, those who are pregnant and parenting, and those generally considered at risk are over-represented in alternative schools (Glassett Farrelly \& Daniels, 2014; Newton et al., 2017).

Conventional High School—Conventional schools are those public high schools which are most commonly charged with providing a comprehensive curriculum which builds from $9^{\text {th }}$ to $12^{\text {th }}$ grade. In Oregon, conventional high schools range in enrollment from more than 2,400 in urban areas to 11 students in one rural district (Oregon School Activities Association, 2019). While also referred to in the literature as traditional high schools (Lagana-Riordan et al., 2011; Mirel, 2006; Perzigian et al., 2017), the term conventional denotes current practice and is used in this document to imply "nonalternative."

Disengagement - Students who disengage from learning in school may start as early as first grade (Alexander et al., 1997). Disengagement can be manifested as off-task behavior, academic underperformance, and eventually leaving school prior to graduation. School systems often react to the student's disengagement through a focus on the student, rather than a focus on its institutional and societal root causes and struggle to connect early disengagement with its final manifestation-leaving school without graduating (Rumberger, 2011).

Dropout - A student who does not earn a high school diploma in 4 years and has left high school temporarily or permanently is referred to as a "dropout." Students who 
drop out of high school do so for a number of reasons, including "a lack of connection to the school environment; a perception that school is boring; feeling unmotivated; academic challenges; and the weight of real world events" (Bridgeland et al., p. iii). Dropping out of high school is more the culmination of years of events rather than a single act. This culmination has been described as "the result of a combination of individual, family, and school experiences" (Garnier et al., 1997, p. 397).

Early Leaver-A student who has not finished high school, whether the student chose to leave, failed to establish any connections with the school, thus "falling out," or was pushed out (Doll et al., 2013). This term is used in this paper to indicate that the student has left high school without graduating. In cases where the reason the student left high school is relevant, the terms "dropout," "pushout" or "fall out" is used.

Ever English Language Learners-This is a term used by some of this study's participants, as well as scholars to describe students who are currently in or have been exited from state programs for teaching English as a Second Language (Burho, 2019).

Historically Underserved Student—-The Oregon Secretary of State, in its 2017 audit of alternative education, defined historically underserved students as those who identify as: Black/African American, Hispanic/Latino, American Indian/Alaska Native or Native Hawaiian/Pacific Islander (Richardson \& Memmott, 2017).

Local Education Agency—A school district, governed by an elected Board of Education, responsible for the operation of public elementary and secondary schools in a specific area within a state (U.S. Department of Education, n.d.). 
Participant - The term participant is used in this study, as opposed to using the term, subject, to denote the people who are participating in interviews from which data are collected. This use of the term is meant to acknowledge the humanity and agency of the individuals participating in the study, rather than imply that they are the passive, objectified recipients of research methodologies subjected on them.

Pushout-The term push-out refers both to a person and to an act. With respect to the person, a push-out is a student who has been overtly required or subtly encouraged to leave a school and either earn a GED, alternative school credential, or simply leave their previous school behind. The act of pushing out can happen through a formal process such as expulsion or students can be "counseled out" of school with the suggestion that they will not be able to earn a diploma. Other even more subtle forms of pushout can be likened to micro-aggressions which communicate to students that they are unwelcome (Rumberger, 2011). The term "pushout" implies a shift away from the deficit model of placing blame on students and their families for a lack of school success and instead calls for an examination of school culture and policies that are unfriendly to groups of students, particularly BIPOC students, students with disabilities, and students in poverty (Johnston-Goodstar \& VeLure Roholt, 2017, p. 33).

Race- This study focuses in part on the intersection of racial inequities and the overrepresentation of BIPOC students in the early leaver student population. A conscious decision has been made when referring to non-White students to use the term BIPOC, as noted earlier. When referring to specific groups of BIPOC students, I use the terms African American, Indigenous, and Chicanx. I use Chicanx as a means of decentering 
Spanish colonialism and anti-Indigenous bias inherent in the terms Latino/a, Latinx, and Hispanic, while maintaining the gender-neutral quality of the term through the final letter (López, 2018). Students of European descent are referred to as White with a deliberate decision to maintain the first letter as capitalized. The reason for this is to assert that White is a color, a race, and a culture, thus rejecting the idea that racial discussions are only about people of color (Singleton, 2015).

Reengagement of Early Learners-Reengagement is the process of identifying students who have left high school prior to graduation, making contact, and supporting them to return to school. Reengagement often occurs in a school that differs from the one the student previously left. Bland et al. (2012) found that $75 \%$ of students who returned to the school from which they previously left as early leavers, left again. Reengagement, then, often means that students enter a different school with a different experience that leads to eventual graduation.

Underserved - The use of the term underserved to characterize people who, as a group, are less privileged and more marginalized within the public schooling system in the United States is an intentional one. The use of this term is also an effort to use language that is not deficit-oriented and which places the onus for educational outcomes on the system which inequitably serves different groups of people on the basis of race, class, family language, and other factors. 


\section{Chapter Two: Literature Review}

\section{Introduction}

Alternative schools in the United States educate some of the most underserved students in the country and play a paramount role in reengaging students who have disengaged from other schools or left them prior to graduation. To fully understand the functions of alternative schools in contemporary society, it is important to understand their historical and political roots, as well as those generally of public schools in the United States.

It is also important to understand the larger social and cultural forces that lead to an overrepresentation of BIPOC students, students in poverty, and students with disabilities enrolled in alternative high schools. Part of this examination of social and cultural forces necessitates an interrogation of the history and functions of state accountability systems which designate the vast majority of alternative schools as failing to meet acceptable standards. As such, the literature reviewed in this chapter falls into the following broad categories: a theoretical framework of critical pedagogy, a conceptual framework and critique of rational systems theory and Taylorism, the history and politics of historical and modern school accountability, alternative accountability, and alternative education. The methodological literature for this proposed study is also reviewed in the section on the critical pedagogy theoretical framework.

Because this dissertation addresses questions of educational policy and their impact on a specific group of underserved students, several relevant documents from 
state agencies and private foundations are reviewed. Additionally, applicable qualitative, quantitative, and mixed-methods studies are reviewed in this chapter, as well as literature that describes the experience of scholars and practitioners. This more descriptive literature is especially present in the review of research methods and procedures. Studies of early leavers, accountability policy, and alternative education that were conducted outside of the United States have been excluded. The proposed study's methodology is further detailed in Chapter Three.

\section{Theoretical Framework}

\section{Critical Pedagogy}

This study builds on existing qualitative research, informed by critical pedagogy, which asserts that public schools reproduce racial, class and other inequities, while creating the necessity for the transfer of some of the most underserved students from conventional to alternative schools (Bickerstaff, 2010; de la Ossa, 2005; Epstein, 1992; Riehl, 1999; Slaten et al., 2015). Critical pedagogy is considered to be an outgrowth of critical theory, which was developed in large part by European theorists such as Karl Marx, Max Horkheimer, Theodor W. Adorno, Walter Benjamin, Leo Lowenthal, Erich Fromm, and Herbert Marcuse (McLaren, 2002). While all of these theorists are notably White men, their legacy rests on leftist traditions of critiquing societies with inequitable social classes, fascist regimes, and genocide, to name a few. Despite the fact that all critical theorists differ somewhat in their approaches, McLaren (2002) argued that they are united in their goal of empowering "the powerless and transform(ing) existing social inequalities and injustices" (p. 186). He also clearly rejected what he called the "prevailing neoconservative social logic, which attributes school failure to individual 
deficiencies on the part of a lazy, apathetic, and intellectually inferior underclass of students or to uncaring or selfish parents” (McLaren, 2002, p. 217). Brantlinger and Brantlinger (2013) mirrored this thinking when noting that critical theorists "dwell on negative aspects of schooling ... and are concerned with social justice, equity, and fairness, rather than competition and hierarchy" (p. 293).

Critical pedagogy, according to Brock (2015), is a "framing tool" (p. 288) that can help both scholars and practitioners to understand the educational system in general, as well as specific pedagogy within the classroom. Brock went on to note that critical pedagogy aims to help students function as competent individuals in a society that is democratic and inclusive and that it "seeks to give those who have been excluded from power the right and the ability to have input into civic life" (p. 291). Kincheloe et al. (2013) noted that any inquiry that carries the "critical" label must be "connected to an attempt to confront the injustice of a particular society or public sphere within a society" (p. 342).

\section{Freire's Pedagogy for Liberation}

One critical pedagogy theorist who provides a particularly important lens for understanding disengaged youth in schools is Freire (1993). Freire's work indirectly addresses many aspects of the early leaver problem; particularly that of youth who fall out of school, due to a lack of connection to educators and to the curriculum.

Freire (1993) developed the concept of a "banking" system of education, in which educators make deposits of information into the students who are treated as the equivalent of empty vessels. Students have no voice in the curriculum or instruction and the authoritarian and unequal practices of the school mirror those of the stratified and 
oppressive society. The student in a banking system of education is treated as an "object of assistance" (Freire, 1993, p. 83), rather than a thinking individual with ideas and opinions to contribute to the pedagogical process. This process, in the words of Freire, is dialectical materialism. His conception of this term can be summarized as a system in which students learn how to objectively analyze existing conditions in the world, including conditions of oppression, while becoming conscious "of both the conditions themselves and their sources, and for changing these conditions through human [social] intervention and action ..." (Au, 2007, p. 177).

Kim and Taylor (2008) took this focus on dialectical materialism into their study of an alternative high school, noting that "critical educators who work toward social change endorse theories that are dialectical” (p. 216). They argued that dialectical thinking in this context refuses to recognize individual problems as solely those of a person, but rather as reflective of problems in a larger social structure. This perspective is aligned with one that rejects deficit thinking about underserved individuals, such as early leaver students.

Freire (1993) asserted that the oppressed must be seen as part of the unjust and unequal society that created the conditions of their oppression, rather than as deviants who do not fit into a "just" society, due to laziness or a lack of capacity. When educators engage students as capable beings whose experience, insights, and opinions are valid and liberate them to develop their own critical consciousness, these students are empowered to transform the unequal society. Freire maintained that "the solution is not to integrate (the students) into 
the structure of oppression, but to transform that structure so that they can become beings for themselves" (p. 3). In the context of early leaver students, this is synonymous with deciding where to focus the problem of students who do not graduate. Much focus goes to repairing the student within a system that creates dramatically different outcomes for different racial, social, linguistic, and economic groups of students, rather than on repairing the system. Early leaver students, when asked why they left school before graduating, consistently cite a lack of connection to the school, a feeling that school is boring, a lack of help from teachers, a lack of interesting or relevant course work, poor teaching, academic challenges, and the weight of real world events (Bridgeland et al., 2006; Doll et al., 2013). None of these reasons lives solely within the individual student.

\section{Sorting Mechanisms}

In addition to Freire's influence on critical pedagogy, the works of other Western Hemisphere thinkers such as John Dewey, Myles Horton, Martin Luther King, Jr., and Malcolm X have influenced critical pedagogy. These additional scholars are all still notably male, but include men of color (McLaren, 2002). Critical pedagogy provides a useful lens for understanding how schools support and reproduce social class and racial hierarchy in the United States and other parts of the world. The idea of the school as a sorting mechanism comes from critical pedagogy (McLaren, 2002). Examples of the sorting mechanism include neighborhood school boundaries that maintain racial and class segregation, policies that route White, middle and upper middle class students into intellectually challenging classes that prepare them for 4-year colleges, while relegating 
other students into tracks that prepare them for less lucrative futures. There are additional examples from school disciplinary policies and practices that can privilege students whose cultures resemble those of educational authorities, while disenfranchising students who are historically underserved.

Sorting mechanisms can be easily be understood within the context of the problem of early leaver students, as well as the status of alternative schools. When lowincome students, BIPOC students, and those with disabilities do not receive equitable academic and social support to thrive in school, a long process of school disengagement is fostered (Alexander et al., 1997). Alexander et al. (1997) published a significant longitudinal study of African American and White students in Baltimore, following a cohort of students from first grade forward to attempt to measure precursors of dropout. While they measured 39 variables for possible correlation with eventual dropout, only 5 of these examined school practices. The other 34 dealt with family demographics and habits (Alexander et al., 1997). Despite this greater focus on student and family characteristics and less on the institutional characteristics of schools, the authors do support the use of critical pedagogy as a lens to understanding the early leaver problem. They asserted:

Prospects for "reengagement" later are not good when children are plagued early in their school careers by self-doubt, are alienated from things academic, are overage for their grades, are relegated to remedial courses, are prone to "problem" behaviors, are labeled troublemakers, and have academic skills that are far lower than the standard at which the curriculum is keyed. Sadly, this "profile" holds for far too many urban youths. (p. 98)

Schools that, from first grade forward, practice sorting in these ways, can also be seen as historical artifacts. Public schools, after all, were originally intended only for 
White people of means. This is evidenced by the fact that it was a crime in southern states through the first half of the nineteenth century to teach an African American person to read (Singleton, 2015). Darling-Hammond (1997) pointed to the history of large, impersonal, factory-model schools as tools to teach "rudimentary skills and unwavering compliance to the children of the poor" (p. 7), while the more affluent were able to access small private options or insulated tracks within larger high schools to nurture skills and habits that would better position them to maintain their privilege.

\section{Hidden Curriculum}

Like the sorting mechanism, the concept of the hidden curriculum is another contribution of critical pedagogy. Kentli (2009) provided a thorough overview of 10 theorists whose work deals with the hidden curriculum of schooling, from Emile

Durkheim in 1961 to Henry Giroux in 1983. Kentli defined the hidden curriculum broadly as the unofficial, non-academic socialization process of schooling. She went on to highlight this phenomenon as one that socializes youth away from the particulars of private, family culture to that of a public sector, promoting norms of independence, achievement, universalism, and specificity, all of which "are required to teach them in order to collaborate with modern industrial society" (p. 84).

One aspect of the hidden curriculum as it applies to the topic of early leaver students is the normative assumption of continuous enrollment in a conventional high school. Bickerstaff (2010) uncovered this idea in the thinking of early leaver students, who express shame and self-loathing for leaving school before they graduate. Bickerstaff further countered this internalization of this hidden curriculum with the fact that more than $63 \%$ of early leavers eventually return to school to earn a high school diploma or 
equivalent, according to data she quoted from the National Education Longitudinal Study (1988) data and the work of scholars extending that data. These early leavers who do later return to school overwhelmingly do so through alternative high schools and alternative programs, though this fact is mostly lost on the public, due in part to the lack of reporting mechanisms to show high school completion beyond 4- or 5-year cohort rate counts (Bickerstaff, 2010).

\section{Critical Qualitative Research}

Merriam and Tisdell (2016) contended that critical research is a broad term applied to research that examines and challenges power dynamics and critiques the status quo in an effort to contribute to a more just society. They went on to argue that critical research can be combined with other qualitative methodologies, such as grounded theory, ethnography, and autoethnography. This focus on examining power critically in research is also described by McNulty and Roseboro (2009), who wrote that:

qualitative research, while not exempt from racist, sexist, classist and other systems of oppression, holds tremendous potential for unearthing oppressive processes by exploring the voices of those who have been systematically excluded from dominant discourses ... It is through qualitative research and writing that authentic voices come forward. (p. 414)

Alternative high school principals do not represent a social group that has been necessarily oppressed or systematically excluded from dominant discourses, as is the case with many of the students who are early leavers or who are enrolled in alternative high schools. This study, therefore, looks to this group of principals for their insights on the ways in which state policies contribute to further educational marginalization of early leaver youth. I am not suggesting that alternative high school principals are a disenfranchised group in and of themselves. 
This study investigated the perspectives of alternative high school principals who serve in schools within the top half of alternative schools in the particular West Coast state, as measured by percentages of BIPOC students. These perspectives are best captured within qualitative interviews for a number of reasons. First, the process of describing one's experience and then reflecting on that orally is a meaning-making process unique to each of the study's participants and may differ from ideas expressed in the literature or by the researcher (Creswell \& Creswell, 2018). Secondly, the topics of alternative education, school accountability, race and marginalization are complex. Creswell and Creswell stated, "qualitative researchers try to develop a complex picture of the problem or issue under study. This involves reporting multiple perspectives, identifying the many factors involved in a situation, and generally sketching the larger picture that emerges (p. 182)." While the group of participants who participated in this study may appear to be very specific, multiple perspectives emerged with respect to some district practices that have a bearing on alternative schools.

A phenomenological approach to this research was considered, but ultimately not chosen. Seidman (2013) described the phenomenological approach as a combination of life history interviewing and in-depth interviewing, relying largely upon open-ended questions that prompt participants to reconstruct and reflect on their own experience. Phenomenology, according to Lunenburg and Irby (2008), "is concerned with clarifying the specific and recognizing phenomena through the eyes of the participants" (p. 90). Phenomenology is a more in-depth approach than some other qualitative approaches. For example, Seidman recommended the researcher conduct three 90-minute interviews with 
each participant. For this study, the three-interview design is not as warranted, because this is less a study about the inner lives and personal experiences of alternative high school principals and more a study of their views of and experiences with a state accountability system and how this may intersect with issues of race and marginalization. Seidman's three-interview approach may give more time and focus to the life histories of principals than a two-interview approach that focuses more directly on their work experiences, as directed by this study's interview questions (see Appendices D, E, and F). On a practical note, all principals are busy people. Asking for three 90-minute interviews may not be realistic and could have had the unintended consequence of influencing participants to opt out of the study. With the purposeful selection of the five participants in this study (see next section), it is clear that there is not a large pool of other participants from which to invite into the study.

Before determining that the qualitative design best fits the research questions, a mixed methods research design was also thoroughly considered and ultimately not chosen. The particular mixed methods design considered was an exploratory, six-step method detailed by Gehlbach and Brinkworth (2011). In this design, a qualitative expert focus group happens first and informs the creation of a survey as the primary datagathering instrument. In thinking through this method, alternative high school students would have served as the experts in the focus group, informing the survey for alternative high school principals throughout the state. Perhaps most interesting about this approach was the chance to have a fully representative sample of the voices of all or most of the principals of this state's 33 public, accountable alternative high schools. The more I 
investigated this approach, however, the more it became clear that a survey could not capture the nuances of this complex issue, nor the ways that practitioners in the field make sense of the phenomena studied.

\section{Conceptual Framework}

\section{Rational Systems Theory and Taylorism}

A critical analysis of rational systems theory, which is largely attributed to the work of Frederick Taylor, also informs this study. In the early 20th century, Taylor's (1911) work was referred to as scientific management theory. While rational systems theory is inclusive of Taylor's scientific management theory, as well as the work of Henri Fayol and Mary Parker Follett (Marion \& Gonzalez, 2014), the emphasis for our purposes here is the work of Taylor. Frederick Taylor was born in 1856 in Pennsylvania and was a mechanical engineer by training (Kaplan \& Owens, 2017; Marion \& Gonzalez, 2014).

According to Kaplan and Owens (2017), Taylor conceived scientific management as a "rational scientific-engineering based approach designed to increase workers' productivity through the systematic analyses of work in painstaking detail" (p. 38). Rational systems theory is concerned with how organizations achieve goals. "Rational systems theory sees organizations as structural arrangements designed to achieve specific organizational goals. Rationality is the degree to which a series of actions is logically organized and implemented to achieve preset goals with maximum efficiency" (Kaplan \& Owings, 2017, p. 15). Taylor was interested in creating a workplace in which standardization and a strict division of labor lead to efficiency. Rational systems theory privileges productivity over other outcomes, while programming workers for efficiency, 
building organizations according to blueprints, and developing workers with specializations rather than general skills (Kaplan \& Owens, 2017).

Rational systems theory has been conceived as aligned both with closed and open systems frameworks. Open systems theory assumes that the outside environment influences the organization, while a closed system assumes that conditions such as efficiency within the workplace or organization can be engineered without the influence of the outside environment (Onday, 2016). Kaplan and Owens (2017) noted Frederick Taylor's particular contribution to rational systems theory, scientific management, asserts that people could be taught to behave like machines and that this was the ultimate expression of efficiency.

Scientific management includes creating a detailed analysis of a workplace to systemize tasks, create routines, and standardization among workers, all in an effort to minimize costs and maximize profits (Kaplan \& Owings, 2017). Taylor (1911) argued in his book, The Principles of Scientific Management, that the United States was suffering a crisis of inefficiency and that this could be solved through the implementation of his approach to management, which he characterizes as "a true science, resting upon clearly defined laws, rules, and principles, as a foundation" (p. 7). Taylor went on to argue that this approach should be applied "to all social activities: to the management of our homes; the management of our farms; the management of the business of our tradesmen, large and small; of our churches, our philanthropic institutions, our universities, and our governmental departments" (p. 8). 
While Taylor (1911) did not specifically mention public schools as institutions for the application of his scientific management approach, he did refer to them in what he described as his "most important law" (p. 120), task management, stating that:

No efficient teacher would think of giving a class of students an indefinite lesson to learn. Each day a definite, clear-cut task is set by the teacher before each scholar, stating that he must learn just so much of the subject; and it is only by this means that proper, systematic progress can be made by the students. (p. 120)

In addition to an implication that all "scholars" are male, the assumptions inherent in this quote are that efficiency equates with learning; that all students learn in the same way and on the same schedule, and that learning is a linear process. Fowler (2014) contended that Taylor's scientific management movement defined the need for hierarchical roles in the workplace and that this idea was adopted by public schools. As she noted, this idea further creates assumptions about "how men and women and people of different races relate to one another" (Fowler, 2014, p. 25).

Marion and Gonzalez (2014) argued that Taylor's intense focus on scientific management can be seen in modern schools as an intense focus on test scores. They contend, "management is about standardizing procedures in order to draw maximum profits (read: test scores) from the organization; that is, it exploits the available human and physical resources to maximize returns" (p. 11). Cutting fine arts, recess and physical education in the name of increased time dedicated to learning reading and math to boost test scores are recent trends that follow this focus on maximum returns. In addition to this focus on raising test scores, maximum returns at present are also measured by ESSA as high percentages of students graduating within a four-year period. Organizing high schools around a standard design that promotes graduation in 4 years can be seen as 
"standardizing procedures in order to draw maximum profits" (Marion \& Gonzalez, p. 11).

In a similar vein, we can observe that schools are organized around grading periods, bell schedules, academic departments, and standardized testing, instruction, and grading policies. Employee contracts explicitly delineate work hours and duties, as well as a division of labor between management and non-supervisory employees, a key feature of Taylor's (1911) theory. State policies promote standardization by dictating the licensure requirements of teachers and other educators, requirements for graduation, and other policies. School schedules are created with attention to minutes within a school day and required annual hours of instruction, following state requirements. This means that passing time, lunch, and recess are all factored in and that bells ring to signal the change of periods or the beginning and end of the school day. Meals are apportioned by federal nutritional weight and calorie regulations, and grades are posted according to schedules and standardized criteria. Schools purchase packaged curricula with pacing guides to keep the students' minds learning and moving forward on a schedule, much like Taylor's concept of task management and much like an assembly line which moves production in a factory.

While Taylor was a mechanical engineer and not an educator, it is clear that his development of industrial workplace efficiency has been applied to schools (Kaplan \& Owens, 2017). Shuttleworth (2003) contended that factory and school architecture in the 19th and 20th centuries shared "a utilitarian and functionalism associated with the housing of assembly lines" (p. 159). The supervisory headquarters of a company with 
branch plants mirrors school district headquarters, while school principals, like branch managers, are responsible for "a predetermined common set of standards, and anticipated outcomes, called the curriculum and programme" (Shuttleworth, 2003, p. 159). Taylor's scientific management techniques, including the reducing of every act of a worker to a mechanical principle, were regarded as instrumental to the success of American industrial production after World War I (Shuttleworth, 2003). It was not long until these techniques moved from the factory floor to the classroom. The Carnegie Foundation for the Advancement of Teaching led the way in advocating for efficiency and scientific management (Shuttleworth, 2003).

Schools are measured by students' performance on standardized tests and on graduation rates. Applying rational systems theory to modern schooling leads to us to see the students as the outputs of the school or as the products, which have been created by the factory. Schools "output" students in a few ways, through graduation (a desirable output), through transfer to another school (a more neutral output) or through a student becoming an early leaver (an output with negative consequences for the student primarily, but also for the school in terms of accountability). In some cases, schools make a cost-benefit analysis and push out a student who is seen as compromising the school's rational efficiency. This can also be understood as an act of boundary maintenance on the part of the school (Riehl, 1999). According to Riehl (1999),

the maintenance of membership boundaries allows an organization some control over its technical pursuit of goals, by including as members those classes of persons who have the qualities deemed necessary to further the organization's goals, either as workers or as clients, and conversely by excluding those persons who would impede goal attainment. (pp. 235-236) 
Following rational systems theory, one would say, then, that it is "rational" for a business to set goals and practice boundary maintenance in ways that ensure that profits are maximized. In schools, rational goals are set and boundaries are maintained to maximize test scores and produce graduates, especially in a 4-year time span. When the lives of real students, however, are complicated with the irrationality of trauma, poverty, racism, disability, and mobility, to name a few, their capacity to achieve the "rational" goal of on-time graduation may be thwarted. In these cases, schools produce fewer graduates, but they also produce early leavers. Schools may strive to increase the numbers of graduates they produce, because of societal expectations that schools produce graduates, not early leavers. Schools may also deviate from these expectations and push out more students if these students compromise the school's ability to present itself as a functional school (Riehl, 1999). In this era of ESSA-defined standards for schools, a functional high school is largely considered one in which high percentages of students graduate in 4 years or "on time."

Rational systems theory and Taylorism provide a useful lens for understanding how the standardization and mechanization of schooling in the United States developed alongside the development of assembly lines and factories. The limitations of schools to operate in more human and less mechanized ways is one possible reason why some students are not well-served by conventional schools and end up leaving them early. The rating of schools through school report cards and standardized accountability systems can be understood as a derivative of the ideas Taylor promoted through the valuing of efficiency (as in graduating within a four-year time period) and rationality (judging 
schools in terms of their conformity to standard criteria). When school systems reject students who do not support their work to be efficient and rational, we see the presence of school pushout. Just as items produced on an assembly line that are discarded for having some kind of variation or defect, we can also view students who are pushed out of conventional schools as discarded. Discarded or pushed out students potentially also internalize the stigma of being considered as less worthy (Bickerstaff, 2010; McNulty \& Roseboro, 2009).

\section{School Accountability}

\section{Early History of School Accountability}

School accountability is often discussed as a modern trend, but debates about how to hold students and educators accountable for student learning can be traced in the United States back to the early nineteenth century. Cuban (2004) described early accountability as the actions of elected school boards who were charged with ensuring that school children had adequate facilities, teachers, and materials. School board members collected the taxes to pay for these expenses and were then either re-elected or defeated in subsequent elections, based on the tax-payers' view of how well the schooling experience served the children. Ravitch (2002) noted one $19^{\text {th }}$ Century accountability practice of holding students accountable to the tests created and administered by their teachers. Those students who did not pass these tests were not considered eligible to move forward into high school. In fact, fewer than one in ten young people - those who were able to pass these exams - attended high school prior to 1900 (Ravitch, 2002). Only 12 states, according to Mazzeo (2001), used state-constructed essay examinations as 
admissions tests for eighth graders seeking enrollment to high school between 1865 and 1915.

Momentum toward the standardization of high schools increased in 1893 with the publication of The Report of the Committee of Ten. The Committee of Ten was a “bluechip panel of educators" (Mirel, 2006, p. 14), most of whom served as university presidents from states in the Northeastern region of the country. This committee was also exclusively male and White. "When the Committee of Ten issued its report in 1893, the high school was a small institution focused on those bright children whose parents were "willing and able to forego their labor"' (Mazzeo, 2001, p. 378). High school enrollment did increase dramatically between 1890 and 1918. According to Mazzeo (2001), high school attendance soared from 202,000 to 1.6 million in this period, an increase of $711 \%$, while the overall population in the United States grew during the same period by $65 \%$.

As the rural-agrarian economy gave way to the rise of the urban-industrial economy, the role of schools and school accountability changed. This shift drove schools to be more universal, compulsory, and comprehensive (Groen, 2012). Testing became less the purview of individual teachers and became more standardized. An example of this, documented by Cuban (2004), is of Boston during the late 1800s when industrialization was gaining momentum and Northeastern cities were growing. Boston schools had more than 7,000 students and the elected Board of Education could no longer manage its fiduciary and educational responsibility exclusively through classroom-based assessments, many of them oral. This resulted in the creation of a 30-item test to be 
administered to students in the eighth grade; the results of this test were published locally (Cuban, 2004).

The 1930s and 1940s are considered more of a progressive era of education, where students' social adjustment in school was paramount. This coincided with the new field of educational psychology, which worked to establish education as a scientifically measurable field. According to Ravitch (2002), professional educators at that time "embraced testing because it seemed to place education on a scientific plane, where decisions could be made on a professional basis and could withstand the entreaties of parents" (para. 6). Testing, however, was not widely considered part of school accountability in this era. Mazzeo (2001) argued that many states tried to develop comprehensive accountability systems between 1865 and 1965, though were not able to make state testing part of an accountability system, despite many attempts, within that 100-year period.

Interest in school accountability did, however, increase dramatically in 1957 with the Soviet Union's launching of the Sputnik satellite (Cross, 2014). In 1958, President Eisenhower, acting upon fears of Soviet space and military dominance, signed the National Defense Education Act into law. This law raised high school graduation requirements in math and science, added programs for gifted students, gave financial support to students and to colleges to allow them to better develop science and language labs, and introduced Advanced Placement (AP) high school courses to help students more quickly transition to college (Cross, 2014; Cuban, 2004). 
In addition to schools "being drafted to fight the Cold War," (Cuban, 2004, p. 22), the post-World War II era included significant changes with respect to civil rights for BIPOC people. The landmark Brown v. Board of Education decision occurred in 1954, leading to the integration of White schools by African-American children and youth. President Lyndon B. Johnson, a former teacher, prevailed with the passing of the Civil Rights Act in 1964 (Cuban, 2004). The Voting Rights Act passed in 1965 and the Open Housing Act passed in 1968 (Mazzeo, 2001). The Elementary and Secondary Education Act also passed in 1965, providing funds for the first time in U.S. history to educate lowincome children (Cuban, 2004). The National Assessment of Educational Progress, which later became known as the "Nation's Report Card" was also enacted in 1965 (Cross, 2014, p. 38).

Another significant event that has had long-standing impact on educational accountability in the United States was the 1966 publication Equality of Educational Opportunity, also known as the Coleman Report, named after its lead author, sociologist, James Coleman (Ravitch, 2002). Coleman focused on the ways in which socio-economic inequality had more impact on children than did public schooling (Cross, 2014). The study was significant in many ways, including "its shift in focus from inputs to results, which followed the authors' decision to examine how school resources affected achievement" (Ravitch, 2002, para. 9).

While many of these educational and accountability policies reflected a push-pull between states' rights and federalism (Cross, 2014), it is also important to see the Coleman Report and several other similar reports that followed through a political lens. 
For example, in 1983, the National Commission on Excellence in Education published the report, A Nation at Risk (M. L. Smith \& Fey, 2000). This commission was comprised of corporate leaders and politicians, as well as educators, and took pains to link mediocre student results on national and international tests with "mediocre economic performance in the global marketplace" (Cuban, 2004, p. 24). According to M. L. Smith and Fey (2000), "the message of that document, and many that followed was that public schools are failing to address and meet ambitious standards and that such failure threatens American economic competitiveness" (p. 335). As President Reagan released the report publicly on April 26, 1983, he took the opportunity to promote his education agendanone of which was part of the report-including prayer in school, tuition tax credits, private schools, and the abolition of the U.S. Department of Education (Cross, 2014). These are poignant examples of the political use of school accountability at the highest levels of the federal government since the late-1950s.

\section{Modern Accountability}

The more recent era of school accountability has grown not just out of A Nation at Risk, but also efforts by the Clinton and George H.W. Bush administrations to define their educational agendas through efforts to increase American student competitiveness in math and science (Cross, 2014). They also worked to increase standards and graduation requirements and to hold teachers and principals accountable for improving academic achievement (Cuban, 2004). The impact of the educational agendas of President Clinton and the first President Bush, however, paled in comparison to the impact on the students, 
teachers, and school administrators of the educational agenda of the second Bush president, George W. Bush.

\section{NCLB and Push-Out}

In January 2001, three days after his inauguration to be the $43^{\text {rd }}$ president of the United States, George W. Bush announced his educational policy NCLB (Cross, 2014). NCLB created a great deal of high stakes accountability, moving the role of the federal government in education to more of a regulatory role and less of a funding stream for states and local districts. NCLB stressed four main principles: testing, flexibility, assisting failing schools, and choice (Cross, 2014). The consequences for failing to meet increasingly higher targets in the first of these principles — testing — placed teachers, administrators, and other educators under enormous pressure. This pressure included the limiting of funding, removing educators from their roles, and publicly labeling schools as failing (The Advancement Project et al., 2011). Each of these tactics has had impacts on the early leaver issue, particularly with respect to the act of pushing out students who might be perceived as dragging down a school's rates for passing tests out of school.

In the state of Texas, which provided the blueprint model for President Bush's NCLB law-a document comprising more than 1,000 pages - more than $60 \%$ of the students followed in one longitudinal study dropped out of school (McNeil et al., 2008). The authors of this study asserted that the disaggregation of student scores by race, which became the norm under NCLB, does not lead to greater equity, as was asserted by President Bush, Texas' former Governor. Rather, this practice puts the most vulnerable youth, those living in poverty, English Language Learners, students with disabilities, and 
BIPOC students at risk of being pushed out of school in service to the school's efforts to show measurable progress, referred to under NCLB as AYP (McNeil et al., 2008).

The Advancement Project et al. (2011) also argued that mandating increases in standardized testing and attaching high stakes sanctions to those who do not achieve according to the federal government's trajectory has influenced educators to push out students who may be lower-performing or perceived as such by their schools. Many of these students are BIPOC students, explicitly identified in racial categories pertinent to NCLB metrics. With the students off the school's enrollment, the school was not held accountable for their achievement, though many continued to receive the funds based on Average Daily Attendance attached to these students (Shaw, 2014). In eras of tight budgets and reduced enrollment through choice options, every test score is seen as potentially helpful or detrimental to the survival of the school. This is another example of students occupying the role of a commodity within the educational system that was influenced by the principles of scientific management theory (Marion \& Gonzalez, 2014).

\section{High School Exit Exams}

Another high stakes accountability practice similar to standardized testing is that of high school exit exams. This practice became increasingly common in the 1990s (Hemelt \& Marcotte, 2013). By 2009, 26 states had implemented or were in the process of implementing some form of exit exams, including the use of criterion-referenced standardized tests. By 2013, 76\% of all public high schools nationwide were using exit exams and these have been particularly prominent in school districts with more BIPOC students and in states with more economically disadvantaged students (Hemelt \& Marcotte, 2013; Jacob, 2001). In 2017, 84\% of all BIPOC students in the United States 
went to schools in which exit exams were required for graduation (Hemelt \& Marcotte, 2013). Researchers Warren et al. (2006) found that high school exit exams are associated with lower public high school graduation rates. They further found a negative association between high school exit exam policies and rates of high school completion in states with increasing racial diversity and rising levels of poverty (Warren et al., 2006).

Baker and Lang (2013) also documented reduced high school graduation rates and increased incarceration rates to be associated with exit exams, although some of the reduced graduation rates in their analysis are offset by increased GED attainment. Given that graduation and incarceration rates already disproportionately impact BIPOC students, this use of standardized tests, which have been found by many researchers to reflect racial bias, is particularly alarming (Au, 2016; Darling-Hammond \& Meier, 2004; Ladson-Billings, 2006).

These findings are further validated by Jacob (2001), who used quasiexperimental, nonrandom control data from 15 states to conclude that students in states with graduation exams score significantly lower on achievement tests and have a higher chance of becoming early leavers. He and Freeman and Simonsen (2015) found that the use of high school exit exams is not a statistically significant cause of dropout for a full sample of students, but that those in the lowest quartile of achievement who live in states with high school exit exams are $25 \%$ more likely to drop out of high school. Marchant and Paulson (2005), drawing from Common Core and College Boards Scholastic Aptitude Test (SAT) databases, concluded that high school exit exams have a significantly negative effect on both graduation rates and SAT scores and that states with 
these exams have graduation rates that are eight points lower than do states without exit exams (Freeman \& Simonsen, 2015; Marchant \& Paulson, 2005).

That high school exit exams increase the numbers of early leavers, particularly those who are BIPOC students is alarming; the fact that a high number of early leavers who have advanced to the 12th grade before dropping out is even more alarming (Hemelt \& Marcotte, 2013; Jacob, 2001; McNeil et al., 2008; Warren et al., 2006). Hemelt and Marcotte (2013) estimated that in states with no alternative pathway to the standardized high school exit exam, the rate at which African American 12th graders consequently do not graduate increases by more than $50 \%$ for boys and $65 \%$ for girls. Additionally, the idea that these exams increase learning and achievement is suspect. Jacob concluded that high school exit exams do not have a positive impact on student achievement and do not raise 12 th grade reading or math scores. This finding remains steady after accounting for prior student achievement and other controls and when applied to students from all ability groups. It is unfortunate that Jacob (2001) did not explicitly examine the role of race or poverty in this part of his analysis.

Many states in recent years have begun to rethink their use of required high school exit exams. In 2019, the number of states requiring exit exams for graduation shrank to 13 (Gewertz, 2019). Four of these 13 states (Maryland, New Jersey, New Mexico, and Washington) require their graduates to pass a national, standardized exam like Partnership for Assessment of Readiness for College and Careers or Smarter Balanced, while the other 9 states (Florida, Indiana, Louisiana, Massachusetts, Mississippi, New York, Ohio, Texas, and Virginia) either use exams uniquely created in 
their states or the SAT or American College Testing college entrance exams or a combination of these (Gewertz, 2019).

Some states, like Oregon, allow for alternative assessments to exit exams. These include performance assessments or work samples which are scored by teachers, using an approved rubric. In 2008, of the 24 states that required high school exit exams, all but five had an option for an alternative pathway. The five states without this alternative pathway are Alabama, California, Louisiana, Minnesota, and Texas (Hemelt \& Marcotte, 2013). Examples of alternative pathways reported by Hemelt and Marcotte (2013, p. 329) are listed in Table 3.

\section{Table 3}

Sample of States With Alternative Pathways for Exit Exams

\begin{tabular}{|l|l|}
\hline \multicolumn{1}{|c|}{ State } & \multicolumn{1}{c|}{ Method } \\
\hline Virginia & Passing Advanced Placement Exams \\
\hline Florida & $\begin{array}{l}\text { Use of Scholastic Aptitude Test (SAT) or American College } \\
\text { Testing (ACT) }\end{array}$ \\
\hline Indiana & $\begin{array}{l}\text { Demonstration of Proficiency through Grades and Teacher } \\
\text { Recommendations }\end{array}$ \\
\hline Maryland and Nevada & Portfolio Assessment \\
\hline Alaska and Georgia & Hardship Waivers \\
\hline South Carolina and Tennessee & Issuing of a Non-Diploma Credential \\
\hline
\end{tabular}

The issue of an alternative to the high school exit exam is significant, because the effect of imposing these exit exams without an alternative is associated with a $23 \%$ higher 12th grade dropout rate in urban districts, a $21.1 \%$ increase in suburban districts, and a $24.6 \%$ increase in rural districts (Hemelt \& Marcotte, 2013). This increase does not 
hold in urban, suburban, and rural districts with alternative assessment policies for high school exit exams (Hemelt \& Marcotte, 2013).

In conclusion, high school exit exams appear to have been implemented by states in an effort to communicate to taxpayers that schools are educating students in measurably rigorous ways. The reality, however, is that these exams have been wrought with the unintended consequences of increasing the number of early leavers and discriminating against BIPOC students and students with disabilities, all while failing to boost academic achievement.

\section{Four-Year Cohort Graduation Rate}

In 2005, Governor Mark Warner of Virginia led the National Governors' Association, when it declared the same year to be the "Year of the High School." The Association signed a graduation compact and agreed to implement a common method for measuring graduation rates (Balfanz \& West, 2006; Curran \& Reyna, 2009). The common method upon which they agreed is the Four-Year Adjusted Cohort Graduation Rate Formula. This formula, according to the Oregon Department of Education (n.d.-b), is "the percentage of students in a cohort, adjusted for transfers into and out of the school, district, or state, that earn a standard diploma within four years of entering high school" (p. 4). The National Governors' Association also agreed to build state data collection capacity, develop additional student outcome indicators, and report annually on their progress toward achieving these goals (Curran \& Reyna, 2009; Princiotta \& Reyna, 2009). At that time, NCLB was the law of the land and the federal government included graduation rates as a measure for high schools (Balfanz \& West, 2006). 
In spite of this federal legislation, however, states were on their own to create their own measures, goals, and rates of progress, effectively neutralizing much of the impact of this aspect of the law. As a result, several states significantly overstated their graduation rates and did not clarify the sobering rates of dropout by BIPOC youth (Balfanz \& West, 2006). Four years after the signing of the pact by all 50 governors, only 20 states had met the terms of the agreement (Balfanz \& West, 2006; Curran \& Reyna, 2009).

\section{Compulsory School Attendance Age}

Each state in the United States sets minimum and maximum compulsory age requirements to be in school (Bridgeland et al., 2006). The age range for when students are eligible for preschool or kindergarten is from age three in Massachusetts to age six in Montana and Pennsylvania. The other end of the spectrum, the range of ages in which states are no longer obligated to provide a free, public education is from age 19 in Montana to age 26 in Texas. In Oregon, students are eligible for public school from age five and up until age 21 (Mikulecky, 2013). The law, however, has a subtle element that makes the provision of a free public school education in Oregon optional after a student who has not graduated turns 19. Oregon Revised Statutes provide that a school district must admit students through age of 21 if the student has a disability and is eligible to receive Special Education services. Districts may, however, admit students through age 21 years of age who are not eligible for Special Education and who have not yet graduated (Oregonlaws.org, 2020b, para. 1). This means that non-disabled early leavers in Oregon can age-out of school without the option to return if they do not graduate before they turn 19. Only one school district in the state of Oregon, Portland Public 
Schools, opts for the "may" provision, allowing all students to remain enrolled through age 21 (K. Pattison, personal communication, 2018).

These varied state laws can be viewed through the lens of what Lorraine McDonnell and Richard Elmore categorize as policy instruments (Fowler, 2014). Such policy instruments or mechanisms exist to move policy goals into concrete actions. According to Fowler (2014), McDonnell and Elmore developed a policy framework that includes five mandates or rules that govern individual and agency actions. Government agencies carry out mandates with the goal of "widespread, uniform behavior of a socially desirable sort" (p. 185). Applying this thinking about the ideal outcome of compulsory attendance laws, we could deduce that having young people in school from about age five until about age 19 is socially desirable. This idea can again be linked to rational systems theory and Taylorism, as it assumes a time-bound system, rather than an outcome-based system. A time-bound system mimics an assembly line and pushes its operators (educators, in this case) to create products (students, in this case) on schedule. What is apparently not anticipated in these laws, however, is whether schools are designed to help all students graduate from high school within the age ranges included in the mandate. Given the high rates of dropout, push out, and fall out, especially for BIPOC students, low-income students, and those with disabilities, there are clearly significant numbers of students who do not graduate in this period.

Bridgeland et al. (2006) found that, in holding focus groups with early leaver youth, many identified "too much freedom" as a significant part of why they left school (p. 16). The researchers went on to question whether compulsory attendance 
laws that require maximum ages under 18 contribute to this experience of too much freedom. They also questioned why many states provide resources for students to attend school through grade 12 , but do not require them to remain in school. While Bridgeland et al.'s qualitative research indicated a possible policy area for review, Landis and Reschly (2011) used quantitative methodology in the form of longitudinal national data sets to examine whether compulsory school age laws are associated with varied levels of high school dropout. They concluded that there is a small relationship between compulsory school attendance age laws and the grade at which students leave high school (Landis \& Reschly, 2011).

Federally-mandated NCLB-style standardized testing, high school exit exams, the four-year cohort graduation rate, and compulsory school attendance age laws are all considered facets of modern school accountability. They also, as has just been discussed, all have roots in the mechanization and standardization of Taylorism and they all have impact on those students who become early leavers. As was previously mentioned, many early leavers do go on to earn a high school diploma or equivalent. For those who do so in a defined alternative high school, as opposed to an alternative program, their school is accountable to all the same laws and requirements as every other public school in their state and nation. Schlessman and Hurtado (2012) argued that this standardization and lack of alternative accountability creates a disincentive for conventional schools to serve at-risk students, as these students will always be seen as a problem for school ratings. Other scholars and policy makers who investigate this phenomenon advocate for 
alternative accountability are Almeida et al. (2010), Jimenez et al. (2018),) Richardson and Memmott ( 2017), and Rumberger (2011).

\section{Alternative Accountability}

Almeida et al. (2010) stressed that state accountability systems for alternative schools and programs must "help schools mediate the tension between holding onto students and holding them to high standards. This is especially important for students who are both older and further behind .... and may have experienced considerable interruptions in their schooling" (p. 11). Without effective systems for alternative accountability, Almeida et al. warned that states push alternative schools and programs into either so much rigidity that they cannot effectively serve students or so much ambiguity that schools do not have the guidance to effectively prepare students for high school graduation and post-secondary success. Schlessman and Hurtado (2012) asserted that "states should give credit within their accountability system to schools and programs that reengage and hold onto students and for hitting key benchmarks toward graduation and postsecondary readiness" (p. 5).

Six of the states that do have alternative accountability laws are California, Colorado, Florida, North Carolina, Oklahoma, and Texas. According to Schlessman and Hurtado (2012), the use of accountability systems varies among these states. Most of the data in Table 4 are taken from Schlessman and Hurtado, with the exception of California's data. The reason for this is that California suspended its long tradition of alternative accountability in 2010, due to reported lack of funding (Schlessman \& 
Hurtado 2012). The state of California, however, implemented a new accountability

system in the fall of 2018. Basic information about the new system is also provided.

\section{Table 4}

Characteristics of Alternative Accountability in Six States

\begin{tabular}{|c|c|}
\hline State & Characteristics \\
\hline California & $\begin{array}{l}\text { Alternative schools in California use the same indicators as non-alternative } \\
\text { schools (Academic Indicator, English Learner Progress Indicator, Graduation } \\
\text { Rate Indicator, Suspension Rate Indicator, College/Career Indicator, Chronic } \\
\text { Absenteeism Indicator), but also have the option of using the one-year } \\
\text { graduation rate (California Department of Education, 2017). }\end{array}$ \\
\hline Colorado & $\begin{array}{l}\text { "Statute requires demonstration of progress toward the key performance } \\
\text { indicators of Achievement, Growth, Postsecondary and Workforce } \\
\text { Readiness, and Student Engagement. Statute stipulates that (alternative } \\
\text { education) frameworks must give the greatest weight to Postsecondary } \\
\text { Readiness and Growth. When available, state data must be included in an } \\
\text { AEC's framework" (Schlessman \& Hurtado, 2012, p. 15). }\end{array}$ \\
\hline Florida & $\begin{array}{l}\text { "Florida's indicator is student growth, learning gains for Reading and Math, } \\
\text { on the state examination with three ways to calculate those gains" } \\
\text { (Schlessman \& Hurtado, p. 15). }\end{array}$ \\
\hline North Carolina & $\begin{array}{l}\text { "Alternative programs are integrated into the state ABC Accountability } \\
\text { Framework; however, alternative program evaluation has distinct criteria as } \\
\text { the basis for labeling these schools" (Schlessman \& Hurtado, 2012, p. 15). }\end{array}$ \\
\hline Oklahoma & $\begin{array}{l}\text { "Oklahoma statute requires its alternative education programs to participate } \\
\text { in a state-wide evaluation. Data are collected on five variables: grades, } \\
\text { courses passed, absences, credits earned, and disciplinary referrals" } \\
\text { (Schlessman \& Hurtado, 2012, p. 15). }\end{array}$ \\
\hline Texas & $\begin{array}{l}\text { "Alternative education accountability uses four base indicators: } \\
\text { - performance on the Texas Assessment of Knowledge and Skills (TAKS), } \\
\text { - English Language Learners Progress, } \\
\text { - Completion Rate, and } \\
\text { - Dropout Rate for grades 7-12” (Schlessman \& Hurtado, 2012, p. 15). }\end{array}$ \\
\hline
\end{tabular}

Note: Adapted from California Department of Education (2017) and Schlessman and Hurtado (2012). 
Recent developments in alternative accountability have updated practices in two of the states featured above: Texas and Colorado. These states have allowed school districts to voluntarily develop local accountability measures for their school districts (Griffin \& Stahl, 2020). Texas House Bill 22, which was approved in 2017, is built on the premise that school districts and charter schools should focus "on key areas identified by internal and external stakeholders through a data review process" (Griffin \& Stahl, 2020, slide 5). The state statutes in Texas allow for districts to use participation in the arts as well as growth metrics in their local accountability plans. The review process for these plans includes requirements that local accountability efforts are equitable, can be audited, and that metrics chosen by the local educational agencies are reliable and valid (Griffin \& Stahl, 2020).

In Colorado, alternative accountability report cards are still in pilot stages and are treated as supplemental to the state accountability report cards. In 2019, the state senate provided funds to five local districts or consortia of districts who applied to be part of the pilot, with intentions of "fairly and accurately [evaluating] student success using multiple measures to develop a more comprehensive understanding of each student's success" (Griffin \& Stahl, 2020, slide 15). The Colorado statute also mentions that alternative accountability is intended to "enable the state to learn from innovation in the field" (Griffin \& Stahl, 2020, slide 15). 


\section{Alternative Education}

\section{Alternative Schools}

In a clear pushing back against the influence of Taylorism and standardization, the growth of alternative schools in the United States is the embodiment of the idea that one size does not fit all (Tissington, 2006). Alternative schools, which first gained momentum in the private sector, as well as in civil rights struggles in the 1960s, also embody Dewey's rejection of the Tayloristic tendency of mass production in education, emphasizing the purpose of education as the "development of free and independent thinkers to live in a democratic society" (Goodman, 1999, p. 11). Alternative schools have served to provide a more inclusive option to low-income urban youth and BIPOC students and as innovation incubators in the suburbs (Raywid, 1999). Alternative schools have historically included schools like Freedom Schools, designed to respond to the needs of the African American community (Tissington, 2006). Similar to the Freedom

Schools movement was the Survival Schools movement, initiated by the American Indian Movement in the early 1970s. Survival Schools, first formed in Minnesota, were efforts to assert self-determination, while serving to teach cultural skills and knowledge to youth (Davis, 2013). Freedom Schools and Survival Schools, in part, encouraged the type of responsive, community-based alternative schools that are common today and serve students for whom conventional schools are not a positive experience.

Contemporary alternative schools, many of which are now part of public school districts, have largely been developed to give students who would not otherwise graduate a chance to do so (Raywid, 2001a). As Lagana-Riordan et al. (2011) noted, "most students who attend alternative schools were unsuccessful in traditional school programs 
and exhibited poor grades, truancy, behavior problems, or experienced special circumstances that impeded their learning" (p. 106). Zweig (2003) noted that "high quality alternative settings can support the positive development of truants, suspended or expelled students, students being reintegrated from the juvenile justice system, and dropouts" (p. 10). Zweig defined "high quality" as those with small class sizes, personalized attention, and support services, not as those sites designed to remove students with behavior problems from mainstream settings without their consent (p. 10). Goodman (1999) added to this line of thinking, asserting that the solution to a student who is unsuccessful in a conventional school is not more of the same.

The number of alternative schools nationally has risen dramatically since the early 1990s. There were 2,606 such schools in 1993 and more than 10,900 in 2001 (LaganaRiordan et al., 2011). Tissington (2006, p. 20) cited six common characteristics of alternative schools, drawn from reviews of the research. These characteristics are:

- Small class sizes

- Emphasis of one-on-one interaction between teachers and students

- Supportive environments

- Opportunities for student success relevant to the students' future

- Flexibility in structure

- Student decision-making

Raywid (1994) argued that contemporary alternative schools mirror their earlier versions in some notable ways, including their innovative cultures, informal ambience, small size, and "departure from bureaucratic rules and procedures" (p. 26). She argued in another article that the characteristics of alternative schools are desirable for all students, 
but essential for students at risk of school failure (Raywid, 2001b). She contended, "this combination of elements that research has collectively verified as the formula for 'good education' - small, personalized schools offering authentic learning and producing student engagement — is essential if we are serious about enabling unsuccessful youngsters to become successful" (Raywid, 2001b, p. 583). In the same article, she went on to perhaps unwittingly invoke a critique of Taylorism:

We've done our best to standardize schools, just as we've standardized cars and clothes, food and housing. But even though schools have been likened to production systems, unsuccessful students aren't like Fords or blue jeans or plumbing that somehow got damaged in the assembly line and needs straightening out. (Raywid, 2001b, p. 582)

\section{The Research Literature: Alternative Schools vs. Conventional Schools}

Several scholars have examined the differences between alternative and conventional high schools, often through qualitative studies in which students who have attended both kinds of high schools offer their contrasting experiences (Bickerstaff, 2010; de la Ossa, 2005; Epstein, 1992; Iachini et al., 2013; Lagana-Riordan et al., 2011; Pevoto, \& Brown, 2007; Rumberger \& Lim, 2008; Saunders \& Saunders, 2001). These studies document alternative high school students' experiences with their previous conventional high schools as unsafe (Bickerstaff, 2010; Burk, 1978; de la Ossa, 2005; Kotok et al., 2016; Lagana-Riordan et al., 2011) and characterized by overly authoritative environments in which they felt targeted by school officials and inflexible rules (Iachini et al., 2013; Lagana-Riordan et al., 2011). Student participants reported that they struggled to make or maintain positive and meaningful peer relationships (Bickerstaff, 2010; Lagana-Riordan et al., 2011). Study participants also reported a feeling that they were not valued by their previous schools (Bickerstaff, 2010; de la Ossa, 2005). The 
alternative school stood in contrast to previous conventional schools in Iachini et al.'s 2013 study in its focus on individualized approach to teaching, positive school climate, and flexible school structure. In her focus group data-gathering, de la Ossa (2005) captured one student's perspective about the transition from conventional to alternative high schools happening because "this is where they send kids who are bringing their average down, basically" (p. 34).

These studies also share their participants' views on their alternative high schools. Saunders and Saunders (2011) document alternative high school student participant experiences with a strong sense of community, noting an "intensity of teacher and staff involvement" (p. 12). Lagana-Riordan et al. (2011) and Saunders and Saunders reported findings that teachers, counselors, and school administrators were seen as helpful and positive. de la Ossa's (2005) study noted that teachers were praised for giving personal attention, while Iachini et al. (2013) documented alternative high school student perception that their teachers and other staff were more involved in individualized planning for graduation in contrast to those in their conventional high schools. In keeping with critical pedagogy, many of these studies move the focus of the problem from assuming that the student is damaged to assuming the institution is damaged. Bickerstaff (2010) noted a preponderance of studies that put the onus on the student for leaving a problematic school environment, rather than on school, community, or societal factors. She referenced others who "argue that these images of students as unmotivated, deviant, or underachieving legitimate schools' exclusionary practices" (p. 38). de la Ossa (2005) also documented the presence of negative public perceptions of 
alternative high schools and their students: "students felt they were viewed and treated as second class citizens by the public, school boards and teachers for choosing an alternative way to be educated" (p. 34). Kim and Taylor (2008) also documented this "second class" status, but coming from alternative school teachers in their case. "Teachers at the alternative school stated that they did not have the same opportunities for professional growth as did teachers in regular schools in the same school district" (p. 215).

\section{Critiques of Alternative Schools}

Despite studies in support of alternative schools, other scholars are critical of these schools. McNulty and Roseboro (2009) used a social justice framework to analyze ethnographic field data and student interviews in one alternative school serving students in middle and high school grades. They argued that the combination of a negative public perception of alternative schools, students' stigmatized identities, a lack of resources afforded alternative schools, and policies that place students rather than allow them to opt into alternative schools all reinforce a negative student experience and problematic student behavior. In the school that they studied, this negativity was met with harsh rules and undemocratic policies, thus exacerbating the problem (McNulty \& Roseboro, 2009).

Zweig (2003) examined the extent to which alternative schools and programs can meet the needs of youth she described as "disconnected" and "vulnerable" (p. 1). She focused her analysis of early leaver students on those who experience teen pregnancy or parenting, those involved in the juvenile justice system, and those leaving the foster care system. Like McNulty and Roseboro (2009), she also cautioned against the practice of involuntary placement of youth into alternative schools, noting that this practice is most likely to happen by school districts with high concentrations of low-income students and 
BIPOC students. In her analysis, these involuntary placements are also almost exclusively focused on what the school perceives as behavior issues, with academic progress less important (Zweig, 2003).

Kim and Taylor (2008) employed a qualitative case study model and used a critical theory framework to examine which practices in a particular alternative high school promoted equity for students. Their findings included both assets and liabilities for the students who are enrolled in this school. For example, they asserted:

We found that the school was successful when it provided a caring environment for the students and gained their trust. However, the school was not successful when it did not encourage students to achieve goals by providing an equitable education. (p. 208)

Ultimately, they concluded that the school lacked the systemic support that it needed to "break the cycle of educational inequality" (p. 216).

\section{Chapter Two Summary}

Many students leave school before graduating with devastating consequences for the students, their communities, and the nation as a whole. Early leaver students have shorter life expectancies (Muennig, 2008), lower incomes, and are more likely to be incarcerated (Sum et al., 2009). Fortunately, more than half of all early leavers do eventually earn a high school diploma or equivalent (Bickerstaff, 2010; McDermott et al., 2016). Many of these who later earn their high school credential are the alumni of alternative high schools.

Alternative schools leverage small school and class sizes, strong personalization, flexibility, the celebration of small successes, and innovative curriculum approaches to meet the needs of their students (Raywid, 2001b; Tissington, 2006). These schools differ 
from conventional high schools in many ways and there is substantial indication in the literature that students who have attended both kinds of schools register higher satisfaction with the alternative schools (Bickerstaff, 2010; de la Ossa, 2005; Epstein, 1992; Iachini et al., 2013; Lagana-Riordan et al., 2011; Saunders \& Saunders, 2001). In spite of this, negative perceptions of the students who attend these schools, their teachers, and the schools themselves persist (Bickerstaff, 2010; de la Ossa, 2005; Kim \& Taylor, 2008). These negative perceptions may have something to do with low ratings on school report cards, a fact as likely related to the previous conventional high schools as it is to societal factors (Almeida et al., 2010).

Because principals are frequently held accountable for school ratings under the educational law (Fowler, 2014), gathering their perspectives adds new understanding to the field. Principals are both hierarchical leaders in school buildings and tax-payer supported public leaders in their communities (Fowler, 2014). Understanding how they leverage this leadership to serve many of the most underserved students in their communities in schools that are often stigmatized will add understanding for scholars and practitioners about how to best measure the work of these schools and how to best support the students who are enrolled in them, as well as the principals who lead these schools.

The framework of critical pedagogy informed this study in an effort to maintain that the principal and other educators, the school, and the students are part of a larger social context which privileges some groups over others. Considering the socio-historical role of rational systems theory and Taylorism and their impact on schools from the early 
1900s forward has given additional conceptual frames through which to understand alternative schools and their place within a larger history and society. The research questions of this study drove it in the direction of a qualitative study for a few critical reasons. First, the numbers of alternative high school principals of schools with higher percentages of BIPOC students within one particular state are not large enough to justify survey or other quantitative methodologies. Secondly, the compelling data for this study lie in the stories these principals tell about their professional journeys and their experiences negotiating underserved students with the challenging realities of modern school accountability. 


\section{Chapter Three: Methodology}

\section{Introduction}

This study has aimed to understand how the state accountability system influences the work of alternative high school principals and their students, who have not been wellserved in conventional high schools (Alliance for Excellence in Education, 2011a, 2011b; Bickerstaff, 2010; Bridgeland et al., 2006; de la Ossa, 2005; Iachini et al., 2013). These alternative high schools on average serve higher percentages of BIPOC students (Balfanz \& Legters, 2004; Balfanz \& West, 2006; Orfield et al., 2004), students living in poverty (Glassett Farrelly \& Daniels, 2014; McNeil et al., 2008; Newton, et al., 2017), and students with disabilities (Lehr et al., 2009; McNeil et al., 2008). While scholars have made efforts to include the perspectives of alternative high school students in the literature (Bickerstaff, 2010; de la Ossa, 2005; Epstein, 1992; Viehweg, 2015), as well as teachers (Knell \& Castro, 2014; Saunders \& Saunders, 2001), there is a stark absence of the perspectives of alternative high school principals. This study sought those perspectives of alternative high school principals whose schools have among the highest percentages of BIPOC students in one West Coast state that is both predominantly White and whose state accountability system also evaluates alternative high schools through the same set of metrics as it evaluates its conventional high schools ((Richardson \& Memmott, 2017). 


\section{Research Methods}

\section{Basic Qualitative Research Study}

This was a basic qualitative research study, using semi-structured interviews and document analysis as the primary methods of data-gathering. Creswell and Creswell (2018) stated that "qualitative research is an approach for exploring and understanding the meaning individuals or groups ascribe to a social or human problem” (p. 4). Merriam and Tisdell (2016) distinguished between basic and applied research. Basic research has a goal of expanding knowledge through the intellectual study of a problem, while applied research "is undertaken to improve the quality of practice of a particular discipline" (Merriam \& Tisdell, 2016, p. 3). While these two research camps are presented by Merriam and Tisdell as distinct, my intent was to better understand the phenomenon of school accountability in alternative high schools through a critical pedagogy lens with the indirect goal of improving policies related to school accountability.

This study's research questions are as follows:

RQ 1: How do alternative high school administrators in one West Coast state describe the experience and the needs of BIPOC students in their school?

$>$ RQ 2: In what ways, if any, do the state accountability measures influence the work of alternative high school administrators in one West Coast state?

RQ 3: How do alternative high school administrators describe their role in their respective school districts as compared to the role of administrators in their districts' conventional high schools?

\section{Participants}

The five participants in this study are principals from among the 16 alternative high schools in one West Coast state with the highest percentages of BIPOC students. Choosing them from among the half of all alternative high schools with the highest 
percentages of BIPOC students was done to help maintain their confidentiality and lessen the chances that participant identities can be revealed. This West Coast state does not use alternative accountability metrics for its alternative high schools and this state has lower overall number of BIPOC students, compared to many other states. The percentages of BIPOC students in this state's alternative high schools ranges from $11 \%$ to $92 \%$ with an average of $31 \%$ (Richardson \& Memmott, 2017). This purposeful sampling calls attention to race for a number of reasons (Merriam \& Tisdell, 2016).

As noted in Chapters 1 and 2 of this dissertation, BIPOC students are less likely to graduate from conventional high schools and are more likely to find their way to alternative high schools than their White counterparts (Balfanz \& Legters, 2004; Balfanz \& West, 2006; Orfield et al., 2004). When focusing specifically on the subject of state and district accountability for alternative high schools, several scholars have linked the overrepresentation of BIPOC students in negatively-rated accountability categories with racial biases of schooling and institutional histories of white supremacy (McNeil et al., 2008; Orfield et al., 2004). The five alternative high schools for this study were identified through the Oregon Secretary of State's 2017 audit of the state's alternative education system (Richardson \& Memmott, 2017).

After identifying the study's potential participants, I contacted the superintendents in each school district to gain their permission to contact these principals (see Appendix A). Once they granted this permission, I then contacted each participant by email to ask them if they were willing to participate in the study (see Appendix B). After each participant agreed to participate, I then began scheduling interviews, also by email. The 
informed consent forms from the Institutional Review Board (IRB) and a copy of the questions (see Appendices C, D, E, and F) were attached to this second email, as was a link for the Google Meet platform, as all interviews were conducted virtually during the COVID-19 pandemic. Each participant granted consent prior to me asking any questions and each granted verbal consent to record the interviews through Google Meets. I asked each participant if they had any questions regarding the informed consent forms. Seidman (2013) argued that there are eight components of informed consent. These are detailed in Table 5 .

Appendix $\mathrm{C}$ includes all of these components, except language pertinent to the protection of children, since only adults were interviewed in this case. This form comes directly from the Portland State University IRB forms and is written at Grade 12 reading level, given that the population of principal participants has a high reading level. Also on the form in Appendix $\mathrm{C}$ is a statement that a gift card was shared with each participant in the study as a token of appreciation, and that the gift card was not considered compensation or a reason to participate. These gift cards and a thank you card were sent to participants after the first interviews were completed. 
Table 5

Components of Informed Consent

\begin{tabular}{|c|c|}
\hline Component & Description \\
\hline Invitation to Participate & $\begin{array}{l}\text { This component explicitly details the purpose, length, and } \\
\text { methodology of the study and whether there are research sponsors. }\end{array}$ \\
\hline Risks & $\begin{array}{l}\text { Potential risks are outlined. These include feelings of discomfort or } \\
\text { vulnerability. }\end{array}$ \\
\hline Rights & $\begin{array}{l}\text { An explicit statement about the voluntary nature of a study and the } \\
\text { lack of penalties for declining to participate at any point in the } \\
\text { process are detailed here. Participant rights also include the right to } \\
\text { review material and have it withheld from final dissemination and } \\
\text { the right to privacy. }\end{array}$ \\
\hline Possible Benefits & Possible benefits for the participant are outlined here. \\
\hline $\begin{array}{l}\text { Confidentiality of } \\
\text { Records }\end{array}$ & $\begin{array}{l}\text { Both the steps I have taken to protect confidentiality and the extent } \\
\text { to which confidentiality may be limited are discussed in this section. }\end{array}$ \\
\hline Dissemination & $\begin{array}{l}\text { A description of how I may plan to disseminate the results of the } \\
\text { research is included in the form. }\end{array}$ \\
\hline $\begin{array}{l}\text { Special Conditions for } \\
\text { Children }\end{array}$ & $\begin{array}{l}\text { A stipulation that parent or guardian permission is required for any } \\
\text { participants under the age of } 18 \text {. }\end{array}$ \\
\hline $\begin{array}{l}\text { Contact Information } \\
\text { and Copies of the Form }\end{array}$ & $\begin{array}{l}\text { This section includes information for the participants to contact the } \\
\text { researcher or the IRB with any questions or concerns. There is also } \\
\text { an assurance that the consent form is written in language that } \\
\text { participants are able to fully understand. }\end{array}$ \\
\hline
\end{tabular}

Note: Adapted from Seidman (2016, pp. 64-65).

As stated in Appendix C, interviews were recorded, transcribed, and coded.

Transcripts and any identifying information are kept in a secure filing cabinet and only

the researcher has access to these documents. Pseudonyms were created for each

participating school and for the participant principals of those schools. This information

is also kept secure by the researcher. Originally, I had intended to seek participant

approval to interview them in their places of work, but this changed due to COVID-19

pandemic restrictions. As a result, the IRB application stated that all interviews would be 
conducted virtually, which is what happened. Had there been no pandemic, the practice of interviewing participants in their workplaces would have allowed for the possibility of observation of relevant artifacts on bulletin boards and other parts of the school and may have facilitated the sharing of more artifacts. Creswell and Creswell (2018) argued in favor of qualitative research happening in a natural setting, as the chance to observe participants behaving within a context under study will add to the richness of the data gathered.

The schools listed in Table 6 are described in a number of ways, which are designed to safeguard confidentiality. First, each has been assigned a pseudonym. Secondly, demographic data and 4- and 5-year graduation data are presented through a ranking system, rather than listed as actual percentages that could be traced to particular schools.

I had originally planned to complete both interviews with one participant before moving on to the next participant. Seidman (2013) recommended spacing interviews three to seven days apart to give participants time to reflect, but not so much time as to lose the connection between interviews. Alternative high school principals have busy jobs and it seemed most realistic to complete two interviews over a 2 -week period with one participant before interviewing the next person. Prior to beginning the interviews, I believed this spacing of interviews would also allow for time for the transcription of interviews, coding, member-checking, and memo-writing. The reality of the research process, conducted during the pandemic, however, did not conform to this plan. Gaining permission from superintendents to interview principals sometimes required multiple 
reminders, as did interview requests to participants. Given all of those dynamics, I ended up conducting all of the first interviews before all of the second interviews.

\section{Table 6}

\section{Schools Participating in Study}

\begin{tabular}{|l|l|l|l|l|}
\hline $\begin{array}{l}\text { Pseudonym } \\
\text { School }\end{array}$ & $\begin{array}{l}\text { School Historically } \\
\text { Underserved } \\
\text { Student \% Masked } \\
\text { for Privacy, } \\
\text { Ranked Among } \\
\text { Participant } \\
\text { Schools* }\end{array}$ & $\begin{array}{l}\text { 4-Year Cohort } \\
\text { Grad Rate \%, } \\
\text { Masked for } \\
\text { Privacy, Ranked } \\
\text { Among } \\
\text { Participant } \\
\text { Schools** }\end{array}$ & $\begin{array}{l}\text { 5-Year Cohort } \\
\text { Grad Rate\%, } \\
\text { Masked for } \\
\text { Privacy, Ranked } \\
\text { Among Participant } \\
\text { Schools*** }\end{array}$ & $\begin{array}{l}\text { Type of } \\
\text { Community }\end{array}$ \\
\hline $\begin{array}{l}\text { Achievement } \\
\text { Alternative HS }\end{array}$ & Tied for 2 & 3 & 4 & Urban \\
\hline $\begin{array}{l}\text { Flexible Learning } \\
\text { Center } \\
\text { Alternative HS }\end{array}$ & 5 & 4 & 3 & Urban \\
\hline $\begin{array}{l}\text { Options } \\
\text { Alternative HS }\end{array}$ & 1 & 2 & 2 & Rural \\
\hline $\begin{array}{l}\text { Victory } \\
\text { Alternative HS }\end{array}$ & 4 & 5 & 5 & Urban \\
\hline $\begin{array}{l}\text { Youth } \\
\text { Development } \\
\text { Alternative HS }\end{array}$ & Tied for 2 & 1 & 1 & Suburban \\
\hline
\end{tabular}

*The range of percentages of Historically Underserved students in this group of schools is from $40 \%$ to $92 \%$.

**The range of 4-year cohort graduation rates for this group of schools is $11.4 \%$ to $53.1 \%$. $* * *$ The range of 5-year cohort graduation rates for this group of schools is $19 \%$ to $69.3 \%$.

\section{Document Analysis}

Merriam and Tisdell (2016) argued that analysis of documents have value both for the direct information they provide as well as for the potential they have to point researchers in new directions that can be pursued through interviews. Creswell and Creswell (2018) pointed out that advantages of document analysis include enabling the 
"researcher to obtain the language and words of participants and [to represent] data to which participants have given attention" (p. 188). They further emphasized that the analysis of documents in qualitative research can be convenient, unobtrusive, and efficient. Disadvantages in document analysis, according to Creswell and Creswell, included concerns that the documents may not be written in coherent or articulate ways, that they may be unavailable due to protected status, incomplete, inaccurate or inauthentic. Using document analysis alone would, therefore, not provide trustworthy findings. Combining this analysis with qualitative interviews, however, did add depth and perspective to the data, even in this limited circumstance.

While I attempted to secure accountability-related school documents from all the participants in this study, only two participants responded to my repeated requests. The information I did receive from the two participants did, however, provide additional insights into the work of these participants. In one case, a participant shared a school improvement plan, while the other participant shared a presentation he had created and made to the senior leadership in his school district. The limitations of only two participants sharing documents on the conclusions of the study are discussed in Chapter 4.

\section{Research Procedures}

\section{Data Collection}

Five alternative high school principals whose schools are among their state's top $50 \%$ of schools for enrolled BIPOC students participated in two interviews each for this study. Each interview lasted about an hour and was conducted via Google Meet from the researcher's home. Participants were either in their homes or their schools during the 
interviews. The original plan was to travel to the schools of the study's participants, but the COVID-19 global pandemic necessitated the socially-distanced, virtual platforms for interviews.

Each interview was recorded with the permission of each participant. Interviews were then uploaded into the Otter.ai transcription service, which created written transcripts of the interviews. After editing the transcripts for clarity, such as removing repeated words or phrases like, "I think, I think" and terms like "um," I shared each transcript with the associated participant to allow for member checking (Creswell \& Creswell, 2018). In the second interviews, each participant had the opportunity to respond to these transcripts, expand upon or clarify earlier responses, and ask questions or raise concerns. This process generated additional data in the second interview that likely would not have been present if only one interview had been planned in the study design.

As I coded and analyzed each first-interview transcript, I noticed that several common themes and ideas emerged and I became interested in probing these more deeply with each participant. As a result, I submitted a request to the Portland State University IRB to request an amendment to the IRB which would allow me to ask additional questions. The amendment was granted. The newer questions are listed in Appendix F.

There are at least two reasons for recording interviews. First, allowing a device to do the recording allows the researcher to maintain eye contact, communicate nonverbally that they are listening, and, thus to build rapport with the participants. Taking too many electronic or hand-written notes can be distracting for the person being 
interviewed. Seidman (2013) stressed that the interviewing relationship "must be marked by respect, interest, attention, and good manners on the part of the interviewer" (p. 99). A second reason for using a recording device is the opportunity it gives to create a full, written transcript of the interview. A full transcript can be shared with participants for member checking or sharing of the transcript with the participant.

Member checking is one of several methods that Creswell and Creswell (2018) recommended for ensuring internal validity in qualitative research. Member checking includes the sharing of interview transcriptions with participants to ask them if they believe the document accurately represents their words. It also can include an ongoing dialogue with participants regarding researcher interpretations of their words (Creswell \& Creswell, 2018). Member checking, however, can raise issues if the participant does not agree with the information on the transcription. Seidman (2013) shared that in his experience, he retains the right to interpret interview data without input from the participant, except in the cases of topics that are concerning or that will make the participant vulnerable. In those cases, he takes input from participants. He also follows what he referred to as the "principle de Laine" (Seidman, 2013, p. 100), which is not writing anything in print that cannot be said directly to the participant. The written transcripts of interviews are being maintained by the researcher in a locked filing cabinet at her home and will remain for a period of 5 years and then be destroyed. The only exception to this is the sharing of interview transcripts with participants as part of the member checking process and as part of participants' rights to review and withhold material (see Appendix B) or should a question arise from the institution's IRB. There is 
no identifying information on the interview transcriptions that could connect the transcripts to the person interviewed.

Following each interview, I wrote a memo to myself, detailing impressions from the interview and anything that stood out to me about each participant and their responses. This was the first step in data analysis, analyzing throughout the datagathering process, rather than postponing analysis until all data were collected. Charmaz (2006) considered memo-writing to be an essential intermediate step between data gathering and analysis. Charmaz contended that writing "successive memos throughout the research process keeps [one] involved in the analysis and helps ... to increase the level of abstraction of . . ideas" (p. 72). Maxwell (2013) characterized the lack of memo-writing during the data-gathering stage of the study as the "research equivalent of having Alzheimer's disease; [one] may not remember ... important insights” (p. 20). Memo-writing in this study happened throughout the research process and focused on impressions in the interview process, insights, comparisons among participants, selfcritique, and other topics, many of which Maxwell suggested would happen.

\section{Instruments and Measures}

The data collection instruments for this qualitative study are two semi-structured interview guides with open-ended questions (see Appendices D, E, and F). Semistructured interviews are characterized by Whiting (2008) as "scheduled in advance ... organized around a set of predetermined questions, [with] other questions [emerging] from dialogue, and usually last from 30 minutes to several hours" (p. 36). The guides for this study are influenced by the three-interview design favored by Seidman (2013), but have been condensed from three to two interviews. They focus on participants' 
experiences with state accountability measures and encourage reflection. The guides include examples of follow-up and expansive prompts that were needed to elicit more detail from participants during the interviews.

During the interviews, some participants did stray from the question to discuss other topics or ideas they had. The role of the researcher is to open the door and note how the participant chooses to walk through it, not to redirect them to a different door. Weiss (1994) noted that some researchers limit the richness of responses that come from openended questions in an effort to drive generalizability that could come from consistent responses and limited choices for responses. Weiss further suggested that "if we want more from [participants] than a choice among categories or brief answers to open-ended items, we would do well to drop the requirement that questions asked of all [participants] be exactly the same" (p. 3). The interview guides, therefore, include potential prompts for expanding upon participants' answers. This choice was an intentional one to create opportunity for unanticipated insights. Along this vein, the second interview was meant as more of a follow up to the first and occurred after member checking to lend itself to reflection by the participants on the first interview questions and transcript. It was also an opportunity for the researcher to ask questions about documents that were shared after the first interview.

In order to ensure that the questions on the two interview guides flowed and lent themselves to participants expanding their ideas, I conducted one pilot interview with a colleague who is also an administrator at an alternative high school, but who did not otherwise participate in this study. Maxwell (2013) recommended piloting interviews 
with individuals much like those who will participate in the study and states that pilot interviews can help ensure that the questions "work as intended" (p. 101).

As stated previously, both the three-interview design of phenomenological studies (Seidman, 2013) and an exploratory mixed methods approach (Gehlbach \& Brinkworth, 2011) were considered as potential methods to answer this study's research questions. On the one hand, the phenomenological approach was not chosen because it delves so much into participants' life histories that the focus on school accountability in alternative high school settings may have been minimized. On the other hand, Gehlbach and Brinworth's (2011) exploratory mixed methods approach may have created so much opportunity to generalize findings through a survey that the richness of responses would be lost. A basic qualitative study, drawing data from semi-structured interviews and document analysis, therefore, is the approach which best allowed for focused depth on the topic of study.

\section{Coding and Analysis}

\section{Interview Coding}

Three types of coding were used in this study; these are descriptive coding, in vivo coding, and provisional coding. Saldaña (2016) described a code in qualitative inquiry as " a word or short phrase that symbolically assigns a summative, salient, essence-capturing and/or evocative attribute for a portion of language-based or visual data" (p. 4). Codes are developed by researchers as a short-hand or translation tool to help categorize data for purposes of analysis and theory-building (Saldaña, 2016).

Coding, according to Saldaña "is not a precise science; it is primarily an interpretive act" (p. 5). 
The first type of coding described by Saldaña (2016) is descriptive coding. Descriptive codes may be as short as one word and written next to a paragraph or excerpt of a transcript to summarize the primary topic of the text. An example from this study includes one participant who discussed the fact that he found it important for all of the staff in his school to develop an analysis of all the factors that lead their students to needing to enroll in an alternative high school. He offered that these reasons include white supremacy, ableism, homophobia, and capitalism, among others. I wrote in the margin of his transcript "Freire, critical consciousness."

The second type of coding used in this study was in vivo coding. An in vivo code uses the words of the participant and is placed in quotation marks, in part to distinguish this code from a descriptive code (Saldaña, 2016). One example of in vivo coding that was used in this study was during the second interview of one participant. This participant was discussing the precarious way that she navigated her school's level of visibility within her district. She described the dual threats of too much scrutiny on the one hand and complete invisibility on the other, which she described as "the process of whiteness, attempting to put [BIPOC students] in a corner so that they can be erased." I wrote "erased" and "erasure" in the margin.

Provisional coding is the third type of coding which was employed in this study. Provisional codes, according to Saldaña (2013), are "generated from such preparatory investigative matters as: literature reviews related to the study, the study's conceptual framework and research questions, previous research findings, pilot study fieldwork, the researcher's previous knowledge and experiences (experiential data), and researcher- 
formulated hypotheses or hunches" (p. 144). Given this study's focus on alternative schools and state accountability, theoretical frameworks of critical pedagogy (Brantlinger \& Brantlinger, 2013; Freire, 1993; McLaren, 2002), rational systems theory and Taylorism (Kaplan \& Owens, 2017; Marion \& Gonzalez, 2014; Riehl, 1999; Taylor, 1911), as well as the researcher's lengthy history of work in the field of alternative education, provisional coding seemed very warranted. Provisional codes drawn from these themes are listed in Appendix G.

\section{Document Coding}

The coding of documents and artifacts has similarities to the coding of interview transcripts. Bowen (2009) contended that skimming, reading, and interpretation are all part of an "iterative process [that] combines elements of content analysis and thematic analysis" (p. 32). Bowen then went on to describe content analysis as the "process of organizing information into categories related to the central questions of the research [and] thematic analysis ... as a form of pattern recognition within the data, with emerging themes becoming the categories for analysis" (p. 32). Thematic analysis, then, lends itself to the construction of codes and themes, much like Saldaña's (2016) process of descriptive coding (see Appendix E). Bowen also suggested using provisional or predefined codes in document analysis. This use of the same coding methodology with two different data sources (interview transcripts and artifacts from the schools) can integrate these two types of data, creating a stronger final analysis (Bowen, 2009).

\section{Role of the Researcher: Positionality, Reflexivity, Bias}

The role of the researcher in qualitative research is so important that some argue that the researcher is the primary instrument for data collection and analysis (Maxwell, 
2013; Merriam \& Tisdell, 2016). Every choice the researcher makes in the description of the research problem, the selection of literature to review, the data-gathering and analysis methodologies chosen, and the research questions constructed are all opportunities for both the values and the biases of the researcher to shape the process. According to Bourke (2014),

Our own biases shape the research process, serving as checkpoints along the way. Through recognition of our biases, we presume to gain insights into how we might approach a research setting, members of particular groups, and how we might seek to engage with participants. (p. 1)

In addition to the role of bias, other aspects of the role of the researcher that are discussed here are researcher positionality and reflexivity.

\section{Positionality}

In examining positionality, it is relevant to say that I am a biracial, heterosexual, cis-gender woman in her 50s with light skin, working as a former alternative high school principal and current school district administrator in a large, urban school district, while pursuing my doctorate in education. Some of these characteristics place me in a privileged position relative to many others in the United States. It would be unwise of me, however, to assume that I am the exact equal of the alternative high school principals I invited to participate in this research. In matters of access to social and financial capital, level of education, ethnic and racial identity, age, sexuality and gender identity, I may be more privileged or less privileged than the study's participants. Only one participant in the group identifies as a person of color and I did not ask participants questions about their sexual orientations or gender identities, but I did present them with a bio I wrote about them with a pseudonym and gender pronouns and each participant approved these 
bios. In all interactions, I strove to practice the qualities that Seidman (2013)

characterized as mandatory in the relationship of qualitative researcher to participant:

"respect, interest, attention, good manners" (p. 99).

As a person who largely shares a professional identity with those I interviewed, another important consideration I worked to embody was that of creating enough distance so that it was clear that the relationship between researcher and participant is a partnership, not a friendship. I did this by addressing participants in my introductory email as Principal ___ (last name) and then asking participants if I could call them by their first names when we spoke virtually (see Appendix B). Weiss (1994) reflected on the role of this relationship in situations where something goes wrong in the interviewing:

What is essential in interviewing is to maintain a working research partnership. You can get away with phrasing questions awkwardly and with a variety of other errors that will make you wince when you listen to the tape later. What you can't get away with is failure to work with the respondent as a partner in the production of useful material. (p. 118)

Another consideration with respect to positionality is what it means for a researcher and participant to discuss race and racism, leaving school without graduating, poverty, and disability. In my case, I attended one high school and graduated with my cohort. (My high school included grades 10, 11, and 12.) My light skin, status as a speaker of English in my home, lack of poverty, and lack of disability all supported this "on time" graduation. Even though some or all of these characteristics may be shared by the participants in this study, it was imperative that I maintained an awareness of and sensitivity to these factors when discussing the students who attend the schools of the study participants. To ignore these facts would be to deny all of the literature reviewed earlier and this would damage the data. 
It is also impossible to ignore my own experience with the topic of school accountability as an alternative high school principal. As recounted in chapter one, I have personal experience listening to other principals who gained national recognition for school reform that included pushing a number of struggling students into a district alternative high school. I have also heard a school district superintendent inaccurately claim that his district's high school graduation rate would have been higher if alternative schools' rates were not factored in. This distancing of officials from struggling students and the schools designed to support them has been troubling to me on many occasions. My interest in this study includes a desire to set this record straight.

One participant volunteered in her first interview that she graduated from an alternative high school in her youth, but others suggested that their educational upbringing was more conventional, like mine. This factor can limit (most of) our insights into what it means for our students to persist through school. I have also tried to stay cognizant about the ethics of investigating race and racism with participants who are mostly more privileged by race and class than are their students. This was relevant to discussions during interviews and to my analysis and interpretations following the interviews. L. T. Smith (2008) asserted that "research ethics is often much more about institutional and professional regulations and codes of conduct than it is about the needs, aspirations, or worldviews of 'marginalized and vulnerable' communities” (p. 134).

\section{Reflexivity}

Reflexivity is an acknowledgement that the researcher is part of the social structure that they study. We, therefore, cannot avoid influencing that social structure or being influenced by it (Maxwell, 2013). Creswell and Creswell (2018) asserted that 
reflexivity requires researchers to be explicit about their past experiences with the issue under study, as well as how these past issues shape interpretations. In my case, there is no doubt that I have past experiences with state accountability in alternative schools that serve disproportionately high numbers of BIPOC students and that this shapes how I interpret the data. The memo-writing, member checking, and use of three kinds of coding were all efforts to mitigate the effects of my relationship with and feelings about the topic of study.

Bias

As mentioned previously, biases in the process of qualitative research are inevitable (Bourke, 2014). Some strategies for mitigating the impact of bias on the research process include peer debriefing (Creswell \& Creswell, 2018), writing memos about intersections between the research and the researcher's identity (Maxwell, 2013), and remaining mindful throughout the process of both the challenges and the benefits of the researcher's previous knowledge and ideas about the topic (Merriam \& Tisdell, 2016). I did use all of these methods throughout the research process. Peer debriefing happened in my discussions with colleagues in my school district, while the process of memo writing happened after each interview. I was also able to debrief many of the findings with my adviser throughout the research process. 


\section{Validity and Reliability}

\section{Validity}

Validity and reliability in qualitative research have several components. Creswell and Creswell (2018) defined validity in the qualitative context as the employment of certain procedures to check for the accuracy of findings. They contended that validity is a strength of qualitative research and increases through a number of strategies. These strategies are listed in Table 7, along with the use of these strategies in this study.

\section{Table 7}

Qualitative Validity Strategies and Their Application to This Study

\begin{tabular}{|l|l|}
\hline \multicolumn{1}{|c|}{ Strategy } & \multicolumn{1}{c|}{ Application to This Study } \\
\hline The triangulation of different data sources & $\begin{array}{l}\text { The use of interview data and document analysis } \\
\text { are the major data sources. }\end{array}$ \\
\hline Member checking & This was used following each interview. \\
\hline $\begin{array}{l}\text { Use of rich descriptive language to convey } \\
\text { findings }\end{array}$ & I have aspired to do this. \\
\hline $\begin{array}{l}\text { Clarification of potential biases the } \\
\text { researcher brings to the study }\end{array}$ & $\begin{array}{l}\text { This is detailed in an earlier section of Chapter } \\
\text { Three of this study. }\end{array}$ \\
\hline $\begin{array}{l}\text { The sharing of negative or discrepant } \\
\text { information that may run counter to the } \\
\text { study's themes }\end{array}$ & $\begin{array}{l}\text { One participant's responses varied greatly from } \\
\text { the others. These discrepant data are an important } \\
\text { finding and is detailed in chapters four and five of } \\
\text { this study, described as "outlier data." }\end{array}$ \\
\hline Spending prolonged time in the field & $\begin{array}{l}\text { While this has not happened as a direct result of } \\
\text { this study, I have been working in this field for } \\
\text { many years. }\end{array}$ \\
\hline Peer debriefing & $\begin{array}{l}\text { I have had the chance to debrief findings with my } \\
\text { adviser and with professional colleagues. }\end{array}$ \\
\hline
\end{tabular}

Source: Creswell and Creswell (2018, pp. 200-201). 


\section{Reliability}

Creswell and Creswell (2018) also had several suggestions for increasing qualitative reliability, which they defined as the consistency of the researcher's approach across different researchers and among different projects. These suggestions, as well as their application to this study, are detailed in Table 8 .

\section{Table 8}

Qualitative Reliability Strategies and Their Application to This Study

\begin{tabular}{|l|l|}
\hline \multicolumn{1}{|c|}{ Strategy } & \multicolumn{1}{c|}{ Application to This Study } \\
\hline $\begin{array}{l}\text { Careful documentation of research } \\
\text { procedures }\end{array}$ & $\begin{array}{l}\text { I have worked on this through the memo-writing } \\
\text { process and by writing while gathering data. }\end{array}$ \\
\hline $\begin{array}{l}\text { Check transcripts to make sure there } \\
\text { are not transcription mistakes }\end{array}$ & $\begin{array}{l}\text { Checking interview transcripts happened through } \\
\text { member checking and during the process of coding. } \\
\text { Additionally, the transcription service lent itself to } \\
\text { thorough transcripts without omissions. }\end{array}$ \\
\hline $\begin{array}{l}\text { Guarding against a "drift" in the } \\
\text { definition of codes }\end{array}$ & $\begin{array}{l}\text { Provisional codes in this case were not as helpful as } \\
\text { the use of in vivo and descriptive coding, but I have } \\
\text { worked at "continually comparing data with the codes } \\
\text { and writing memos about the codes and their } \\
\text { definitions" (Creswell and Creswell p. 202). }\end{array}$ \\
\hline $\begin{array}{l}\text { Cross-checking codes developed by } \\
\text { different researchers in an effort to } \\
\text { develop intercoder agreement }\end{array}$ & This strategy was not used in this case. \\
\hline
\end{tabular}

Source: Creswell and Creswell (2018, pp. 200-201).

In summary, there are many strategies that can help qualitative research to be both valid and reliable. These include a recognition of possible biases and subjectivity on the part of all researchers. If the ultimate goal is widespread trustworthiness of the research process and conclusions, Seidman (2013) argued that formulaic approaches to increase validity and reliability are less important than are an "understanding . . . and respect for 
the issues that underlie those terms. We must grapple with them, doing our best to increase our ways of knowing and avoiding ignorance, realizing our efforts are quite small in the larger scale of things" (p. 30).

\section{Chapter Three Summary}

This chapter on methodology started with a re-introduction of the purpose of the study and moved into an argument that a basic qualitative approach, using interviews and document analysis, are the best methods to answer this study's research questions. The chapter discusses the purposeful selection of participants and all of the procedures used in this study (Merriam \& Tisdell, 2016). These procedures include participant recruitment, gaining of informed consent, and the guarding of confidential data and materials. Interview guides have been developed and explained in this chapter and are included as Appendices D, E, and F. Coding and data analysis have also been developed and discussed. The role of the researcher, including positionality, reflexivity, and guarding against bias have all also been shared in this chapter. The chapter ends with a final discussion of validity and reliability in the qualitative context and its application to this study. 


\section{Chapter Four: Findings}

\section{Introduction}

As discussed in Chapter 3, this study used semi-structured interviews and document analysis to examine how alternative high school principals in one state in the Pacific Northwest navigate state accountability systems. Related research questions include how the ratings of state report cards influence their work and how these administrators compare their work to that of their conventional high school counterparts. A particular focus of the study's analysis is on the intersection of race and BIPOC students who drop out, fall out, or are pushed out of conventional schools and into alternative schools.

The results of these interviews, document review, and accompanying data analysis are reported in this chapter in three ways. First, profiles of the study's participants and key categories and themes from their interviews are reported. Second, essential categories and themes from all interviews which emerged are reported. Third, divergent or outlier responses, reported by one participant, are shared in their own section. Responses from all participants, including those not common to the group, form the basis of several recommendations and insights discussed in Chapter 5 . 
Table 9

Principal Participants in Study

\begin{tabular}{|l|l|l|l|l|}
\hline $\begin{array}{l}\text { Pseudonym Participant and } \\
\text { School }\end{array}$ & Gender & $\begin{array}{l}\text { Number of } \\
\text { Years at School }\end{array}$ & $\begin{array}{l}\text { Most Recent Previous } \\
\text { Job in Education }\end{array}$ & $\begin{array}{l}\text { Type of } \\
\text { Community }\end{array}$ \\
\hline $\begin{array}{l}\text { Bernadette--Flexible } \\
\text { Learning Center Alternative } \\
\text { High School }\end{array}$ & Female & $1-3$ years & $\begin{array}{l}\text { District Office } \\
\text { Administrator }\end{array}$ & Urban \\
\hline $\begin{array}{l}\text { Sarah--Youth Development } \\
\text { Alternative High School }\end{array}$ & Female & $1-3$ years & $\begin{array}{l}\text { Alternative School } \\
\text { Coordinator }\end{array}$ & Suburban \\
\hline $\begin{array}{l}\text { Larry--Achievement } \\
\text { Alternative High School }\end{array}$ & Male & $4-6$ years & $\begin{array}{l}\text { Small 5-12 School } \\
\text { Principal }\end{array}$ & Urban \\
\hline $\begin{array}{l}\text { Mike--Victory Alternative } \\
\text { High School }\end{array}$ & Male & $1-3$ years & $\begin{array}{l}\text { Comprehensive High } \\
\text { School Principal }\end{array}$ & Urban \\
\hline $\begin{array}{l}\text { Patricia--Options } \\
\text { Alternative High School }\end{array}$ & Female & $6-9$ years & $\begin{array}{l}\text { Small High School } \\
\text { Principal }\end{array}$ & Rural \\
\hline
\end{tabular}

\section{Types of Data Gathered}

\section{Introduction}

As discussed in Chapter 3, two types of data were gathered for this study: semistructured interviews with study participants and artifacts from the participants for document analysis. Each participant was interviewed twice (see Appendices D, E, and F). These interviews were recorded and transcripts were shared with each participant to allow for member checking. Additionally, I wrote a memo to myself following each interview to help capture additional insights and details. There was only one request that came from one participant in the member checking. This was to take care in the way that 
trauma and abuse information shared about students is reflected in this dissertation. I have made every attempt to honor this request not just for the participant who made the request, but for all participants.

\section{Participant Interviews}

The five participants in this study each agreed to two interviews each. These interviews took place virtually from the homes or school offices of each participant and the home of the researcher. I used the Google Meet platform to conduct and record these interviews and then uploaded each one into Otter ai transcription software. I wrote myself a memo about each interview when I finished it and shared interview transcripts with participants after these were generated. I used descriptive, in vivo, and provisional codes on all of the interview transcripts following the interviews (Saldaña, 2016).

\section{Document Analysis}

As part of the first interview with each participant, I asked if they would share with me relevant documents such as school handbooks, newsletters, correspondence or presentations. Only two of the participants shared documents with me. Participants gave various reasons for not sharing these documents with me. Reasons include that they used district publications rather than create their own and that they found written correspondence to be an ineffective way to communicate with the students and families in their school communities. It is also important to note that participants were all working a significant amount of time from their homes, due to the COVID-19 pandemic; paper files and artifacts were not readily available to them. The responses of who did and did not share these items, as well as information about the documents I did receive are reported later in this chapter. 


\section{Participant Profiles}

This section includes information about each participant who participated in the interviews for this study, as well as their responses to the interview questions in Appendices D, E, and F. Quotes from interviews are edited only to preserve confidentiality, and occasionally for clarity, as described earlier in this chapter.

\section{Bernadette}

Principal Bernadette has held a number of leadership and administrative roles for multiple school districts, in addition to being a special education teacher for a number of years. A woman of color, she graduated from an alternative high school before earning multiple higher education degrees. The first school year impacted by the global COVID19 pandemic falls within the first three years of her tenure as principal of Flexible Alternative Learning Center High School, as well as the year in which she participated in interviews for this study.

Bernadette shared she believes that alternative schools are an antidote to the deadening of creativity and divergent thinking which she claimed is prevalent in conventional schools. In her second interview, she stated:

I feel like a lot of times, especially in the comprehensive environments, we spend a lot of our time dealing with our students' divergence. We've heard that we start killing [divergent thinking] in kindergarten and it goes away by eighth grade. If we recognize that as a problem, and then simultaneously recognize that there are alternative settings that see divergent thought as an asset and as something that we need in our society, why wouldn't we be growing that in the same way that we grow magnet programs? I want to be the magnet for divergent thinking and for critical consciousness and radical love, because that's what our society really needs as much as it needs engineers, statisticians, artists, and math competitions.

Bernadette's school, The Flexible Learning Center, serves a diverse student body

of about 140 students. The school stopped enrolling new students last year, as the 
superintendent has signaled to the school community and the district that there will be some kind of redesign of the school model in the near future. According to the school district's webpage, Flexible Learning Center has higher percentages of multi-racial, Indigenous, and Chicanx students than the district's comprehensive high school and comparable percentages of African-American and White students. Asian students are under-represented at Flexible. According to Bernadette, students with disabilities and mental health struggles from all racial groups, including those with IEPs and 504 plans, are over-represented at Flexible Learning Center. She also pointed to a disproportionately high population of “ever English Language Learner” students and a significant number of students who have attempted suicide in the past.

Bernadette asserted that she believes the term "alternative" incorrectly implies a lack of rigor. In reference to conventional schools, she argued,

It's interesting that we really want to encourage entrepreneurship and growth and difference and invention, but then we put students in school environments that don't give them the opportunity for that and say that that's the hard school. The "hard school" is where you have to memorize. It's like that's the hard thing--like going through the comprehensive setting and being a part of the machine is the hard thing. Really the hardest thing is really having to drive your own learning and determine what you need in order to become a better learner. There's so much more depth in the critical thought and the radical love as action through community membership. And I don't think that you can measure that. There's not an SAT score for emotional quotient, right? Like, you can't measure those pieces. So it looks like it doesn't exist.

Bernadette discussed how she believes that large comprehensive high schools are able to both create and hide inequities through focusing on majority populations in the student body, as well as by focusing on quantitative data to the exclusion of students' shared stories and experiences. She contended: 
So we end up with these little secret pockets of kids with really deep and nuanced stories, that when you don't look at those really deep and nuanced stories, you can begin to hide inequities by looking at the batch numbers. I feel like when we stop listening to those individual stories and those individual pieces, we can look at just the whole group and say everything's going fine.

She illustrated this point with the example of her district's comprehensive high school, which has a high 4-year cohort graduation rate, compared to others in the state. In the midst of this overall high rate, the comprehensive high school posted a drop of more than $30 \%$ in the graduation rate of one sub-group of BIPOC students.

Bernadette described the challenge of wanting the successes of her school to be more visible, while also feeling afraid of the school receiving more exposure. This fear was realized shortly before our second interview when she shared data about the success of her school's work to re-engage out-of-school youth with district leadership. Instead of receiving feedback that senior leadership was happy that these youth were back in school, she said that she was met with questions about the cost of that program. She has also felt that she had to defend the school's staffing allocation in relation to questions about relatively lower state testing and graduation rate numbers. She stated,

I really want to share with you the celebrations but I'm scared that if I share with you the celebrations then all of a sudden, these very linear things rooted in Whiteness--money, time, timelines, plans, outlines--those things become a part of the conversation in a way that I didn't necessarily want them to.

Bernadette added that she believes the personalization and out-of-the-box thinking prevalent in alternative education have something to offer for all students. She said,

I kind of want what we do to become normal and desired everywhere. I want teachers in comprehensive settings to come and look at what we're doing and what's really working for our kids ... I want [Flexible Learning Center] to be a place that people want to be and want to go to. I want them to be knocking the doors down. 


\section{Sarah}

Principal Sarah, a White female, worked as a Special Education teacher in regular and alternative high schools before falling in love with an alternative school and pursuing the leadership of that school. She is now principal of her second alternative school, Youth Development Alternative High School, and has been there for 3 years. In that time, Youth Development has become not just home to their district's alternative high school, but also to both middle and high school programs for expelled students, the district teen parent services program, home instruction, and a GED program. Youth Development has higher percentages of BIPOC students, students who qualify for Free/Reduced Lunch, and students with disabilities. Sarah compared her school's demographics to those of the school district as a whole in one of the school's documents she shared for this study: "Compared to district demographics, [Youth Development] holds almost twice the percentage of Latino students (60\%), twice the percentage of Ever English Language Learners (35\%) and three times the percentage of students with disabilities (40\%)." Sarah also noted that the numbers of students suffering with mental health challenges is very high in her school.

Sarah expressed an interest in improving her school's data and ratings. For example, the school's state improvement plan notes that they have been rated by the state's ESSA plan system at Level 1 for Chicanx student 4-year graduation rate, which puts them in the bottom $5 \%$ of schools in the state. They also rate at Level 4 for Chicanx student 5-year graduation rate, which means they are within the range of 44-90\% of Oregon schools in that category (Oregon Department of Education, n.d.-d). These ratings indicate that Youth Development struggles to graduate Chicanx students 4 years from 
when these students entered ninth grade (overwhelmingly at a different school), but that most will meet this goal with one additional year of high school. One of Sarah's strategies for changing this rating is to recruit more ninth and tenth grade students to the school. She explained,

we're getting students that are way behind as juniors. And just speeding them up and getting them out the door in 4 years is not the goal of our school. Learning and getting them prepped and ready for their next steps is the goal of our school. And when they're so far behind, it takes a little longer. So, if we can get those kids identified and over to us earlier, I think it's going to benefit them and I think it would reflect in our 4-year graduation data.

Another area in which Sarah and her school have positively impacted school district data is in the area of expelled students, though this is not an explicit part of the state report card. The middle and high school support programs for expelled students had been slated for closure in the previous school year, but Sarah and her vice principal went to the school district leadership to advocate for not closing the programs. She recalled arguing, "we can't talk about closing [the program] as a budget issue. This is an equity issue, and I kind of got shut down. [They said] 'this is the budget; you need to house them." The alternative school ended up integrating these programs into the school and also shifting the focus toward collaborative problem solving with the support of community partners. She recalled:

Anytime there was a kid up for an expulsion, we required the district to come in and do a case team which had people from the county, support people, and other administrators or counselors or social workers from the district. They now come in and meet with the school-based team to talk about [the] incident, to talk about the kid, to talk about the family, to talk about what supports can we implement before we push this kid out of their school community. [It is meant] to help support the school and to help support the kid and the family so that kids aren't disproportionately pushed out. And we did that and we really cut down our number of expulsions. 
In fact, Youth Development posts a $67 \%$ reduction in the number of expelled students from last year to the current school year, according to Sarah.

Mike

Principal Mike, a White male, served many years as a high school teacher, vice principal, and high school principal in a few small towns in his state. He later moved to a nearby larger district to become the principal of Victory Alternative High School and has held that position for one year. Victory Alternative High School is home to eight different schools and programs in one of the largest school districts in the state. These programs include what Mike referred to as a "last chance high school," an early college school, teen parent program, 2 GED programs, and a school for expelled students. One of the challenges for Mike and the school staff of having all these programs under one umbrella is the challenge of monitoring progress for each part of Victory. He explained,

So we don't really have an ability to pull separate data for each program and see if that is serving the kids that . . . it has in it. But [the school district] does use graduation rate and completer rates as the main metrics that they cite. The completion rate, that's one of the things for me that I think is important. I don't feel a lot of pressure. I feel like probably less pressure on me from the district than I think I should be receiving related to accountability and those normal metrics of a high school principal, because I don't have regular data coming to me. And so one of the things that we're working on with each program and then overall is just tracking individual student growth by credit attainment, [comparing levels before and after entering alternative education].

Despite this, Mike is aware of negative stereotypes held in his community about his school. He explained, there's all the "perception stuff around being an expelled kid. And you know we also have other stereotypical things that occur, as far as comprehensives . . . but [Victory] has always been considered negative because of being alt ed." Mike shared his belief that these stigmas are the result of the fact that his school 
includes a program for expelled students, not because of his school's state report card ratings.

Mike also acknowledged that the problem of pushing students out of conventional schools into alternative schools exists and that his school district is working to address this problem. He stated:

So all of our administrators have gone through some training now where we identified ... things like discipline practice. We've talked about that for a long time, disproportionate discipline, disciplinary practices, and we're expelling more students of color per capita than exist within our school, so it's disproportionate. But the other piece of that that we're looking at is the less overt types of push out. And our program and other programs have been built around [that].

Mike drew some of this insight from his years as a rural, comprehensive high school principal in a nearby town. He explained that being the principal of Victory is much more rewarding for him than his previous position and that this experience also informs his current work in the alternative school. In his words,

I feel like in the comprehensive I spent a lot of time on things that were not really directly supporting kids and their education of becoming scholars or anything. It was a lot of focus on a different sort of socio political context. And I think that this job is more about how we're trying to identify an environment that will make all of our students successful.

Mike expressed a lot of gratitude to his current school district for their support of his school and for their commitment to engaging in equity professional development. He appreciates the lower student to staff ratios that he has in the alternative school and he feels hopeful about a redesign process that the district is beginning for the alternative school, largely because he has been able to solicit student, parent, and community voice for the redesign. He explained in his second interview that the redesign was prompted by 
a lack of transportation to some of the school's disparate sites, as well as a need to

consolidate some of these sites. It has, however, expanded in focus:

So ... the redesign started out at almost purely as consolidation and because of lack of transportation, but through some of the work that our district is doing, looking at culturally responsive school leadership and looking at implementing restorative justice and social emotional growth and trying to embed that for students, it realized that, in addition to just putting things together we had, that was a barrier. But we also found some other barriers and some groups of students that weren't served well. So it turned into what's our model for our school, being a school of choice, but not like an exclusive, application school, but you're applying, you're asking to go to this school.

This idea of a school of choice counters the "last-chance school" image that Mike described as a stubborn stereotype of all the programs and sites represented in his school. He continued:

I'm happy for kids that haven't been successful to come to my school. Like that's in no way a problem. What I want to do though, is expand our options within the [local community] to allow for students who would like whatever this model is that we pick. If we pick a wraparound model and they want exposure to smaller class sizes or they want a smaller sort of cohort that they're working with, if they want access to social services, a social worker within the school, if they want access to an internship or classes at the community college, if they want access to any of those services that we have. Then I want to make sure that more kids have those options. And that we're getting to know our kids so well and giving them a voice and that our curriculum is developed with their history and background involved as a part of it instead of just the standard sort of, just the canon.

Larry

Principal Larry, a White male, served as a principal in a small, diverse, multilevel school in the Midwest before coming to the Pacific Northwest. He has been the principal of Achievement Alternative High School for 5 years. Achievement Alternative High School is the only in-district alternative high school in the school's urban district and has been consolidated from a two-campus model in recent years to one campus. The school serves about 200 students, whom Larry described as racially, ethnically, 
linguistically diverse, but not as diverse as the student body in the much larger district comprehensive high school. He clarified that the alternative school "serves more Latino students and fewer Asian students" than the comprehensive high school. Achievement Alternative also represents students with roughly 10 home languages, while the comprehensive high school counts 52 home languages. The nature of multiple enrollment opportunities at Achievement also means that demographics are a "snapshot of the moment" and do change, according to Larry.

Where Achievement Alternative High School does differ consistently from their district's comprehensive high school is in having an over-representation of students who qualify for special education services under the Individuals with Disabilities Act and an over-representation of students who qualify for the free and reduced meals program. With respect to the school's demographics, Larry shared that he believes in the importance of helping both his staff and his students to be able to analyze how societal forces impact student achievement:

Everybody on my team talks about this quite a bit that it's really important for us to have an analysis of all of the factors that lead to our kids needing to access the alternative high school. That means having a real commitment to ongoing education around White supremacy and ableism, and homophobia and capitalism, and all the things that make it so that we have kids who suddenly lost their mom and became homeless in fourth grade. And so they didn't go to fourth grade. And they've been off track ever since .... What comes up for us a lot is that some of our students come here because they've had a really hard time because they've been experiencing racism or homophobia or ableism or classism within their school setting, and that was the barrier.

Indeed, Larry contended that the greatest challenge he faces as an alternative high school principal is leading a school whose students have experienced so much trauma in their lives: 
I think the hardest part is the trauma factor, that you're just working with kids who are activated so much of the time and that by March and April, it really takes a toll on the teaching staff. And I think one of the hardest things that I've had to learn how to do as a school leader is to be able to sort of lead the staff and model taking care of myself and them taking care of themselves within that context of working in just a sort of consistently emotionally heightened context. And that's not something I learned in grad school ... In addition to all of this teaching and learning heavy-lifting and the work with the kids is the emotional work of ourselves that has to be done if we're going to make it from March to June.

Larry reported that he feels strongly that public schools need to be accountable to their communities and transparent about how students are or are not progressing academically. He asserted, "I want to be clear that I really believe in the importance of things like school report cards and tracking data and having state testing information being public." He went on to explain that some of the reason he feels strongly about this is his previous experience in the Midwest where he saw BIPOC students and students in poverty who regularly attended school and did not learn to read or do math at grade level "swept under the rug for years and years." At the same time, he stated that he wishes there was more information in school report cards that could show growth and improvement, such as through Northwest Evaluation Association Measures of Academic Progress test scores, measures of student engagement, changes in attendance from previous schools to the current school. He noted that his school enrolls students who missed months or years of school in elementary grades due to homelessness, trauma, and other experiences and whose skills have barely progressed since third or fourth grade. According to Larry, this has bearing on Achievement Alternative High School's low performance rating by the state.

The state report card in Oregon includes many data points, but the English Language Arts and Math achievement, measured by the SBAC exam in the 11th grade 
and a school's 4-year and 5-year cohort graduation rates are double-weighted in the calculation of the report card (Oregon Department of Education, n.d.-b). When it comes to measuring students' skills on the SBAC, Larry noted that Achievement Alternative High School enrolls many students mid-way through their junior year in high school and then has to assess their skills, which appear on the report card to be a reflection of Achievement's quality as a school. He asserted:

With the state testing, often we're not getting kids until their junior year of high school and so we may have had that kid for a couple months before they take those tests . . . . What I have seen with them is that they're under so much pressure to earn the credits that they need, before they graduate, that when they're here, they want to spend every single second working on something that's going to earn them credits. And so to ask them to take time out of that to take this test that takes a really long time, and do all of this math and do all this writing for something that's not going to get them any high school credits. If you sat me down and said, I want you to spend five hours taking math tests, but the outcome doesn't really make any difference and also, you've got this huge other pile of work to do, you're not going to get your best math out of me. I think just like the incentives for my kids to do their best on that assessment just aren't there. So, yeah, I don't think our state report card does a good job of showing what we do.

Additionally, Larry shared that his superintendent and executive leadership have asked him to investigate other models of alternative high schools in an effort to begin a re-design process. Larry understands that the school does not "fit within their vision and their model of how they want to meet student needs within the district." This is due in part to Achievement's teachers needing to improvise with curriculum when teaching students at multiple academic levels who enter the school at different periods throughout the year. He contended:

For an observer who doesn't know a whole lot about it, or even someone who does, you're going to come in and see a lot of a lot of room for improvement there. Because teachers were doing stuff, like they're working with the curriculum and then seeing that "oh, all my kids need to learn this, and it's not in here." And they think they got to go and figure out some lessons and figure out some 
YouTube videos and kind of cobble it together. And so I think as a district instructional leader, when you walk in you see that, you're going to flinch a little bit because like what you want to see fidelity to the curriculum. But there's a mismatch between our curriculum and what our students need. And so like, I think that's a big piece of kind of where their discomfort is . . . They're really wanting to see something more coherent. And I think like they're wanting to see some more kind of alignment between what the board picked in terms of a curriculum, what the committee picked in terms of the curriculum, and what's happening in the classroom. But when you've got a group of kids who are all there, because they missed third grade because they were homeless, or something like that and there's a bunch of gaps, you're going to have to go back and fill in.

\section{Patricia}

Principal Patricia, a White female, worked in multiple programs in a few states to support underserved high school students to be successful in college, then worked as a teacher and a principal in one of her current district's regular high schools. She has been the principal of Options Alternative High School for seven years. Patricia's experience as an alternative high school principal has some parallels to that of the study's other participants. Her school is over-represented for students with disabilities and the awareness she and her staff members have of the abundance of trauma experienced by her students is enormous, as is the case with each participant. Beyond that, however, Options High School presents an outlier picture compared to each of the other four schools in this study.

When Patricia first arrived at Options, the school was located across town from the district's other school buildings and was using an old church as their learning space. She shared, "[Options] ... was in really bad shape, like less than half of the kids were graduating on time, if at all. Things were just pretty rough.” There was also not a clear system for referring students to Options, which led to a great deal of push out from the 
conventional high schools. Patricia was, in fact, the principal of one of those high schools, though her school did not refer very many students to Options.

Patricia stated that the teaching staff at Options requested her and that her "inner justice warrior" and her love of challenge propelled her toward the new job. Even though she came to the alternative school from within the district, she was shocked to see the condition of the school. Upon arrival to the school, Patricia said she realized how bad things were:

I just how really unfair the process was, and then how that was impacting students so even kids that were coming to [Options] were not doing really well. They felt awful about themselves. They felt like failures, even if they were succeeding, because they had been shipped off and sent away.

Patricia believed that she and her school and district were all able to change Options into a highly functioning alternative high school by addressing two needs of students and the district's broken referral process. The student needs were a lack of advocacy and trauma. Regarding the advocacy, she stated:

There were kids who didn't have an advocate; they didn't have a thing that they were really good at. So, if you're the really good football player and you're struggling with your grades or your attendance, your test scores, then you've got an advocate who's going to help keep you around. And if you're really good at art or you're really good at band. And these were all kids who didn't have a thing. And they didn't really have an advocate.

In addition to a lack of advocacy for students who were being referred to Options,

Patricia stated she believes there was a common thread of students who had experienced severe trauma. She reflected on specific cases, sharing:

[there were] kids who had been homeless with just the lack of acknowledgement of those things from their original school. Yeah, she failed all her classes last year, and then you find out well, her dad died in November. Of course, you failed your classes last year. 
The information Patricia shared about the district's once broken referral system, which has since been greatly improved, according to Patricia, is shared in a different section later in this chapter.

\section{Synthesis of Participant Profiles}

The five individuals who participated in two interviews each for this study shared many characteristics, including a strong enthusiasm for their work and their students' wellbeing, a desire for their students' strengths to be recognized and understood, and concern for the complex needs of their students, especially in light of limited resources to meet these needs. Universally, when these participants talked about their students' needs, they were recognizing the challenges of trauma and mental health concerns as primary and learning as secondary. They shared concerns about how their schools and students were not well-represented by state accountability practices, but also appeared resigned to the fact that this is part of being an alternative high school administrator. Four of the five principals described their BIPOC students as over-represented in their schools, compared to their district and saw this as both an opportunity to provide innovative programming to this group of students and as an unfortunate aspect of institutionalized racism.

\section{Document Analysis}

As part of the first interview with each participant, I asked if they would share with me relevant documents such as school handbooks, newsletters, correspondence or presentations. Only two of the participants shared documents with me. Participants gave various reasons for not sharing these documents with me. Reasons include that they used district publications rather than create their own and that they found written correspondence to be an ineffective way to communicate with the students and families 
in their school communities. It is also important to note that participants were all working a significant amount of time from their homes, due to the COVID-19 pandemic; paper files and artifacts were not readily available to them. The pandemic also changed my original plan of interviewing participants in their schools, where I might have been able to pick up materials more available in the school offices. The responses of who did and did not share these items, as well as information about the documents I did receive are reported in the next section of this chapter.

Participant Larry did share a copy of a presentation he gave to his school district leadership, but also stated,

You know, I'll say, that's never been my strong suit as a school leader. I think I tend to err on the side of being internally focused. I don't know if you've looked at my website, but it's out of date. And doing . . . the Facebook stuff and the web, it's not my great strength as a school leader. I'm better with the kids.

Patricia noted that her school changes so frequently that handbooks are out of date and Mike noted that he was surprised upon arriving to his alternative high school to find that the handbook there shocked him, "because it's remarkably similar to comprehensive" handbook. In response to my request of Bernadette for documents from her school, she remarked, "I don't know if that's really possible or not, just because of COVID. But even if we weren't in COVID right now ... the hard part is we're in rebuilding right now, so our handbook is irrelevant."

\section{Youth Development Alternative High School Documents}

Principal Sarah at Youth Development Alternative High School shared four documents with me pertinent to her school. These are the school's student and family handbook, the staff handbook, a slide deck explaining the school learning plan, and the 
school's continuous learning plan. While these documents are all designed for different audiences and serve different purposes, all but the school's continuous learning plan reflect a lack of focus on the state report card, graduation rate, state testing goals or other accountability measures. They are focused on communication, collaboration, social justice, equity, individual student achievement, and community-building.

The school learning plan slide deck includes an overview of the school's programs and services, as well as three problems of practice. These include equity, math credit attainment, and in-district collaboration to encourage more ninth and tenth grade students to enroll at the school. This last point is also present in the school learning plan, which is the only shared document that references graduation rate:

Factors that lead to a high 5 year graduation rate and a low 4 year graduation rate can be seen in our distribution of students and their grade level when they start at [Youth Development]. The majority of our students are 11th/12th/5th year seniors. To increase our 4 year graduation rate we need to serve more 9 th and 10th graders.

The same learning plan also references the state school report card in its reference to the school's ratings for sub-group graduation rate:

In 18-19 [Youth Development's] Latinx graduation rates showed both a success and a challenge. In a 1-5 Every Student Succeeds Act scale, [Youth Development's] scored a Level 1 for four-year cohort graduation rate for Latino students. [YD] scored a level 4 for five-year cohort graduation rate for Latinx.

In her second interview, Sarah commented on these ratings:

Yeah, I think it's kind of driving why it would be beneficial to have more ninth and tenth graders in our school. Well, it's not just the driver, but it is kind of one example and the numbers of why it would be beneficial, because we're getting students that are way behind as juniors. 
Achievement Alternative High School Documents

The copy of the presentation slides that Larry shared focused primarily on creditearning trends among his students at Achievement Alternative High School. His graphs showed that his students passed approximately $45 \%$ of the classes they attempted prior to enrolling in the alternative school and $77 \%$ while at Achievement. Another slide noted that Achievement High School's "courses are based on the same common core standards as [the comprehensive] High School" and attributes the increase in credit-earning to smaller class sizes and longer periods. These characteristics, according to the presentation, "allow teachers to provide better differentiated support to students as they work towards mastery of those standards . . . . and allow for more individual support within classes."

The Achievement Alternative High School presentation shows an overall 4-year graduation rate for the school of $40 \%$ and a 5-year completion rate of 53\%. Subsequent slides also show higher graduation rates for African-American and Chicanx students at Achievement, compared to other schools. 


\section{Data Analysis}

\section{Organization of Data Analysis}

Data generated from participant interviews and document analysis are presented in this chapter as participant profiles, document profiles, analysis of categories that were present in all interviews and analysis of outlier categories. As advised by qualitative research methodologists (Creswell \& Creswell, 2018; Maxwell, 2013), data were mostly analyzed continuously throughout the research process, simultaneous to the data collection. At times, this process was adjusted based on the availability of the participants. What was consistent, however, was the transcribing of each interview immediately after it was completed, the writing of an after-interview memo shortly thereafter, and the sharing of each transcript with the participants before the second interviews occurred. The coding of interviews happened shortly after the memo-writing.

\section{Data Coding}

As noted in Chapter 3, three kinds of codes were used in this study: descriptive coding, in vivo coding, and provisional coding (Saldaña, 2016). Descriptive and in vivo codes were written by hand in the margins of interview transcripts. For provisional coding, I printed Appendix G and continuously compared those terms to the transcripts as I read and re-read them. What I found through this process is that the descriptive and in vivo codes yielded the richest data and allowed me to identify many of the important quotes from participants, shared earlier in this chapter. The provisional codes, which I had identified from the literature, infrequently appeared in the interviews. 


\section{Findings}

\section{Categories Consistent Among All Participants}

Participants chosen for this study have several professional characteristics in common; each is a principal of a public alternative high school, all from one state; each school has a population within the top $50 \%$ of BIPOC students in that state. Thus, is not be surprising that several common categories related to how alternative high school principals navigate state accountability systems, how state report card ratings influence their work, and how the principals compare their work to that of their conventional high school counterparts, emerged from the data: trauma-sensitive safe havens, the overrepresentation of students with disabilities, an acknowledgement that standardized accountability metrics poorly capture the work of alternative high schools, the importance of promoting alternative schools as schools of choice, and an ambivalence about district support for low student-staff ratios. Each of these categories is detailed below. Mental Health Concerns and the Need for Trauma-Sensitive Safe Havens

Every participant interviewed for this study noted that the mental health of their school's students is a major concern. Bernadette shared that many of her students have attempted death by suicide in the past, currently live in group homes, and are engaged in mental health therapy. Sarah noted that she has specifically seen depression, anxiety, and death by suicide all have a major impact on the students in her school. Mike stated that many of the students in his school are considered at risk due to high levels of threat assessment, which he linked to struggles with trauma and mental health. He added that his hope in working at his school is to make a difference for his students who are suffering in crisis. Larry linked his students' mental health challenges to systemic racism, 
homophobia, ableism, poverty and homelessness, as well as to the fact that students' previous school experiences sometimes compounded those challenges. Patricia also noted that many students in her school have had harrowing experiences with abuse and loss and that there has been a "lack of acknowledgement of those things from their original school[s]."

In response to this consistent concern, each participant described how their school incorporates flexibility, support, and unique programming to support the mental health needs of their students. Bernadette's school, for example, has worked with a social services agency to embed mental health treatment into its daily routine. Sarah's school has adopted a social emotional program into its onboarding process for all new students and has shifted her district's approach to expulsion from one of punishment to a collaborative problem-solving team that includes mental health professionals. Nevertheless, Sarah asserted that “mental health needs are really high here and I don't know that we have the resources to meet those needs." Mike pointed to features of his school programming which support students with mental health needs; these include a daily advisory class, restorative justice practices, intentional community-building, and the addition of a social worker to the staff. Larry also has social workers in his school through a community partnership and also provides many of his students and staff with an opportunity to participate in a wilderness outing that involves a ropes course, trust building, and other social emotional growth opportunities. Finally, Patricia's school replaced their counselor with a school social worker. She contended,

I think the biggest thing is just putting the priority of the students first and really the student well-being, I guess I should say first, because you just have to 
prioritize dealing with the trauma or dealing with the life emergencies first, and recognize that the learning components and the instructional components are not going to make a difference if someone's in crisis, right?

\section{An Over-Representation of Students With Disabilities}

In addition to high reported levels of mental health crisis and corresponding needs to create schools that are trauma-sensitive safe havens, every principal in this study mentioned the over-representation of students with disabilities in their schools. In looking at state school and district profiles, this statistic did prove true; these five alternative schools have, on average, $11 \%$ higher special education populations than their districts in general. This is most dramatic for the Youth Development Alternative High School, with a rate of students with disabilities that is three times higher than the overall district rate (see Table 10). Additionally, three of the five participants in this study-Bernadette, Sarah, and Larry—worked as special education assistants, teachers, specialists, and/or administrators prior to becoming alternative high school principals. 
Table 10

Comparison of Special Education Levels in Alternative Schools and Their Districts

\begin{tabular}{|l|l|l|l|}
\hline \multicolumn{1}{|c|}{ Alt School } & \multicolumn{1}{|c|}{$\begin{array}{c}\text { District SPED } \\
\text { Level }\end{array}$} & \multicolumn{1}{|c|}{$\begin{array}{c}\text { Alt School SPED } \\
\text { Level }\end{array}$} & Difference \\
\hline Flexible Learning Center & $10-15 \%$ & $20-25 \%$ & +9 \\
\hline $\begin{array}{l}\text { Youth Development Alternative High } \\
\text { School }\end{array}$ & $10-15 \%$ & $35-40 \%$ & +26 \\
\hline Victory Alternative High School & $15-20 \%$ & $20-25 \%$ & +3 \\
\hline Achievement Alternative High School & $14-19 \%$ & $23 \%$ & +7 \\
\hline Options Alternative High School & $10-15 \%$ & $19-24 \%$ & +10.8 \\
\hline Average & $15.2 \%$ & $26 \%$ & +9 \\
\hline
\end{tabular}

Note: Data from 2018-2019 Oregon Department of Education At-A-Glance School Profiles (Oregon Department of Education, 2020). Each percentage is expressed in a range to protect the identity of each school and school district.

All study participants except Patricia led schools that include specialized programs for students with emotional or behavioral disabilities, while also having students with a variety of disabilities enrolled in other parts of their schools. In the case of Larry's school, Achievement Alternative High School, his district had two separate alternative schools in the past, one which specifically served students who qualified for special education through emotional disturbance eligibilities. During the summer a few years ago, the two campuses were combined and teachers were expected to adapt to this change with little notice or professional development. He recalled, 
My first year here, this building was so quiet. I remember the struggle to get kids to talk in class at all ... And then all of a sudden [we] had this group of students with emotional disturbance just kind of thrown into that mix. And so that was a huge challenge to lead this group through learning how to teach differently ... What we ended up doing was looking at restorative practices in a different way than ... before and having some tough conversations about how do we talk about kids in this building? I started hearing a lot of conversations that started with "I don't think this kid is a good fit for the school." And so we really spent a lot of time unpacking that statement and talking about what does that statement mean, in a public school?

This advocacy for students with disabilities and commitment to serve their complex needs was expressed by every participant. At the same time, Sarah, whose school serves students with disabilities at a rate three times higher than her district as a whole, made clear the relationship between the alternative school in her school district and the conventional middle and high schools:

Alternative schools can't be enabling our systems. And I love the work we do; I love it. But ... right now our school is $40 \%$ special education or more, we're disproportionate with our students of color and it ... just like makes me want to cry. Like we can't be this enabling, last chance spot for kids to land that aren't served by the bigger system. We've got to figure out ways to serve these kids everywhere.

\section{Standardized Accountability Metrics Poorly Capture the Work of Alternative High Schools}

Because this topic is closely related to one of three research questions of this study, I spoke in depth with each participant about how they navigate a state accountability system in which $75 \%$ of alternative schools nationally are characterized by ESSA as comprehensive support and improvement schools or those needing additional support (Atwell et al., 2019). Each participant shared experiences with the state accountability systems and described its limitations for illustrating what is happening in their schools. Patricia noted that these limitations also impact students: 
[The accountability system] needs to change, because that would change the way that communities talk about alternative schools too. It's kind of self fulfilling. If you set up a system where $75 \%$ of alternative schools are identified as being lowperforming schools, then who would want their child to go there?

Bernadette argued that her school and its school report card rating were largely ignored until people in her district questioned how a low rating could intersect with the cost of a low staff-student ratio. She continued, "they just say, 'Oh, yeah, it's the alternative school. They're not gonna graduate there.'. . . And then they're like, 'wait, they get how much money? Why should we be giving them that if they're not graduating?"' All participants spoke about a desire for the state to use different metrics to measure and inform their work both for the purposes of internal progress monitoring and to communicate to their communities how their schools are doing. Larry captured this sentiment when he said:

I do wish that there was something like the NWEA MAP [Northwest Evaluation Association Measures of Academic Progress] tests . . . If I had this range of kids come in the fall, and this is what they knew about math, and this is what they knew in the spring, to be able to track a little bit more. How are students engaging in school before they got to the alternative setting and then how did they engage afterwards? What was their attendance like? Were they passing classes? Just something that would show a little bit more of that would be able to take a student and compare himself or herself to their previous performance, rather than comparing them to the performance of the cohort the year before, or the performance of the cohort at the comprehensive high school.

\section{The Importance of Promoting Alternative Schools as Schools of Choice}

The alternative high school principals interviewed for this study painted a picture of their schools as over-represented for BIPOC students, students with disabilities, and low-income students. They described how they believe they are making a difference in the lives of these students and how this story is not adequately told by state report cards and other accountability ratings. They shared stories of how school district senior 
leadership did not seem to understand what they were doing or did not pay much attention to this work of which they personally are very proud. In the midst of these statements they shared, the topic of alternative schools as schools of choice was raised by all five participants. Larry stated,

I think that it's important for students and families that [school] options not feel like they are at increasing levels of severity. That it shouldn't be like you escalate from ... the [general education] setting, and then ... you go to something more restrictive and then you go to something up here. I think in an ideal world that all the options that there are to finish high school would feel more like, okay, here's six things on a plate; what's the thing that that works best for you?

\section{Ambivalence About District Support for Low Student-Staff Ratios}

While interview participants stated that they appreciate the fact that each of their schools has lower student to staff ratios, this alone does not meet all of the schools' needs. Bernadette commented:

I don't have a science lab with running water. I don't have five counselors, College Possible, Latino Network, TRiO, MeCHA (contracted community services). I don't have all the resources ... It's like, yeah, we might have more FTE and teachers, but we have significantly less partner contracts. We spend money in different ways.

Patricia stated that her district has been very generous in building the alternative school a new campus and in its allocation of resources. The only thing she really wants but does not have is a home-school liaison staff person. Because that position is not funded, she and her social worker or secretary make frequent home visits.

An important point to this category is that lower student-staff ratios help more alternative high school students finish high school, but they do not necessarily translate into higher 4-year cohort graduation rates, due to the fact that so many alternative school students arrive at these schools credit-deficient. Youth Development Alternative High 
School illustrates this fact best through their ESSA rating of 1 (the lowest) for their 4year graduation rate of Chicanx students and a rating of 4 (almost the highest) for their 5year Chicanx student graduation rate. Clearly, Youth Development is graduating Chicanx students, but most consistently after the students' fifth year of high school. Sarah, therefore, shared her belief that the best strategy to change this rating is to enroll more 9th and 10th grade students before they become credit-deficient.

\section{Outlier Categories}

While the study's five participants all had similar trends in student demographics, especially with respect to students with disabilities and mental health challenges, the overall experience of one participant, Patricia, differed from the others. Patricia has had a longer tenure at her school, Options Alternative High School, than any of the other participants. Another way that her school differs from the others is that both the alternative high school and the conventional high schools in her district have similar racial demographics. All of these high schools have a majority of BIPOC students. In all other cases in this study, BIPOC students are over-represented in the alternative high schools.

In both interviews, Patricia described how she and her district were able to move the school from one of the lowest categories on the state report card to one of the highest. These changes were not the result of Options Alternative High School pushing out struggling students or refusing to serve these students; they were achieved through stronger collaboration with the conventional high schools and stronger practices that maintain the accountability of the conventional schools to students who need an alternative approach to high school. Several elements Patricia shared that support her 
school, students, and the district as a whole include: student-centered collaboration between the alternative school and the conventional schools in the district, a team approach, use of state enrollment options to discourage student push out, and an understanding that support for the alternative high school benefits the whole district, including the conventional high schools.

Patricia characterized her school of a decade earlier as "at the bottom of the state in everything except dropout rate, where we were the highest in the state." She offered that, "in 2013, the district did a shuffle and [Options], the alternative school, was in really bad shape, like less than half of the kids were graduating on time, if at all. Things were just pretty rough." She attributed much of this sad situation to a broken referral process from the regular high schools to the alternative high school. As an example, she described incidents in which high school administrators grew frustrated with students and called their parents to tell them that they were transferring the following day to the alternative school, without any notice to the school or participation in the decision-making process by the alternative school or the family, much less the student. She recalled, "it isn't really a choice if students are just being sent there." She continued, "I'm sure that was not legal. It was terrible and you can imagine how that would feel to a kid just to literally get sent away?"

In those years, Options High School was considered a "Priority" school by the state of Oregon. Priority schools, according to the Oregon Secretary of State (n.d.), are designated as such for any of the following reasons: being a School Improvement Grant (SIG) school with a Tier I or Tier II rating, having a graduation rate below $60 \%$ or being 
among the lowest $5 \%$ of Title 1 schools in the state, according to metrics associated with the reading and math state testing. Patricia felt that she could leverage this priority school status to push back on the broken referral system to create something more collaborative. She recalled, "for a couple of years I was not very popular, because I was really pushing back on some practices that just weren't good." She attributed her pushing and the willingness of new administrators in the conventional high schools, as instrumental in the development of a new enrollment system.

The current system is one in which all the high school principals, including the Options Alternative High School principal, meet weekly and discuss potential students to refer to the alternative high school. Patricia shared that before potential students are discussed by this group, it is the responsibility of referring principals to meet with the students in question and discuss a possible transfer with their parents or guardians. The decision whether to transfer then, is a collaborative one among all the principals. Students referred to Options are either at the end of their freshman year and needing to "get back on track" to recover credits or older students who are off-track for a 4-year graduation. The younger students have the option of returning to their last school or staying at Options. All transfer students, however, remain technically enrolled in their previous high school until they reach the point of earning 15 credits. Following a provision in the state for categorizing enrollment as either an "attending school" or an "enrollment school," those at Options with fewer than 15 credits are enrolled at their previous high school and Options is listed as their attending high school. The student's achievement and graduation rate data are reflected on the accountability reports of the enrollment school 
until a change of enrollment happens at the 15-credit mark. This essentially eliminates the practice of pushing out students to improve a school's ratings. Patricia stated that the state allows this in a similar way as they create options for the transfer of non-resident students from one district to another and "that every district has separate reporting fields in their Student Information System that differentiate between Resident and Attendance districts and Resident and Attendance schools.”

According to Patricia, these changes in how students are transferred to Options and which school is held accountable for the transferring student's achievement have transformed Options. They have also had a positive effect on the regular high schools in the district. Options still has lagging state test scores, compared to the regular schools, but is approaching a 4-year graduation rate this year at or near $90 \%$, significantly higher than the state's overall high school graduation rate of $80 \%$ for the Class of 2019 (Oregon Department of Education, n.d.-a). For Options, the school has become a stable, enjoyable place to work and learn, according to Patricia. The school district invested heavily in a new building for the school and located this building close to the main high school campus and district office, which she says have also contributed significantly to the school's improvement. For the regular high schools, there has also been a benefit. Patricia commented:

It's really hard when your scores and your ranking as a school is at the top of the state because you have sent students to the alternative school. It's really hard to make substantive changes as a leader to say, we need to improve instruction in our school, we need to improve advising in our school, we need to improve all these things at our school. It's really hard to get leverage to do that when it looks like your school has everything figured out. So there was a benefit to... our students, but I think it was also recognizing that in order to make real changes within their school and just make their own schools better, they had to 
acknowledge that there were students whose needs weren't being met, in spite of it looking really good before.

Patricia has attempted to share her district's model with others in the state. She recalled, I actually was on the [state] ESSA committee ... the school accountability one. When I signed up for it, and there were lots of alt ed administrators who had signed up for it, lots of small districts, the people who the accountability system doesn't work for and we had all kinds of these grand ideas, none of which ended up in [the state's ESSA plan] .

The fact that, according to Patricia, several alternative education administrators from throughout the state were not able to influence their state's plan is another important finding that reaffirms a lack of concern about these schools and the students they serve.

\section{Limitations}

As is the case with all studies, there are several limitations in this one as well. As a basic qualitative study, it is possible to describe phenomena presented by the data, but much more difficult to draw conclusions that can be universally applied to a larger set of alternative schools from a data set of five alternative high school principals. An additional limitation is the reluctance of most of the participants to share documents and materials, combined with the challenges of a shift to home-based and online school business during the pandemic, created a situation in which the shared documents add a deeper picture to only two of the five cases for this study.

A third limitation comes from the shift during the study to a different interview schedule for the second interview. Originally, the second interview was conceived as a follow up to the first, an opportunity to clarify any questions that lingered and confirm data through the member-checking process. As I began to gather and analyze the data, however, I was struck by the consistency of responses I was receiving from the first 
several participants. This led me to seek and later receive an amendment from the university IRB to add new questions. To further complicate this fact, perhaps due to the complexity of the pandemic, one participant stopped returning my repeated emails and attempts to contact her and schedule the second interview. When she did then finally respond to a previous request for the second interview, I had not yet received IRB approval for the new interview questions on the second interview. As a result, I used the originally approved interview questions (see Appendix E). The participant did contribute rich responses to the originally approved follow-up questions, but the questions did differ from what other participants were asked at their second interviews (see Appendix F). It seemed important to move forward with this participant in the moment, as I feared I might not otherwise have another opportunity to conduct her second interview.

Finally, the information provided by the final participant I interviewed, Patricia from Options Alternative High School, significantly helped to shape many of the recommendations in Chapter 5. The Options Alternative High School district is part of a rural community and has some unique characteristics among communities and districts in the state. Many of these unique characteristics cannot be shared here, as they would potentially identify the community, and thus, participant Patricia. In Appendix H, I offer specific recommendations on creating equitable systems to better serve early leaver students to school district personnel. In that appendix, I attempt to differentiate the recommendations between large and small — or urban, rural, and suburban — school districts. 


\section{Chapter Four Summary}

In this chapter, I have introduced you to the five alternative high school principals selected for this study. Each principal leads a school that is within the half of alternative high schools in their state with the most BIPOC students. In addition to descriptions of the individuals and the sharing of their words to talk about their work, I have shared information about how these interviews were coded and the categories of data that emerged from the group, including outlier data that came from one participant. Documents that were shared by the participants were further coded and described here. Finally, the study's limitations are acknowledged in the penultimate section of this chapter. 


\section{Chapter Five: Discussion, Conclusions, and Recommendations}

\section{Introduction}

The aim of this study was to understand how the state accountability system may influence the work of alternative high school principals and their students, those who have not been well-served in the conventional schools in one state (Alliance for Excellence in Education, 2011a, 2011b; Bickerstaff, 2010; Bridgeland et al., 2006; de la Ossa, 2005; Iachini et al., 2013). A particular additional focus of this study has been how state accountability systems label alternative high schools and what effect this labeling may have on the work of providing an alternative school option for the enrolled students. Finally, this study sought to examine how the role of alternative high schools and state accountability intersect with race and the over-representation of students of color in alternative schools throughout the United States (Orfield et al., 2004). By exploring the experiences and perspectives of five alternative high school principals, this study has identified a potential counter narrative to the prevailing ideas of alternative high schools as failing (The Advancement Project et al., 2011) or deviant (Bickerstaff, 2010).

\section{Synthesis of Findings}

Data for this study were collected through qualitative interviews with five alternative high school principals and through the examination and analysis of school materials provided by two of those principals. Study participants' insights, reflections, and descriptions of their work largely reinforced what the research literature has 
previously documented; the study extends the literature by identifying outlier categories for further study. The salient categories revealed in these interviews regarding how state accountability systems influence the work of alternative high school principals and their students include the following: mental health concerns and the need for trauma-sensitive safe havens, an over-representation of students with disabilities, standardized accountability metrics poorly capture the work of alternative high schools, the importance of promoting alternative schools as schools of choice, and an ambivalence about district support for low student-staff ratios. Outlier categories were also identified, and they have a significant bearing on the recommendations for future policy, research, and practice. These outlier categories represent school district policies and practices not common in the research literature and also distinct from the data provided by four of the five study participants.

\section{Validation of Research Literature on Early Leavers}

Several categories which emerged in this study mirror those well-documented in the research literature. For example, four out of the five study participants stated that their alternative high schools are over-represented for students of color, as is also documented by Balfanz and Legters (2004), Balfanz and West (2006), Forste and Tienda (1992), Orfield et al. (2004), and Perzigian et al., (2017). Lehr et al. (2009) documented the overrepresentation of students with disabilities in alternative high schools, which was also a finding in this study. Many scholars have also identified higher mental health concerns among alternative high school students compared to their overall school districts, as was found in this study (Hagan \& Foster, 2001; Koch \& McGeary, 2005; Krohn et al., 1997; Wilcox-Gök et al., 2004). This study found that participants emphasized the importance 
of developing a school culture that is a trauma-sensitive safe haven for students impacted by mental health concerns, a finding also documented by de la Ossa (2005), Iachini et al. (2013), and Newton et al. (2017).

Critical to the recommendations that follow later in this chapter is this study's finding that standardized accountability metrics poorly capture the work of alternative high schools, the subject of much analysis in the research literature (Almeida et al., 2010; Jimenez et al., 2018; Schlessman \& Hurtado, 2012). This study's participants offered many ideas and insights about how best to remedy this gap between standardized accountability metrics and the work of their schools.

Each participant shared ways in which they are working to engage in continuous improvement, to better support students earlier in their high school career, and to communicate the strengths of their programs. Principal Sarah of Youth Development Alternative High School described how she is working in her school to enroll more 9th and 10th grade students, students who are likely to be less credit-deficient than the typical 11th and 12th graders who enroll at her school. Enrolling younger students would have a positive impact, according to this participant, on both the students and on the school's report card. Another participant, Mike from Victory Alternative High School, talked about the fact that many different programs and options are included in his school, including an early college option, and how he wishes the stigma of alternative education did not deter students from considering his school as a good option for them. He shared his belief that better communication about program options, improved transportation access, and a future consolidation of his school's multiple campuses will all support a 
growing sense of community in his school. All other participants noted that their schools were undergoing a program overhaul or had recently completed one. The participants were all seeking ways to better support their students and better communicate to their school districts the value of their schools. The participants' ideas about how to better market or structure their schools into schools of choice, rather than "last chance" schools for failing students or those deserving of punishment harkens back to earlier ideals of alternative education documented by Raywid (1994, 1999, 2001b) and Tissington (2006) in which alternative schools are not presented as "last chance" or "failing" schools, but rather as personalized, creative schools which validate students' individual and cultural identities.

Finally, many of the participants in this study noted that their school districts were "generous" in the staffing levels provided to alternative schools and that this generosity in some cases included efforts to provide better facilities. Even as they expressed their appreciation for this support of their schools, they also discussed their ambivalence that this support did not exempt their schools from feeling invisible to the rest of the school district and did not always exempt their students from a sense that they were less than other students for going to an alternative school.

This feeling that their students are viewed with a deficit mindset is one area where the responses from Patricia, principal of Options Alternative High School, differed significantly from other participants. When her school district solicited their local tax payers for a facilities bond, the first building that they planned to build was for Options. When the bond was passed, Options was built on land close to the district office and the 
district's conventional high schools. This kind of support has improved collaboration among all of the district's high school principals, including Patricia. These principals work together to evaluate when and whether students should transfer to Options. In the cases of transfer, the original school maintains accountability for the transferring students on the state report cards until the student has earned 15 credits, the equivalent of junior status in this school district. These practices have stopped student push-out in this school district and have boosted the district graduation rate, as well as that of Options, while barely affecting that of the individual conventional high schools. According to Patricia, the reason for this is that the work to value all students has improved performance at all high schools in the district. This experience is in sharp contrast to the experience of the other four alternative schools, whose principals shared multiple examples of invisibility, stigma, and the expectation of little or no accountability to the students by their former conventional high schools.

\section{Larger Context of Findings}

\section{The Value of Alternative Schools vs. Taylorism}

As noted in Chapter One of this dissertation, high school graduates experience lower poverty, better health, lower incarceration, and a longer life expectancy than is the case for non-graduates (Hanover Research, 2015; Meunnig, 2008; Rumberger, 2013; Sum et al., 2009). Alternative high schools are doing the work of reengaging students who otherwise would have become early leavers, helping them and their communities avoid the drastic ramifications of life without a high school diploma (Jimenez et al., 2018). 
Because many students are credit-deficient at the time they enroll in alternative schools, it is very difficult for alternative high school students to graduate from high school 4 years after they first began ninth grade or "on time" (Jimenez et al., 2018). Because on time or four-year graduation is a crucial metric on state report cards (Balfanz \& West, 2006; Curran \& Reyna, 2009), this helps to explain why $75 \%$ of alternative high schools in the United States were designated as significantly not meeting their states' school report card standards in 2017 (Lovell, 2019).

The very term "off-track" invokes the image of the factory approach to schooling and the traditions of Taylorism detailed in Chapter 2 of this dissertation. According to Kaplan and Owings (2017), Frederich Taylor's scientific management theory has been described as a "rational scientific-engineering based approach designed to increase workers' productivity through the systematic analyses of work in painstaking detail" (p. 38). When applied to schools, the legacy of scientific management theory can be seen in standardized school schedules, grading, state testing, and universal targets for graduation timelines. Students who do not academically or socially conform to this standardization are often those students who become early leavers from high school. Designating the schools that serve these students as failing, based solely on state report cards, further stigmatizes these students, as well as the schools that have reengaged them.

\section{Alternative School Report Cards vs. District Solutions}

The ESSA of 2015 permits any state to develop different metrics for alternative high school state report cards, but only a handful of states have done so (Almeida et al., 2010; Jimenez et al., 2018; Schlessman \& Hurtado, 2012). As a researcher, I had expected that participants would believe that an alternative report card in the state where I 
work might have gone a long way to help the public recognize the value of alternative schools to early leaver students. I also expected this study's participants would have talked more about an alternative report card. Only one participant, Larry, pointed to the benefits of growth metrics to measure student progress. In fact, Principal Mike stated that he felt less pressure to improve his school's state report card because the system for measuring achievement is so ineffective. Bernadette discussed the shortcomings she perceives in the accountability system both for her school and for conventional high schools, but she did not mention an alternative state report card with different metrics as a remedy. Overall, the data did not validate alternative report cards as the only or even the best solution to school pushout.

Given the graduation rate successes of Options Alternative High School and the positive experiences described by participant Patricia, the data point to local remedies of communication and collaboration, as well as an extension of accountability for conventional schools when their students transfer. The Options approach of collaboratively moving students among their conventional and alternative schools, while continuing a commitment to the student's accountable school performance through their enrollment system requires shifts in school and district practice, not a change in federal or state law. This shift could potentially support conventional and alternative high schools to better focus their efforts on improving systems for all students, support the intentional transfer of potential early leaver students over push out, and raise school and district graduation rates. The costs of this approach are likely to be nominal, as it does not require 
a new curriculum adoption, new buildings, extensive professional development or even additional hiring of staff members. These findings are illustrated in Table 11.

\section{Table 11}

Contrasting Majority and Outlier Themes in the Data

\begin{tabular}{|c|c|c|c|}
\hline & Communication & Collaboration & Shared Accountability \\
\hline $\begin{array}{l}\text { Flexible, Youth } \\
\text { Development, } \\
\text { Victory, } \\
\text { Achievement } \\
\text { Alternative } \\
\text { High Schools }\end{array}$ & $\begin{array}{l}\text { No communication } \\
\text { systems between } \\
\text { conventional and } \\
\text { alternative high } \\
\text { schools were } \\
\text { described. }\end{array}$ & $\begin{array}{l}\text { No system of dialogue } \\
\text { with the previous } \\
\text { schools of new } \\
\text { students was noted by } \\
\text { participants as part of } \\
\text { the intake and } \\
\text { enrollment process for } \\
\text { students transferring } \\
\text { into their alternative } \\
\text { high schools. }\end{array}$ & $\begin{array}{l}\text { When the student leaves a } \\
\text { conventional high school } \\
\text { and enrolls in the } \\
\text { alternative high school, the } \\
\text { alternative high school is } \\
\text { immediately accountable in } \\
\text { the sense that the student's } \\
\text { test scores and graduation } \\
\text { rate are solely attributed to } \\
\text { the new schools. }\end{array}$ \\
\hline $\begin{array}{l}\text { Options } \\
\text { Alternative } \\
\text { High School }\end{array}$ & $\begin{array}{l}\text { Conventional high } \\
\text { schools in the same } \\
\text { district are required } \\
\text { to communicate } \\
\text { with the students } \\
\text { and families of } \\
\text { potential alternative } \\
\text { high school students } \\
\text { prior to referring } \\
\text { them to Options. }\end{array}$ & $\begin{array}{l}\text { There is a weekly } \\
\text { meeting among all } \\
\text { conventional and } \\
\text { alternative high school } \\
\text { principals in this } \\
\text { school district. } \\
\text { Students who are } \\
\text { referred to Options are } \\
\text { discussed in this } \\
\text { meeting and the group } \\
\text { must reach consensus } \\
\text { in order to finalize a } \\
\text { transfer. }\end{array}$ & $\begin{array}{l}\text { Options students are coded } \\
\text { as "attending" Options and } \\
\text { "enrolled" in their previous } \\
\text { high schools until the point } \\
\text { that they have earned } 15 \\
\text { credits. Their test scores } \\
\text { and cohort graduation data, } \\
\text { then, reflect on their } \\
\text { enrolled high school until } \\
\text { they have the equivalent } \\
\text { credits of an } 11^{\text {th }} \text { grade } \\
\text { student. }\end{array}$ \\
\hline
\end{tabular}

While the research literature does not specifically point to communication, collaboration, and shared accountability as outright solutions to low alternative high school ratings or the early leaver crisis, these practices stand in contrast to Taylorism and rational systems theory and also address other themes in the published literature. 
Taylorism, for example, assumes that people can be taught to behave like machines (Kaplan \& Owens, 2017). This is counter to the sometimes time-consuming, back and forth process of communicating with students, families, and principal colleagues that is critical to the enrollment process in the home school district of Options Alternative High School.

Marion and Gonzalez's (2014) analysis of rational systems theory’s insistence upon standardization is that it is designed to "draw maximum profits (read: test scores) from the organization; that is, it exploits the available human and physical resources to maximize returns" (p. 11). The enrollment and transfer practices for Options Alternative High School have redefined the organizational goals away from this definition of individual school profit in favor of student well-being. The outcomes for Options and its school district also provide a counter story to the notion of a zero sum game. While all participants in this study were concerned with their students' well-being, the other four did not indicate that their conventional high school colleagues were as invested in this as they were.

The work of Riehl (1999) referenced another aspect of rational systems theory, schools' use of member boundary maintenance as an effort to meet organizational goals, such as high ratings on school report cards. In this context, the push-out of students is seen as one method for raising report card ratings in conventional high schools. According to participant Patricia, pushing out low performing students was a common practice in her school district in the past. Changing this process of enrollment and transfer has helped to improve the experience of students in both the alternative school and the 
conventional schools in her district. While Schlessman and Hurtado (2012) argued that the lack of alternative accountability creates a disincentive for conventional schools to serve at-risk students, the Options School District has found a way to share the accountability for its most struggling students and increase its graduation rate among all high schools.

These practices stand in contrast also to the experience of stigma associated with alternative school enrollment documented by several scholars. Bickerstaff (2010) for example, noted that early leaver students express shame and self-loathing for leaving school before they graduate and McNulty and Roseboro (2009) argued that students with behavior problems who are involuntarily placed in alternative schools often notice conditions such as crumbling facilities and outdated curriculum and assume that these are punitive measures. McNulty and Roseboro went on to argue that these ideas become internalized for these students who believe they are "bad kids" (p. 423), considered less worthy of a quality education and, therefore, attend the bad school. The work of de la Ossa (2005), finally, also pointed to this stigma through the words of one of her study's participants who had transferred from a conventional school to an alternative school: "this is where they send kids who are bringing their average down, basically" (p. 34). No student should bear the burden of believing that their right to a public education counts for less than the reputation of their school and the adults who work there. 


\section{Implications and Recommendations}

The specific recommendations in this section are all related to accountability.

These recommendations for school districts are detailed later in this chapter and abbreviated as follows:

1. Increase school district transparency in order to increase accountability.

2. Promote accountability for all schools and to all students through enrollment designations in which schools maintain responsibility for student achievement after students are transferred to alternative schools.

3. Use growth metrics to support accountability for continuous improvement in all schools.

4. Refine communication and collaboration practices to paint a truer picture of student growth and achievement for their local and state constituencies.

This focus on accountability is not meant to simply refer to state report cards, incentives and sanctions. Fullan et al. (2015) differentiated external from internal accountability. In a construct they advance, external accountability refers to the ways that school leaders assure the public that schools are responsibly using public tax dollars to effectively educate students. Internal accountability, on the other hand, "occurs when individuals and groups willingly take on personal, professional and collective responsibility for continuous improvement and success for all students" (Fullan et al., 2015, p. 4). They went on to assert that internal accountability must precede external accountability to maintain lasting improvement for students. Rather than a system in which schools are only accountable to students until they drop out, fall out or are pushed out of the school (Doll et al., 2013), Fullan et al.'s construct of internal accountability implies that our responsibility and commitment to our students extends after they transfer, and at least until they graduate from high school. This use of the term 
accountability also implies that a school district is working as a system, not just as a collection of autonomous schools competing against one another for higher ratings. The term that I believe best conveys the sense of commitment to each student's educational success and well-being is shared accountability (Abadzi, 2017). Shared accountability uses internal accountability as a means to both improving student achievement for the sake of the students' well-being, while also meeting the demands of external accountability. Alternative schools cannot achieve shared accountability on their own, especially since the reality of credit-deficient students did not solely happen while the students were enrolled in an alternative school.

\section{Shared Accountability and Transparency}

In the state of Oregon, schools must report annually on early leavers, using six categories of codes to explain the reason or reasons students have left school (Oregon Department of Education, 2017). The Oregon Department of Education explained these categories as follows:

1 - Indicates students who are expected to continue to be enrolled in the district.

2 - Indicates evidence has been received that the student transferred out of the district, exited to home school/private school, or has left the country.

3 - Indicates students who have not received a diploma or certificate and are no longer receiving K-12 educational services (e.g., drop-outs, exceeded age requirements, permanent expulsion).

4 - Indicates students who have completed an approved program or met certain criteria (includes diplomas, GEDs, and certificates).

5 - Indicates students who are no longer enrolled in the district for various reasons but are expected to return.

6 - Indicates students who are deceased or have returned after receiving a completion credential and exited again. (para. 1) 
These reports are used to calculate per-pupil school funding or average daily membership, weighted, and to determine numbers of dropouts. Average daily membership, weighted, indicates per-pupil funding, which may be increased for some students. For example, a student in Oregon who qualifies for Special Education has a double weight and is double-funded (McComb, 2004). Early Leaver reports can also be used to document names of early leaver students who could be contacted by districts in an effort to re-engage them.

It is unclear whether districts use this data currently, whether they report it only to comply with state law or a combination of both. If all districts were to use this existing data, however, to interrogate the reasons why students are leaving a conventional school, these reports could shed light on trends affecting early leaver students. Nationally, when early leaver students are asked why they left school before graduating, they cite a lack of connection to the school, a feeling that school is boring, a lack of help from teachers, a lack of interesting or relevant course work, poor teaching, academic challenges, and the weight of real world events (Bridgeland et al., 2006; Doll et al., 2013). It is also clear that some of these challenges, such as not being prepared academically for high school, have antecedents in earlier educational experiences (Alexander et al., 1997; Ream \& Rumberger, 2008). These trends could be analyzed and interrupted through focused efforts within these schools, which could then work to address the challenges and prevent future students from disengaging.

Every participant in this study reported that their schools are over-represented for students with disabilities. Four of the five stated that BIPOC students are also over- 
represented, compared to their districts as a whole. Their alternative high schools have assumed responsibility for educating students that conventional schools are no longer responsible for, also assuming responsibility for the students' cohort graduation data. As Principal Mike commented, 'I'm happy for kids that haven't been successful to come to my school." He went on to say that he wants his school to be able to respond to the educational needs and goals of all his students, whether this includes the ability to do an internship, take community college classes, receive wraparound services or small classes. He added:

I want to make sure that more kids have those options and that we're getting to know our kids so well and giving them a voice and that our curriculum is developed with their history and background involved as a part of it instead of just the standard sort of just the canon.

If Mike's school district followed the practices of the district in which Options High school is located, students could continue receiving the benefits of the alternative education, but the alternative school and its students would not bear the stigma of not graduating from high school in 4 years.

This transparency could shift the focus of improving report card ratings away from pushout as a strategy to a continuous improvement focused on changing the school experience for potential early leavers. Conventional schools could borrow some of the strategies used by the alternative schools in this study, such as hiring school social workers, centering curriculum in students' lived experience (Freire, 1993), and using restorative practices to reduce exclusionary discipline. Such re-focusing of school efforts requires schools to question the assembly line culture and assumptions that have been ingrained into school organizational culture through Taylorism. Schools like Youth 
Development, then, would be more focused on providing interventions and supports for students and less focused on enrolling younger students in order to also boost their report card ratings.

\section{Shared Accountability through Enrollment Designations}

The deft use of enrollment designations used at Options Alternative High School and its conventional school counterparts is a model for other school districts nationally and in Oregon. If the school district in which Youth Development Alternative High School is located required its conventional high schools to maintain accountability for its transferring students and also employed the collaborative decision-making process among all of its principals that Options Alternative High School uses, they may no longer find themselves with twice the rate of students with disabilities in their alternative school as is found in the district's conventional schools. They also may not characterize conditions as Sarah did in her second interview:

Alternative schools can't be enabling our systems. And I love the work we do; I love it. But ... right now our school is $40 \%$ special education or more, we're disproportionate with our students of color and it . . just like makes me want to cry. Like we can't be this enabling, last chance spot for kids to land that aren't served by the bigger system. We've got to figure out ways to serve these kids everywhere.

Alternative schools do not exist in a vacuum, but the current accountability system rates schools as if they were fully autonomous, closed systems whose accountability data are not influenced by other schools or outside factors. Nurturing shared accountability through enrollment designations is one way to acknowledge the complexity of student achievement. 


\section{Shared Accountability through Growth Metrics}

Three of this study's participants talked about how the use of normed growth assessments like the Northwest Evaluation Association Measures of Academic Progress test could improve their functioning as a school. Growth assessments can be given to students when they enroll in a school to establish a baseline and then again after a period of time in which students are participating in instruction to measure growth. Such growth metrics would communicate to individual students and their families how much they are learning, serve as an interim or formative measure for their teachers to know whether to adjust their curriculum and instruction and for the larger community to evaluate school quality.

This approach differs from the current practice of giving a standardized test once during high school to communicate a ranking among schools and a comparison of one group of students to previous and subsequent groups of students. An additional benefit of using growth metrics in alternative schools is that these schools primarily enroll transfer students, many of whom are highly mobile (Richardson \& Emmott, 2017). Creating a baseline view of students' skills when they transfer into the alternative school and then monitoring progress over time demonstrates this idea of accountability and responsibility to the student's learning and well-being.

\section{Shared Accountability through Communication and Collaboration}

Communication and collaboration are also essential to shared accountability. For example, the Options Alternative High School principal, Patricia, meets weekly with her conventional high school counterparts. This group of principals decides collaboratively which students should transfer to the alternative high school. In order to recommend a 
student for transfer, the group has agreed that the current school will discuss the potential transfer first with the student and the student's parent(s) or guardian(s) to make sure they understand and agree with the recommendation.

This practice does two things. First, it eliminates the pushing out of students who may negatively impact the ratings of the original school by ensuring that students and their families have a voice in the decision-making and are not burdened with the rejection of having to leave their school involuntarily. Transfer to the alternative high school then becomes de-identified with discipline and failure and, rather, is communicated as a supportive intervention. Second, this practice requires a new level of awareness of and commitment to struggling students in the conventional high schools. In order for a principal to recommend a student for transfer, that principal or their staff will have already communicated with the student and family and will have already tried some interventions prior to the transfer recommendation. While this detail was not discussed in my interviews with Patricia, my hope is that the conventional high schools in Patricia's school district also follow best practice and documentation in their student interventions. Doing so helps to maintain the accountability for student failures with the professional educators, rather than expecting struggling students to carry the full responsibility. For conventional high schools to create these interventions first before initiating a transfer preserves the alternative school enrollment for students who have the greatest need, while focusing the conventional high school on improving practices for other struggling students. 
The school district in which Options Alternative High School resides boasts 4and 5-year graduation and completion rates that exceed the state averages. As a reminder, this school's demographics include high percentages of students of color, students in poverty, and students whose first language is not English. The demographics at Options mirror those of the district as a whole, another fact that separates Options from the other schools in this sample. This is one indication that this district is universally highachieving and not an example of disparate performance between alternative and nonalternative high schools. Options is the only alternative high school represented in this study that is not identified by the state as in need of comprehensive supports, also known as a comprehensive support and improvement school.

\section{Recommendations for Further Research}

Transparency, enrollment designations, growth metrics, communication and principal collaboration do not account for all of the success for any school, including Options Alternative High School. Additional research, including a case study design, could shed light on more reasons why Options Alternative High School has found success. Such a case study design could include qualitative research data from student, family, and educator interviews. Options is one of the $25 \%$ of alternative schools nationally that are not identified for comprehensive supports under ESSA. Additional quantitative studies that examine student demographic information, school district enrollment and transfer practices, and community characteristics could help answer whether other schools have developed success in the same way as Options. This additional data could support scholars and practitioners who may want to replicate or adapt some or all of these successful practices. Qualitative research that includes students 
enrolled in alternative schools as participants can further shed light on the issues of accountability raised in this study.

\section{Chapter Five Summary}

The focus of this chapter has been on shared accountability and how district-level policies and practices can support a system that is itself more accountable to struggling students than is a group of autonomous schools competing with one another. In order to achieve this system of accountability to those students who are most under-served in society and often in schools, districts must increase transparency, communication, and collaboration. Districts would also be wise to adopt growth metrics to guide instruction and make reporting on student progress and school effectiveness more meaningful and accurate. Finally, further research can uncover additional promising practices that lead to success for all students, specifically early leavers.

Students who do not graduate from high school, students who have been described in this study as early leavers, are more likely to face poverty, poor health, and incarceration than their counterparts with high school diplomas (Hanover Research, 2015; Meunnig, 2008; Rumberger, 2013; Sum et al., 2009). Fortunately for these early leavers, many have the opportunity to resume their studies in an alternative high school. In the state of Oregon, $10 \%$ of all high school students are enrolled in an alternative school or alternative program (Richardson \& Memmott, 2017). According to Richardson \& Memmott (2017), the Oregon Department of Education should "evaluate methods to increase accountability for traditional high schools that transfer students to alternative 
schools and programs" (p. 35). This study has shown that at least one district in the state has figured this out.

The practices recommended here bring me back to the personal significance of this study. The first time I heard an award-winning principal publically explain that moving struggling students to his local alternative high school was a method for boosting his school's graduation rate, I wondered if he had known that there might be another way to support these students, without students having to bear the stigma of pushout. With the benefit of what I have learned in this study, I wonder now if he would develop an understanding that he could improve his high school as measured by raising test scores and increasing graduation rates without pushing students out. Developing shared accountability can improve conventional high schools, alternative high schools, and the school district as a whole. Most importantly, it can also help students avoid stigma, stay engaged in school, and leave school as proud graduates. These practices that elevate and affirm the humanity of all students should be the stuff of national awards. 


\section{References}

Abadzi, H. (2017). Accountability and its educational implications: Culture, linguistics and psychological research. Global Monitoring Report of the United Nations Educational, Scientific, and Cultural Organization (UNESCO). https://unesdoc. unesco.org/ark:/48223/pf0000259573/PDF/259573eng.pdf.multi

The Advancement Project, Education Law Center-PA, FairTest, The Forum for Education and Democracy, Juvenile Law Center, NAACP Legal Defense, \& Educational Fund, Inc. (2011). Federal policy, ESEA reauthorization, and the school-to-prison pipeline [Joint position paper]. https://www.elc-pa.org/wpcontent/uploads/2013/11/FederalPolicy_ESEA_and_SchoolToPrisonPipeline. 03.09.11.pdf

Alexander, K. L., Entwisle, D. R., \& Horsey, C. S. (1997). From first grade forward: Early foundations of high school dropout. Sociology of Education, 70(2), 87-107.

Alliance for Excellent Education. (2011a). Helping students get back on track: What federal policymakers can learn from New York City's Multiple Pathways to Graduation initiative [Issue brief]. https://all4ed.org/reports-factsheets/helpingstudents-get-back-on-track-what-federal-policymakers-can-learn-from-new-yorkcitys-multiple-pathways-to-graduation-initiative/

Alliance for Excellent Education. (2011b). The high cost of high school dropouts: What the nation pays for inadequate high schools [Issue brief]. https://all4ed.org/wpcontent/uploads/2013/06/HighCost.pdf

Almeida, C., Le, C., Steinberg, A., \& Cervantes, R. (2010, September). Reinventing alternative education: An assessment of current state policy and how to improve it. Jobs for the Future.

Amos, J. (2006, September 18). Comparison places the United States near the bottom in high school graduation rates and college graduates. Alliance for Excellent Education, 16(17). https://all4ed.org/articles/education-at-a-glance-internationalcomparison-places-the-united-states-near-the-bottom-in-high-school-graduationrates-and-college-graduates/\#: : text=In $\% 20$ fact $\% 2 \mathrm{C} \% 20$ the $\% 20 \mathrm{OECD} \%$ 20analysis,Norway\%2C\%20Germany\%2C\%20and\%20Korea

Atwell, M. N., Balfanz, R., Bridgeland, J., \& Ingram, E. (2019). Building a grad nation: Progress and challenge in raising high school graduation rates, annual update 2019. https://www.americaspromise.org/2019-building-grad-nation-report 
Au, W. (2007, November). Epistemology of the oppressed: The dialectics of Paulo Freire's theory of knowledge. Journal for Critical Education Policy Studies, 5(2), 175-196. http://www.jceps.com/wp-content/uploads/PDFs/05-2-06.pdf

$\mathrm{Au}, \mathrm{W}$. (2016). Meritocracy 2.0: High-stakes, standardized testing as a racial project of neoliberal multiculturalism. Educational Policy, 30(1), 39-62.

Baker, O., \& Lang, K. (2013). The effect of high school exit exams on graduation, employment, wages, and incarceration. National Bureau of Economic Research. https://www.nber.org/system/files/ working_papers/w19182/w19182.pdf

Balfanz, R., \& Legters, N. (2004). Locating the dropout crisis. Johns Hopkins University, Center for Social Organization of Schools. https://files.eric.ed.gov/fulltext/ ED484525.pdf

Balfanz, R., \& West, T. C. (2006). Progress toward increasing national and state graduation rates. Raising graduation rates: A series of data briefs. Johns Hopkins University, Center for Social Organization of Schools. http://new. every1graduates.org/wp-content/uploads/2012/03/StateProgressReport.pdf

Bickerstaff, S. (2010). "I felt untraditional": High school leavers negotiating dominant discourses on "dropout." The Journal of Education, 190(3), 37-45. https://doi.org/10.1177/002205741019000305

Bland, P., Church, E., Neill, S., \& Terry P. (2012). Lessons from successful alternative education: A guide for secondary school reform. Eastern Education Journal, 37(1), 29-42. https://castle.eiu.edu/edjournal/ successfulalternativeeducation.pdf

Bourke, B. (2014). Positionality: Reflecting on the research process. The Qualitative Report, 19(33), 1-9. https://nsuworks.nova.edu/tqr/vol19/iss33/3

Bowen, G. A. (2009). Document analysis as a qualitative research method. Qualitative Research Journal 9(2), 27-40. https://www.researchgate.net/publication/ 240807798_Document_Analysis_as_a_Qualitative_Research_Method

Boylan, R., \& Renzulli, L. (2014). Routes and reasons out, paths back: The influence of push and pull reasons for leaving school on students' school reengagement. Youth \& Society, $1,1-26$.

Bradley, C. L., \& Renzulli, L.A. (2011). The complexity of non-completion: Being pushed or pulled to drop out of high school. Social Forces, 90(2), 521-545.

Brantlinger, A., \& Brantlinger, E. (2013). Social class in education: Implications for educational leadership. In L. C. Tillman \& J. J. Scheurich (Eds.), Handbook of research on educational leadership for equity and diversity (pp. 287-308). Routledge. 
Bridgeland, J., Dilulio, J. J., Jr., \& Morison, K. B. (2006). The silent epidemic: Perspectives of high school dropouts [A report by Civic Enterprises in association with Peter D. Hart Research Associates for the Bill \& Melinda Gates Foundation]. https://docs.gatesfoundation.org/documents/ thesilentepidemic3-06final.pdf

Brock, R. (2015). Conclusion: Speaking truth on and about critical pedagogy. In P. W. Orelus \& R. Brock (Eds.), Interrogating critical pedagogy: The voices of educators of color in the movement (pp. 281-293). Routledge.

Burho, J. (2019). Oregon's use of the ever English learner category for reporting, accountability, and research: An AERA presentation from the partnership. http://blogs.oregonstate.edu/odeosuellpartnership/2019/05/13/oregons-use-of-theever-english-learner-category-for-reporting-accountability-and-research-anaerapresentation-from-the-partnership/

Burk, R. P. (1978). Organizational interaction in alternative high schools: Race, personality, and role perception (Publication No. 251741718) [Doctoral dissertation, University of Chicago]. ProQuest Dissertations and Theses Global. https://search-proquest-com.proxy.lib.pdx.edu/pqdtglobal/docview/251741718/ EFECF421179742FEPQ/15? accountid=13265

California Department of Education. (2017, November). What is the dashboard alternative school status program? https://www.cde.ca.gov/ta/ac/cm/documents/ dassdashboardflyer.pdf

Chang, H. N., Bauer, L., \& Byrnes, V. (2018, September). Data matters: Using chronic absence to accelerate action for student success. Attendance Works and Everyone Graduates Center.

Charmaz, K. (2006). Constructing grounded theory: A practical guide through qualitative analysis. Sage.

Creswell, J. W., \& Creswell, J. D. (2018). Research design: Qualitative, quantitative, and mixed methods approaches ( $5^{\text {th }}$ ed.). Sage.

Cross, C. T. (2014). Political education: Setting the course for state and federal policy ( $2^{\text {nd }}$ ed.). Teachers College Press.

Cuban, L. (2004). Looking through the rearview mirror at school accountability. In K. A. Sirotnik (Ed.), Holding accountability accountable: What ought to matter in public education (pp. 18-34). Teachers College Press.

Curran, B., \& Reyna, R. (2009, July). Implementing graduation counts: State progress to date, 2009. https://files.eric.ed.gov/fulltext/ED507634.pdf

Darling-Hammond, L. (1997). The right to learn. Jossey-Bass. 
Darling-Hammond, L., \& Meier, D. (2004). From "separate but equal" to "No Child Left Behind": The collision of new standards and old inequalities. In D. Meier \& G. Wood (Eds.), How the No Child Left Behind Act is damaging our children and our schools: Many children left behind (pp. 3-32). Beacon Press.

Davis, J. L. (2013). Survival schools: The American Indian movement and community education in the Twin Cities. The University of Minnesota Press.

de la Ossa, P. (2005, Fall). "Hear my voice:” Alternative high school students' perceptions and implications for school change. American Secondary Education 34(1), 24-39.

Doll, J. J., Eslami, Z., \& Walters, L. (2013). Understanding why students drop out of high school, according to their own reports. Sage Open, 3(4), 1-5.

Elementary and Secondary Education Act, Pub. L. No. 89-329 (1965).

Ensminger, M. E., \& Slusarcick, A. L. (1992). Paths to high school graduation or dropout: A longitudinal study of a first-grade cohort. Sociology of Education, 65, 95-113.

Ensminger, M. E., Hanson, S. G., Riley, A. W., \& Juong, H.-S. (2003). Maternal psychological distress: Adult sons' and daughters' mental health and educational attainment. Journal of the American Academy of Child and Adolescent Psychiatry, 42, 1108-1115.

Epstein, K. K. (1992). Case studies in dropping out and dropping back. The Journal of Education, 174(3), 55-65.

Every Student Succeeds Act, Pub. L. No. 114-95 (2015).

Finn, J. D. (1989). Withdrawing from school. Review of Educational Research, 59(2), 117-142.

Finn, J. D., Gerber, S. B., \& Boyd-Zaharias, J. (2005). Small classes in the early grades, academic achievement, and graduating from high school. Journal of Educational Psychology, 82, 214-223.

Forste, R., \& Tienda, M. (1992). Race and ethnic variation in the schooling consequences of female adolescent sexual activity. Social Science Quarterly, 73, 12-30.

Fowler, F. (2014). Policy studies for educational leaders: An introduction (4 $4^{\text {th }}$ ed.). Pearson Education. 
Freeman, J., \& Simonsen, B. (2015). Examining the impact of policy and practice interventions on high school dropout and school completion rates: A systematic review of the literature. Review of Educational Research, 85(2), 205-248.

Freire, P. (1993). Pedagogy of the oppressed, chapter two. Continuum Books. http://faculty.webster.edu/corbetre/philosophy/education/freire/freire2.html

Fullan, M., Rincon-Gallardo, S., \& Hargreaves, A. (2015). Professional capital as accountability. Education Policy Analysis Archives, 23(15), 1-17. https://doi.org/10.14507/epaa.v23.1998

Garnier, H. E., Stein, J. A., \& Jacobs, J. K. (1997). The process of dropping out of high school: A 19-year perspective. American Educational Research Journal, 54(2), 395-419.

Gehlbach, H., \& Brinkworth, M. (2011). Measure twice, cut down error: A process for enhancing the validity of survey scales. Review of General Psychology, 15, 380387.

Gewertz, C. (2019, April 9). Which states require an exam to graduate? An interactive breakdown of states' 2016-17 testing plans. Education Week, 36(21). https://www. edweek.org/ew/section/multimedia/states-require-exam-tograduate.html

Glassett Farrelly, S. \& Daniels, E (2014). Understanding alternative education: A mixed methods examination of student experiences. NCPEA Education Leadership Review of Doctoral Research, 1(1), 106-121.

Goodman, G. S. (1999). Alternatives in education: Critical pedagogy for disaffected youth. Peter Lang.

Griffin, J., \& Stahl, M. (2020, November 20). Empowering innovation through local accountability pilot programs. Presentation given at the 2020 Reaching AtPromise Student Association (RAPSA) conference.

Groen, M. (2012). NCLB - The educational accountability paradigm in historical perspective. American Educational History Journal, 39(1), 1-14.

Hagan, J., \& Foster, H. (2001). Youth violence and the end of adolescence. American Sociological Review, 66(6), 874-899.

Hall, D. (2005, June). Getting honest about grad rates: How states play the numbers and students lose. The Education Trust. http://edtrust.org/wp-content/uploads/2013/ 10/Getting_Honest.pdf 
Hanover Research. (2015, October). Best practices in supporting 18-21-year-old students in k12 education. http://www.hanoverresearch.com/

Harris, K. (2013). In school + on track: Attorney general's 2013 report on California's elementary school truancy and absenteeism crisis. California Attorney General.

Heilig, J. V. (2001). Understanding the interaction between high-stakes graduation tests and English learners. Teachers College Record, 113(12), 2633-2669.

Hemelt, S. W., \& Marcotte, D. E. (2013). High school exit exams and dropout in an era of increased accountability. Journal of Policy Analysis and Management, 32(2), 323-349.

Iachini, A. L., Buettner, C., Anderson-Butcher, D., \& Reno, R. (2013). Exploring students' perceptions of academic disengagement and reengagement in a dropout recovery charter school setting. Children and Schools, 35(2), 113-120.

Jacob, B. A. (2001). Getting tough? The impact of high school graduation exams. Educational Evaluation and Policy Analysis, 23(2), 99-121.

Jimenez, L., Rothman, M., Roth, E., \& Sargrad, S. (2018). Blueprint for accountability systems for alternative high schools. Center for American Progress. https://www.americanprogress.org/issues/education-k-12/reports/ 2018/06/15/452011/blueprint-accountability-systems-alternative-high-schools/

Johnston-Goodstar, K., \& VeLure Roholt, R. (2017). Our kids aren't dropping out; they're being pushed out: Native American students and racial microaggressions in schools. Journal of Ethnic and Cultural Diversity in Social Work, 26(1-2), $30-47$.

Jordan, W. J., Lara, J., \& McPartland, J.M. (1996). Exploring the causes of early dropout among race-ethnic and gender groups. Youth and Society, 28(1), 62-94.

Kaplan, L. S., \& Owings, W. A. (2017). Organizational behavior for school leadership: Leveraging your school for success. Routledge.

Kentli, F. D. (2009). Comparison of hidden curriculum theories. European Journal of Educational Studies, 1(2), 83-88.

Kim, J.-H., \& Taylor, K. A. (2008). Rethinking alternative education to break the cycle of educational inequality and inequity. The Journal of Educational Research, 101(4), 207-219.

Kincheloe, J. L., McLaren, P., \& Steinberg, S. R. (2013). Critical pedagogy and qualitative research: Moving to the bricolage. In N. K. Denzin, \& Y. S. Lincoln (Eds.), The landscape of qualitative research ( $4^{\text {th }}$ ed.; pp. 339-370). Sage. 
Knell, P. F., \& Castro, A. J. (2014). Why people choose to teach in urban schools: The case for a push-pull factor analysis. The Educational Forum, 78(2), 150-163.

Koch, S. F., \& McGeary, K. A. (2005). The effect of youth alcohol initiation on high school completion. Economic Inquiry, 43, 750-765.

Kotok, S., Ikoma, S., \& Bodovski, K. (2016). School climate and dropping out of school in the era of accountability. American Journal of Education, 122(4), 569-599.

Krohn, M. D., Lizotte, A. J., \& Perez, C.M. (1997). The interrelationship between substance use and precocious transitions to adult statuses. Journal of Health and Social Behavior, 38, 87-103.

Ladson-Billings, G. (2006). From the achievement gap to the education debt: Understanding achievement in U.S. schools. Educational Researcher, 35(7), 3-12.

Lagana-Riordan, C., Aguilar, J. P., Franklin, C., Streeter, C. L., Kim, J. S., Tripodi, S. J., \& Hopson, L. M. (2011). At-risk students' perceptions of traditional schools and a solution-focused public alternative school. Preventing School Failure, 55(3), $105-114$.

Landis, R. N., \& Reschly, A. L. (2011). An examination of compulsory school attendance ages and high school dropout and completion. Educational Policy, 25(5), 719761.

Lee, V. E., \& Burkam, D. T. (2003). Dropping out of high school: The role of school organization and structure. American Educational Research Journal, 40, 2, 353393.

Lehr, C. A., Tan, C. S., \& Ysseldyke, J. (2009). Alternative schools: A synthesis of statelevel policy and research. Remedial and Special Education, 30(1), 19-32.

López, M. (2018). Why I still believe in Chicanx studies. English Language Notes, 56(2), 104-106.

Lovell, P. (2019, November 14). Every child a graduate, prepared for success. Presentation at the Reaching At-Promise Student Association (RAPSA) conference, San Diego, CA.

Lunenburg, F. C., \& Irby, B. J. (2008). Writing a successful thesis or dissertation: Tips and strategies for students in the social and behavioral sciences. Corwin Press.

Marchant, G. J., \& Paulson, S. E. (2005). The relationship of high school graduation exams to graduation rates and SAT scores. Education Policy Analysis Archives, 13(6). http://epaa.asu.edu/ojs/article/view/111 
Marion, R., \& Gonzalez, L. (2014), Leadership in education: Organizational theory for the practitioner $\left(2^{\text {nd }}\right.$ ed.). Waveland Press.

Maxwell, J. A. (2013). Qualitative research design: An interactive process. Sage.

Mazzeo, C. (2001). Frameworks of state: Assessment policy in historical perspective. Teachers' College Record, 103(3), 367-397.

McComb, J. (2004). Background brief on funding K-12 schools. Oregon Legislative Committee services, background brief. https://www.oregonlegislature.gov/lpro/ Publications/2004DE_Funding\%20K_12_Schools.pdf

McDermott, E. R., Donlan, A. E., Zaff, J. F., \& Prescott, J. E. (2016). A psychometric analysis of hope, persistence, and engagement among reengaged youth. Journal of Psychoeducational Assessment, 34(2), 136-152.

McLaren, P. (2002). Life in schools: An introduction to critical pedagogy in the foundations of education ( $4^{\text {th }}$ ed.). Allyn \& Bacon.

McNeil, L. M., Coppola, E., Radigan, J., \& Heilig, J. V. (2008). Avoidable losses: High stakes accountability and the dropout crisis. Education Policy Analysis Archives, $16(3), 1-45$.

McNulty, C. P., \& Roseboro, D. L. (2009). "I'm not really that bad": Alternative school students, stigma, and identity politics. Equity and Excellence in Education, 42(4), $412-427$.

Merriam, S. B., \& Tisdell, E. J. (2016). Qualitative research: A guide to design and implementation $\left(4^{\text {th }}\right.$ ed.). Jossey-Bass.

Mikulecky, M. (2013). School attendance age limits. Education Commission of the States. https://www.ecs.org/clearinghouse/01/07/04/10704.pdf

Miller, T., (2011). Partnering for education reform [Presentation transcript]. United States Department of Education. https://www.ed.gov/news/speeches/partneringeducation-reform

Mirel, J. (2006, Winter). The traditional high school. Education Next, 6(1), 14-21. https://www.educationnext.org/the-traditional-high-school/

Muennig, P. (2008). Consequences in health status and costs, in Belfield, C. R., \& Levin, H. M. (Eds.). The Price We Pay: Economic and Social Consequences of Inadequate Education. https://ebookcentral-proquest-com.proxy.lib.pdx.edu. 
Newton, X. A., Thompson, S. R., Oh, B., \& Ferullo, L. (2017). Improving opportunities for bridging social capital: The story of a full-service community school initiative at an alternative high school. The Educational Forum, 81(4), 418-431.

No Child Left Behind Act of 2001, Pub. L. No. 107-110 (2002).

Onday, O. (2016, April). The relationship between concepts of rational, natural and open systems: Managing organizations today. International Journal of Management Sciences and Business Research, 5(4), 83-88.

Oregon Department of Education (n.d.-a). Cohort graduation rate. Retrieved November 15, 2020, from https://www.oregon.gov/ode/reports-and-data/students/Pages/ Cohort-Graduation-Rate.aspx

Oregon Department of Education. (n.d.-b). Cohort graduation rate: Policy and technical manual. Retrieved November 15, 2020, from https://www.oregon.gov/ode/ reports-and-data/students/Documents/cohort-graduation-rate-policymanual_201516.pdf

Oregon Department of Education. (n.d.-c). The Oregon plan. The Every Student Succeeds Act. Retrieved September 28, 2019, from https://www.oregon.gov/ode/rules-andpolicies/ESSA/Documents/OregonPlan1-pager.pdf

Oregon Department of Education (n.d.-d). Report card FAQ. Retrieved July 30, 2020, from https://www.ode.state.or.us/data/reportcard/docs/report-card-faq.pdf

Oregon Department of Education. (2020). At a glance profiles and accountability details. https://www.ode.state.or.us/data/reportcard/reports.aspx

Oregon Department of Education. (2018). Oregon statewide report card for the 2017-18 school year. https://www.oregon.gov/ode/schools-and-districts/reportcards/ Documents/rptcard2018.pdf

Oregon Department of Education. (2017). Cumulative ADM end date codes. Retrieved November 17, 2020, from https://district.ode.state.or.us/wma/training/docs/ cumadmenddatecodes.pdf

Oregonlaws.org. (2020a). ORS 336.615: Definition for ORS 336.615 to 336.665. Retrieved December 13, 2020, from https://www.oregonlaws.org/ors/336.615

Oregonlaws.org (2020b). ORS 339.115: Admission of students, waiver, denial. Retrieved December 13, 2020, from https://www.oregonlaws.org/ors/339.115

Oregon Learns. (2018). Oregon's aspirations for attainment match the stakes. https://oregonlearns.org/oregons-challenge/the-40-40-20-goal/ 
Oregon School Activities Association. (2019). School classifications and districts. Retrieved November 10, 2019, from http://www.osaa.org/schools/classificationsdistricts

Oregon Secretary of State. (n.d.). Oregon Department of Education: Chapter 581, Division 17: Strategic investments. Retrieved July 30, 2020, from https://secure. sos.state.or.us/oard/displayDivisionRules.action?selectedDivision=2558

Orfield, G., Losen, D., Wald, J., \& Swanson, C. B. (2004). Losing our future: How minority youth are being left behind by the graduation rate crisis. Joint release by Harvard University Civil Rights Project, The Urban Institute, Advocates for Children of New York, and The Civil Society Institute.

https://civilrightsproject.ucla.edu/research/k-12-education/school-dropouts/losingour-future-how-minority-youth-are-being-left-behind-by-the-graduation-ratecrisis/orfield-losing-our-future-2004.pdf

Ou, S. R., Mersky, J. P., Reynolds, A. J., \& Kohler, K. M. (2007). Alterable predictors of educational attainment, income, and crime: Findings from an inner-city cohort. Social Service Review, 81, 85-128.

Perzigian, A. B., Afacan, K., Justin, W., \& Wilkerson, K. L. (2017). Characteristics of students in traditional versus alternative high schools: A cross-sectional analysis of enrollment in one urban district. Education and Urban Society, 49(7), 676-700.

Pevoto, B., \& Brown, E.Y. (2007). Educational reform in Texas through alternative education: A successful case study. Essays in Education, 19(11). https://openriver.winona.edu/eie/vol19/iss 1/11

Princiotta, D., \& Reyna, R. (2009). Achieving graduation for all: A governor's guide to dropout prevention and recovery. National Governor's Center for Best Practices. Retrieved March 6, 2019, from https://www.nga.org/cms/center

Ravitch, D. (2002, October 30). A brief history of testing and accountability. Hoover Digest, 4. https://www.hoover.org/research/brief-history-testing-andaccountability

Raywid, M. A. (1994, September). Alternative schools: The state of the art. Educational Leadership, 52(1), 26-31.

Raywid, M. A. (1999, May). History and issues of alternative schools. The High School Magazine, pp. 47-51.

Raywid, M. A. (2001a). Alternative schools as a model for public education. Theory Into Practice, 22(3), 190-197. 
Raywid, M. A. (2001b, April). What to do with students who are not succeeding. Phi Delta Kappan, 82(8), 582-584.

Ream, R. K., \& Rumberger, R. W. (2008). Student engagement, peer social capital, and school dropout among Mexican American and non-Latino White students. Sociology of Education, 81(2), 109-139.

Resmovits, J. (2014). Graduation rate hits record high for high school students: Government report. The Huffington Post. http://www.huffingtonpost.com/ 2013/01/22/graduation-rate-record-high-school-students_n_2522128.html

Richardson, D., \& Memmott, K. Stronger accountability, oversight, and support would improve results for academically at-risk students in alternative and online education (Report 2017-30). http://sos.oregon.gov/audits/ Documents/201730.pdf

Riehl, C. (1999). Labeling and letting go: An organizational analysis of how high school students are discharged as dropouts. Research in Sociology of Education and Socialization, 12, 231-268.

Robison, S., Jaggers, J., Rhodes, Blackmon, J., Bret, J., \& Church, W. (2017). Correlates of educational success: Predictors of school dropout and graduation for urban students in the Deep South. Children and Youth Services Review, Elsevier, 73, $37-46$.

Rumberger, R. W. (2011). Dropping out: Why students drop out of high school and what can be done about it. Harvard University Press.

Rumberger, R. W. (2013). Poverty and high school dropouts: The impact of family and community poverty on high school dropouts. The SES Indicator, American Psychological Association. http://www.apa.org/pi/ses/resources/indicator/ 2013/05/poverty-dropouts.aspx

Rumberger, R. W., \& Lim, S. A. (2008). Why students drop out of school: A review of 25 years of research (California Dropout Research Project Report \#15). www.lmri.ucsb.edu/dropouts

Saldaña, J. (2013). The coding manual for qualitative researchers ( $2^{\text {nd }}$ ed.). Sage.

Saldaña, J. (2016). The coding manual for qualitative researchers ( $3^{\text {rd }}$ ed.). Sage.

Saultz, A., Fusarelli, L. D., \& McEachin, A. (2017). The Every Student Succeeds Act, the decline of the federal role in education policy, and the curbing of executive authority. Publius: The Journal of Federalism, 47(3), 426-444. 
Saunders, J. A., \& Saunders, E. J. (2001). Alternative school students' perceptions of past [traditional] and current [alternative] school environments. The High School Journal, 85(2), 12-23.

Schlessman, A., \& Hurtado, K. (2012, April 17). A comparison of state alternative education accountability policies and frameworks. Paper presented at American Educational Research Association (AERA) annual meeting, Vancouver, British Columbia. https://files.eric.ed.gov/fulltext/ED534083.pdf

Seidman, I. (2013). Interviewing as qualitative research: A guide for the researchers in education and the social sciences ( $4^{\text {th }}$ ed.). Teachers College Press.

Shaw, K. (2014). The intersection of No Child Left Behind and the school-to-prison pipeline: The irony of a progressive act. Lawyers' Committee for Civil Rights Under Law. https://lawyerscommittee.org/2014/07/ the-intersection-of-no-childleft-behind-and-the-school-to-prison-pipeline-the-irony-of-a-progressive-act/

Shuttleworth, D. E. (2003). School management in transition: Schooling on the edge. RoutledgeFalmer.

Singleton, G. E. (2015). Courageous conversations about race: A field guide for achieving equity in schools $\left(2^{\text {nd }}\right.$ ed.). Corwin.

Slaten, C. D., Decoteau, J. I., Tate, K., \& Rivera, R. (2015). Towards a critically conscious approach to social and emotional learning in urban alternative education: School staff members' perspectives. Journal for Social Action in Counseling and Psychology, 7(1), 41-63.

Smith, L. T. (2008). On tricky ground: Researching the Native in the age of uncertainty. In N. K. Denzin \& Y. S. Lincoln (Eds.), The landscape of qualitative research. (pp. 113-143). Sage.

Smith, M. L., \& Fey, P. (2000). Validity and accountability in high stakes testing. Journal of Teacher Education, 51(5), 334-344.

Stearns, E., \& Glennie, E. J. (2006). When and why dropouts leave high school. Youth \& Society, 38, 29-57. 
Sum, A., Khatiwada, I., McLaughlin, J., \& Palma, S. (2009, October). The consequences of dropping out of high school: Joblessness and jailing for high school dropouts and the high cost for taxpayers, $22 \%$ daily jailing rate for young Black men who drop out of high school. Northeastern University, Center for Labor Market Studies. https://repository.library.northeastern.edu/downloads/ neu:376324?datastream_id=content

Swanson, C. B., \& Chaplin, D. (2003). Counting high school graduates when graduates count: Measuring graduation rates under the high stakes of NCLB [Report of the Education Policy Center of the Urban Institute]. https://www.urban.org/sites/ default/files/publication/59251/410641-Counting-High-School-Graduates-whenGraduates-Count.PDF

Sweeten, G. (2006). Who will graduate? Disruption of high school education by arrest and court involvement. Justice Quarterly, 23, 462-480.

Taylor, F. W. (1911). The principles of scientific management. The Plimpton Press. https://archive.org/stream/principlesofscie00taylrich\#page/ 62/mode/2up/search/directly+antagonistic+to+the+old

Tissington, L. D. (2006). History: Our hope for the future. Preventing School Failure: Alternative Education for Children and Youth, 51(1), 19-25.

United Health Foundation. (2017). America's health rankings. https://www. americashealthrankings.org/explore/2016-annual-report/state/OR

United States Department of Education. (n.d.). Race to the top district competition draft definitions. Retrieved April 2, 2018, from https://www.ed.gov/race-top/districtcompetition/definitions

Viehweg, M. M. (2015). Claiming the dream: A study of pushed out students becoming reengaged in school work [Unpublished doctoral dissertation, University of California, East Bay]. Google Scholar. http://csueastbay-dspace.calstate.edu/ bitstream/handle/10211.3/147696/Viehweg_csueastbay_1548E_10077.pdf?seque nce $=1$

Warren, J. R., Jenkins, K. N., \& Kulick, R. B. (2006). High school exit examinations and state-level completion and GED rates, 1975 through 2002. Educational Evaluation and Policy Analysis, 28(2), 131-152.

Weiss, R. S. (1994). Learning from strangers: The art and method of qualitative interview studies. The Free Press.

Whiting, L. S. (2008). Semi-structured interviews: Guidance for novice researchers. Nursing Standard, 22(23), 35-40. 
Wilcox-Gök, V., Marcotte, D. E., Farahati, F., \& Borkoski, C. (2004). Early onset depression and high school dropout. In D. E. Marcotte \& V. Wilcox-Gök (Eds.), Research in human capital and development: Vol. 15. The Economics of gender and mental illness (pp. 27-51). Emerald Group.

Zammit, K. \& Anderson-Ketchmark. (2011). Understanding dropout recovery. Children and Schools, 33(4), 249-251.

Zweig, J. A. (2003). Vulnerable youth: Identifying their need for alternative educational settings. The Urban Institute. https://www.urban.org/research/publication/ vulnerable-youth-identifying-their-need-alternative-educational-settings 


\title{
Appendix A: Letter to Superintendents
}

\author{
Request to Interview Principal XXX
}

Date: May 4, 2020

Dear Superintendent XXX,

Hello. My name is Lorna Fast Buffalo Horse and I work for Portland Public Schools as the director of Multiple Pathways to Graduation. I am also a doctoral candidate in the College of Education at Portland State University and a former alternative high school principal. For my doctoral dissertation at PSU, I am studying how alternative high school principals navigate the state accountability system. I am particularly interested in understanding this process for principals whose schools are among the $50 \%$ of alternative high schools whose enrollment of students of color is higher than the state median.

Because XXX in your district meets that criteria, I am reaching out to you to request permission to contact Principal XXX and request a one to two hour confidential interview, followed up by a shorter interview (about 30 minutes). These interviews, along with the interviews I plan to conduct with other principals, will help me to understand how the work of the principal intersects with the state's ESSA plan and accountability framework. The interviews will take place over a virtual platform like Google Hangouts or Zoom and the results of this study will be published in my final dissertation. All identifying information about the individuals, schools, and school districts participating in the study will be masked so that no person reading the final dissertation will be able to link quotes, demographic data or other information to the people interviewed.

I thank you for your assistance in my research and if you approve, the permission to contact the principal about their participation. If you have any questions whatsoever about this request or the research itself, please feel free to contact me, Lorna Fast Buffalo Horse, at 503.XXX-XXXX, fastbuf2@pdx.edu, or my Portland State University doctoral program adviser, Dr. Deborah Peterson, at 503.XXX-XXXX, dpeterso@pdx.edu. I would greatly appreciate your approval to include your alternative high school principal in the study.

Sincerely,

Lorna Fast Buffalo Horse, Ed.D. Candidate 


\section{Appendix B: Letter to Research Participants}

Date: May 5, 2020

Dear Principal XXX,

Hello. My name is Lorna Fast Buffalo Horse. I work at Portland Public Schools as the director of Multiple Pathways to Graduation. I am also a doctoral candidate in the College of Education at Portland State University and a former alternative high school principal. For my doctoral dissertation at PSU, I am studying how alternative high school principals navigate the state accountability system. I am particularly interested in understanding this process for principals whose schools are among the $50 \%$ of alternative high schools whose enrollment of students of color is higher than the state median.

Because your school meets that criteria, I reached out to your superintendent and have received permission from them to reach out to you to request a one to two hour confidential interview, followed up by a shorter interview (about 30 minutes) to understand your work as a principal and your work within the state's accountability system. The interviews will take place on a virtual platform like Google Hangouts or Zoom and the results of this study will be published in my final dissertation.

Your participation and all your answers are confidential, and there will be no way to tie the responses to you, your school, or district. I will share interview transcripts with you to confirm accuracy and that I have protected your confidentiality. I plan to interview principals from several alternative schools throughout the state. When I write the dissertation, all participants, their schools, and school districts will be described with pseudonyms and any public data about your school will be masked so that nobody could link your responses to you.

Your participation is voluntary. If you choose to participate, then let me thank you in advance for your assistance in my research. In addition, after the study begins, you may choose to stop your participation at any time during this study. If you have any questions whatsoever about this request or the research itself, please feel free to contact me, Lorna Fast Buffalo Horse, at 503.XXX-XXXX, fastbuf2@pdx.edu, or my Portland State University doctoral program adviser, Dr. Deborah Peterson, at 503.XXX-XXXX, dpeterso@pdx.edu.

If you are interested in participating in this study of alternative high school principals and state accountability in Oregon please respond to me at fastbuf2@pdx.edu by May 12, 2020.

Sincerely,

Lorna Fast Buffalo Horse, Ed.D. Candidate 
Appendix C: Informed Consent Form

\section{Consent to Participate in Research}

Project Title: Creating Systems of Shared Accountability for Early Leaver Students: Perspectives of Principals

Population: $\quad$ Alternative High School Principals in one Pacific Northwest State

Researcher: $\quad$ Lorna Fast Buffalo Horse, School of Education

Portland State University

Researcher Contact: fastbuf2@pdx.edu; 503.XXX-XXXX

You are being asked to take part in a research study. The box below highlights key information about this research for you to consider when making a decision whether or not to participate. Carefully review the information provided on this form. Please ask questions about any of the information you do not understand before you decide to participate.

\section{Key Information for You to Consider}

- Voluntary Consent. You are being asked to volunteer for a research study. It is up to you whether you choose to participate or not. There is no penalty if you choose not to participate or discontinue participation.

- Purpose. The purpose of this research is understand how school accountability measures may impact the students in alternative high schools, according to their principals.

- Duration. It is expected that your participation will include two interviews, each up to 90 minutes long over a period of two or more weeks. One of these interviews could be face to face and the second via phone or internet video chatting platform. With your consent, these interviews will be recorded.

- Procedures and Activities. You will be asked to answer questions from an interview guide and also to voluntarily share school artifacts like newsletters or handbooks. There are no right or wrong answers; I am interested in your perspective.

- Risks. Some possible risks of taking part in this study include being uncomfortable during the interview due to feelings of vulnerability as you share 
your experience. I will work to minimize feelings of discomfort. Additional (though unlikely) risks include possible identification through your answers. I will work to minimize these risks by ensuring your interview recordings and transcripts are kept secure and that when I write and speak about your experience, I do not provide detail that would link back to you. Additionally, I will use a pseudonym for you and your school when I write about my results.

- Benefits. Some of the benefits that may be expected include the ability to have your experience amplified within state and national discussions about alternative high school accountability. A gift card will be shared with each participant in the study as a token of appreciation, but is not considered compensation or a reason to participate.

- Alternatives. Participation is voluntary and the only alternative is to not participate.

- Participation is entirely voluntary. Your decision to participate or not will not affect your relationship with the university or with me in any way. If you decide to take part in this research, you may choose to withdraw at any time without penalty.

\section{What happens to the information collected?}

Information collected for this research will be used to complete a doctoral dissertation on educational policy and leadership, with a specialization in educational administration. The dissertation will be defended publicly and parts of it may be re-written in the future for potential publication in an educational research platform. You have a right to review transcripts from the interviews in which you participate and withhold any part of that interview. Member-checking will include sharing transcripts with you and a reminder of this right to withhold. No identifiable information will be included in the writing or oral description or defense of this study.

\section{How will my privacy and data confidentiality be protected?}

I will take measures to protect your privacy including separating your personal information from your interview quotes and using pseudonyms when sharing your experiences. The potential group of schools identified in this study also have been given pseudonyms and public data linked to these schools has been de-identified. All interview transcripts, recordings, and related documents will be kept in secure password-protected electronic locations, and physical documents will be kept in locked locations. Quotes will be de-identified to ensure anonymity in data storage.

Individuals and organizations that conduct or monitor this research may be permitted access to inspect research records, and this may include private information. These individuals and organizations include the Institutional Review Board that reviewed this 
research. Confidentiality will be maintained except when instances of elder, child, or sexual abuse are disclosed. As a mandatory reporter, I am obligated to report those instances. Despite taking steps to protect your privacy, I can never fully guarantee that your privacy will be protected.

\section{What are my responsibilities if I choose to participate?}

If you take part in this research, you will be responsible for voluntarily answering questions from two interview guides and voluntarily sharing paper or electronic documents relevant to the topic of study. Interview appointments will be agreed upon in advance between you and the researcher.

\section{What if I want to stop participating in this research?}

Your participation is voluntary. You do not have to take part in this study, but if you do, you may stop at any time. You have the right to choose not to participate in any study activity or completely withdraw from participation at any point without penalty or loss of benefits to which you are otherwise entitled. Your decision whether or not to participate will not affect your relationship with the researchers or Portland State University.

\section{Who can answer my questions about this research?}

If you have questions or concerns about the research, contact Lorna Fast Buffalo Horse at fastbuf2@pdx.edu or 503.XXX-XXXX. You can also contact my dissertation advisor (Principal Investigator), Deborah Peterson at dpeterso@pdx.edu at 503.XXX-XXXX.

\section{Who can I speak to about my rights as a research participant?}

The Portland State University Institutional Review Board ("IRB") is overseeing this research. The IRB is a group of people who independently review research studies to ensure the rights and welfare of participants are protected. The Office of Research Integrity is the office at Portland State University that supports the IRB. If you have questions about your rights, or wish to speak with someone other than the research team, you may contact:

Office of Research Integrity

PO Box 751

Portland, OR 97207-0751

Phone: (503) 725-5484

Toll Free: 1 (877) 480-4400

Email:psuirb@pdx.edu 


\section{Consent Statement}

I have had the opportunity to read and consider the information in this form. I have asked any questions necessary to make a decision about my participation. I understand that I can ask additional questions throughout my participation.

By signing below, I understand that I am volunteering to participate in this research. I understand that I am not waiving any legal rights. I have been provided with a copy of this consent form. I understand that if my ability to consent for myself changes, either I or my legal representative may be asked to provide consent prior to me continuing in the study.

I consent to participate in this study.

Name of Adult Participant

Signature of Adult Participant

Date

Researcher Signature (to be completed at time of informed consent)

I have explained the research to the participant and answered all of their questions. I believe that they understand the information described in this consent form and freely consent to participate.

Name of Research Team Member

Signature of Research Team Member

$\overline{\text { Date }}$ 


\section{Appendix D: Interview One Guide}

The goal of the first interview is to create a context for the subsequent interviews (Seidman, 2013), creating data which will eventually in part answer this study's research questions:

RQ 1: How do alternative high school administrators in one West Coast state describe the experience and the needs of BIPOC students in their school?

RQ 2: In what ways, if any, do the state accountability measures influence the work of alternative high school administrators in one West Coast state?

RQ 3: How do alternative high school administrators describe their role in their respective school districts as compared to the role of administrators in their districts' conventional high schools?

1. Could you tell me a little about why you decided to become an alternative high school administrator? (RQ 1)

2. How do you balance the many competing priorities of being an alternative high school principal? (RQ 1)

3. Could you talk about the demographics of your school and how these compare with the district as a whole? (RQ 1)

4. How is your job different from the job of conventional high school principals? (RQ 3)

5. How do you believe your district superintendent, school board or other officials view your work as compared to the work of your conventional high school colleagues? (RQ 3)

6. Does having a more diverse student body change how your school operates? (RQ 1)

7. Do you have the resources you need to effectively serve your students? (RQ 1)

8. What are some of your greatest accomplishments in this job? (RQ 1)

9. Please talk about what is most challenging in your work. (RQ 1)

10. How does your school district measure your school's progress (and your work, by extension)? (RQ 2)

11. How do you feel about your school's state report card rating and data? (RQ 2) 
12. Do you think the state report card adequately tells the story of your school? Why or why not? (RQ 2)

13. If your school could be measured by one or more outcomes, what would they be? (RQ 2)

14. How do you believe your school is perceived by others in the district? Do you think the school accountability ratings have an impact on this perception? (RQ 2)

15. Do you have any documents like parent newsletters, staff or student handbooks or others that describe your school's impact on students or success with accountability metrics that you could share with me? (RQ 1, 2, 3)

Anticipated Follow Up Prompts During the Interview:

- Can you elaborate?

- Say more about that.

- That must have been ___ Why do you think that is?

- What I hear you saying is ___. Is that correct? 


\section{Appendix E: Original Interview Two Guide}

The second interview is conceived as a follow up to the first, in an effort to clarify any additional questions, perform member-checking, and invite participants to share any new insights that have come to them since the first interview. This will happen after participants have received a transcript of their first interview. It will also potentially happen through a video-assisted platform like Google Hangout, Zoom or WebEx.

Anticipated Questions for this interview:

1. Did you get a chance to read part or all of the transcript from the first interview? What reflections do you have on that transcript?

2. I noticed in the materials you shared with me. Can you tell me more about that?

3. Is there anything else you would like to add?

Anticipated Follow Up Prompts During the Interview:

- Can you elaborate?

- Say more about that.

- That must have been ___ Why do you think that is?

- What I hear you saying is ___. Is that correct? 


\section{Appendix F: Newer Interview Two Guide, Approved by IRB Amendment}

RQ 1: How do alternative high school administrators in one West Coast state describe the experience and the needs of BIPOC students in their school?

$>$ RQ 2: In what ways, if any, do the state accountability measures influence the work of alternative high school administrators in one West Coast state?

RQ 3: How do alternative high school administrators describe their role in their respective school districts as compared to the role of administrators in their districts' conventional high schools?

1. Did you get a chance to read part or all of the transcript from the first interview? What reflections do you have on that transcript? (RQ 1,2,3)

2. I noticed more about that? (RQ 1,2,3) in the materials you shared with me. Can you tell me

3. Many people I have interviewed for this study have expressed a lot of enthusiasm for their work and for their school. Could you talk a little more about that? (RQ 1)

4. Some people interviewed for this study (or during your first interview, you) mentioned that you don't want your school to be seen as a last-chance model school for students. What are your thoughts about that (or could you talk a little more about that)? (RQ 2)

5. Every principal interviewed for this study stated that their alternative high school is either going through, about to go through, or has recently gone through a major change in focus or design. Could you talk more about the goals and purposes of the redesign? 
6. Many of the people I interviewed (including you - if relevant) expressed a feeling that your school or your students are misunderstood or invisible to the rest of your school district or district officials. (Is that also true for you?) (If so,) could you talk a little (more) about that feeling? (RQ 1 and potentially RQ 2)

7. If you could help your school district and your community better understand your school and your students, what would you say to them? (RQ 3)

8. Is there anything else you would like to add? (RQ 1, 2, 3)

Anticipated Follow Up Prompts During the Interview:

- Can you elaborate?

- Say more about that.

- That must have been ___ Why do you think that is?

- What I hear you saying is ___. Is that correct? 


\section{Appendix G: Provisional Codes From Literature}

Given this study's focus on alternative schools and state accountability, theoretical framework of critical pedagogy (McLaren, 2002) and conceptual frameworks of rational systems theory (Kaplan \& Owens, 2017; Marion \& Gonzalez, 2014; Raywid, 1994; Riehl, 1999; Taylor, 1911) and push, pull, and fall out factors (Doll et al., 2013), as well as the researcher's lengthy history of work in the field of alternative education, the following codes have been developed:

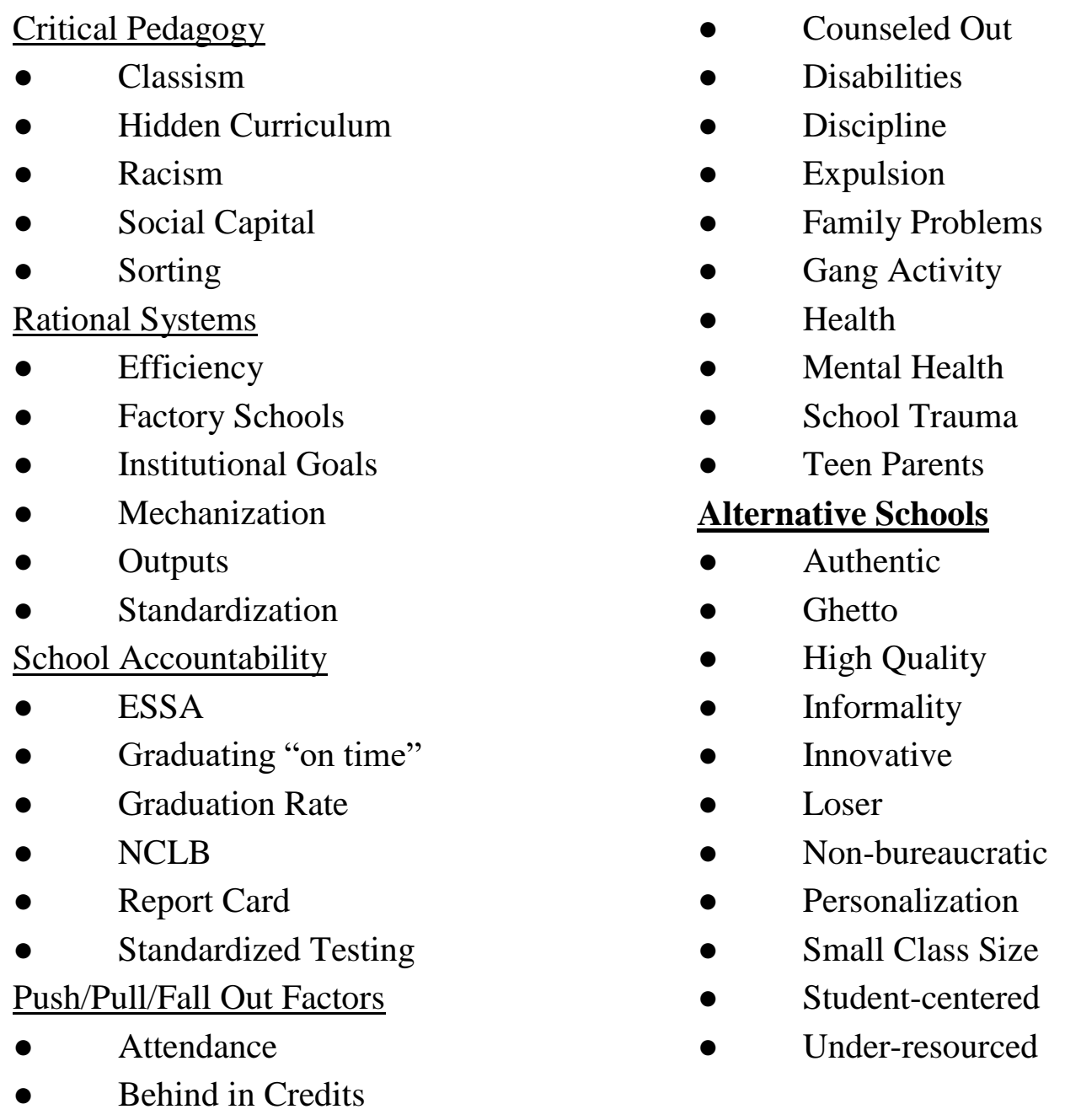




\title{
Appendix H: Guidance for School District Leaders on Shared Accountability for Early Leaver Students and Improved Graduation Rates
}

\author{
Guidance for School District Leaders on Shared Accountability for \\ Early Leaver Students and Improved Graduation Rates
}

\section{Introduction}

In December 2015, the Every Student Succeeds Act (ESSA) became the educational law of the United States, empowering each state to develop its own plan, using chosen indicators to measure school performance (Chang et al., 2018). While Oregon's state ESSA plan for high schools includes ratings for several important indicators, the English Language Arts and math achievement ratings and the graduation rate data are double-weighted (Oregon Department of Education, n.d.-c). This places additional importance on state testing and 4- and 5-year cohort graduation rates for districts working to improve ratings.

Two years after the passage of ESSA, the Oregon Secretary of State's office audited the state's alternative school system, focusing attention on low cohort graduation rates in the majority of these schools (Richardson \& Memmot, 2017). This trend mirrors national data, in which $75 \%$ of all alternative high schools in the United States fail to meet the 67\% four-year cohort graduation rate that is required by ESSA (Lovell, 2019). Some communities in Oregon boast graduation rates above the state average in their comprehensive high schools, while their alternative high school rates are an abysmal fraction of their comprehensive counterparts' rates. Not coincidentally, many of the students served in those alternative schools were transferred from the same comprehensive high schools, whose rates rose when credit-deficient students unenrolled. Alternative high school students in Oregon and other states are more likely to be students of color, low-income students, and students with disabilities. This trend of involuntarily moving students, especially historically underserved students, from one school to another as a function of improving graduation rates in the comprehensive schools ultimately does a significant disservice to students and should be avoided.

\section{Shifting Practice in the Interest of All Students}

A successful strategy to change the experience of Historically Underserved students is to develop systems that share accountability and increase responsibility for serving struggling students among all of a district's high schools. Such a system engages students and their families in decisions regarding transfer from one school to another and ensures that a school's accountability to students and their data does not end when a student transfers within the school district. Such a system would remove the incentive to move students to alternative schools to improve comprehensive school data. 
The components of shared accountability include the following: regular communication, modified enrollment designations, and collaboration and consensus decision-making. The table below illustrates how these components are operationalized in school district practice:

\section{Shared Accountability Components in Practice}

\begin{tabular}{|l|l|}
\hline Component & How it Looks in Practice \\
\hline Regular & $\bullet \begin{array}{l}\text { Alternative high school leaders should meet regularly with their } \\
\text { comprehensive high school peers to discuss the students who are or } \\
\text { have been enrolled in district schools. }\end{array}$ \\
$\begin{array}{l}\text { One district in Oregon convenes a weekly meeting of these } \\
\text { Enrollment } \\
\text { Designations }\end{array}$ & $\begin{array}{l}\text { When a student transfers from a comprehensive high school to an } \\
\text { alternative high school, there is no reason that the alternative high } \\
\text { school should be held solely responsible for that student's school } \\
\text { accountability data. The student's data should be reflected initially } \\
\text { with the sending school and only later with the alternative school. }\end{array}$ \\
\hline $\begin{array}{l}\text { In one school district, transfer students to alternative schools continue } \\
\text { to be designated as enrolled in the original high school and attending } \\
\text { the newer high school until they have earned 15 credits toward } \\
\text { graduation. }\end{array}$ \\
$\begin{array}{l}\text { Collaboration and } \\
\text { Decision-Making }\end{array}$ & $\begin{array}{l}\text { When principals meet regularly, they will likely develop more trust } \\
\text { and the ability to collaborate and practice consensus decision-making } \\
\text { regarding whether transferring students to an alternative school is in } \\
\text { the student's best interest. } \\
\text { One way principals can exercise collaborative decision making } \\
\text { regarding student transfer to an alternative high school is to agree that } \\
\text { students are only transferred to alternative high schools after the } \\
\text { current school has engaged the student and family in a conversation } \\
\text { about the potential benefits to the student of a transfer. These } \\
\text { principals can also develop a practice of reaching consensus on each } \\
\text { potential transfer student. }\end{array}$ \\
\hline
\end{tabular}

\section{Conclusion}

In practice, this approach to shared accountability can improve the high school experience for students, as well as have the graduation rates of both comprehensive and alternative high schools accurately reflect the work of each school. Students who experience subtle or overt school push-out are not well-served by these kinds of discharging practices and have reported that being pushed out makes them less engaged in school (McNulty \& Roseboro, 2009; Kim \& Taylor, 2008; Zweig, 2003). However, when students and their families are given the option of transfer, students reap the benefits of alternative schools, which typically include smaller class sizes, flexibility, personalization, social emotional and vocational supports. 
Comprehensive high schools who rely on student pushout to alternative schools can also benefit from this different approach. If a high school is boasting a high cohort graduation rate by discharging its struggling students, there is likely little incentive on the part of its staff to improve practice. Shifting to a system in which this discharging is less guaranteed, educational leaders may find that they have more leverage with their stakeholders to make the kinds of changes that will improve school climate and achievement for all students (Bland et al., 2012). This kind of improvement can improve the graduation rates of all district high schools and, thus, of the district as a whole. Ultimately, this practice most benefits struggling students who are most likely to be students of color, low-income students, and students with disabilities. 